Characteristics of the Alaskan 1-Km Advanced Very High Resolution Radiometer Data Sets Used for Analysis of Vegetation Biophysical Properties

By Carl J. Markon

Open-File Report 99-401 


\section{TABLE OF CONTENTS}

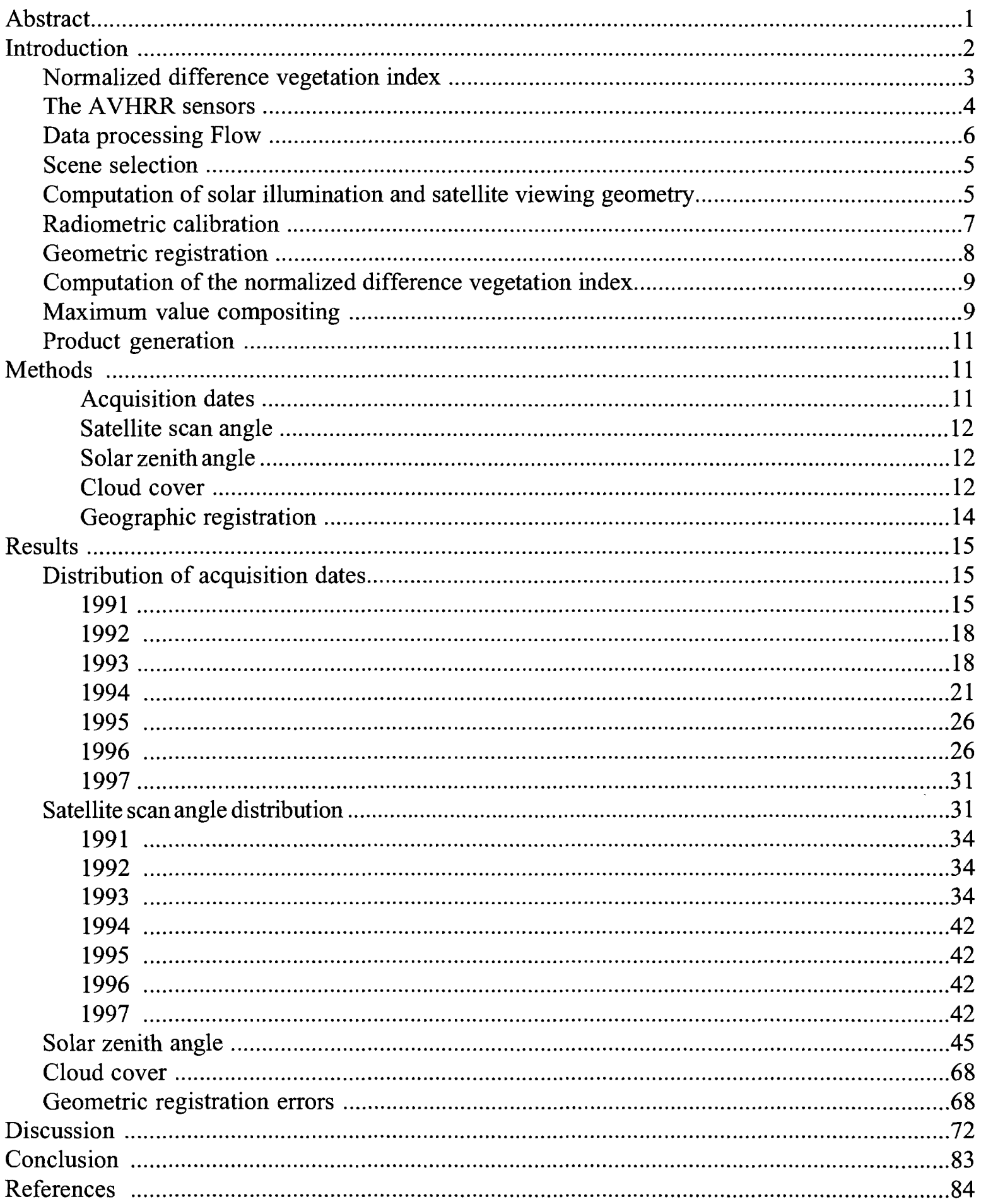




\section{LIST OF TABLES}

Table 1. Spectral characteristics and common uses of the NOAA AVHRR sensor....................4

Table 2. Projection parameters for the Alaska AVHRR data sets..........................................8

Table 3. Data layers making up the final AVHRR composite data sets.................................11

Table 4. Biweekly time periods, corresponding Julian dates, and time period abbreviation for 1991 through 1994 (one day was added to the 1992 Julian days to account for leap

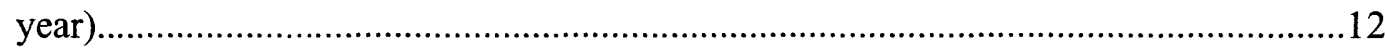

Table 5. Biweekly time periods, corresponding Julian dates, and time period abbreviation for 1995 and 1997 (one day was added to the 1996 Julian days to account for leap

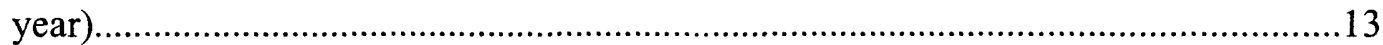

Table 6. Conversion factors used to translate the byte AVHRR reflectance and thermal data back to actual reflectance.................................................................................. 13

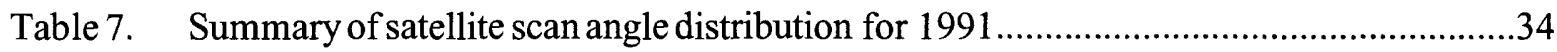

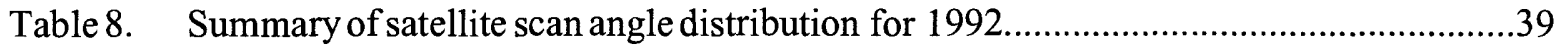

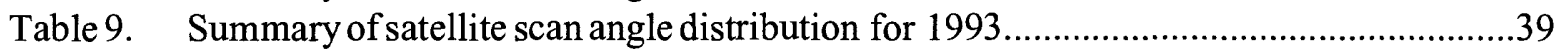

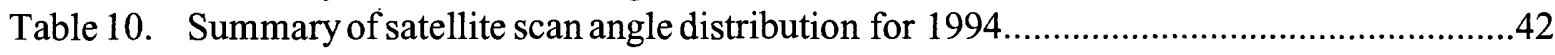

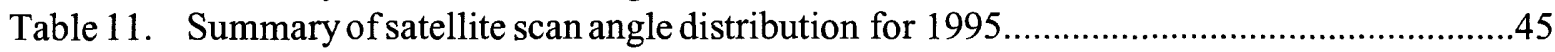

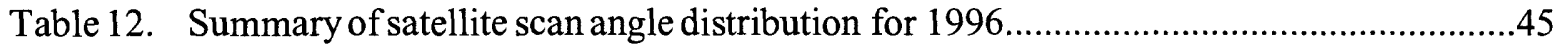

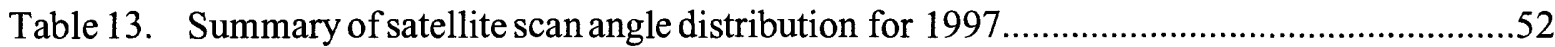

Table 14. Summarized solar zenith angles by composite period for each year.........................53

Table 15. Cloud test summary for the Alaskan AVHRR data sets.........................................69

Table 16. Registration error estimate (in meters unless otherwise noted) for the 1991 Alaskan

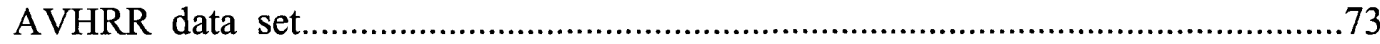

Table 17. Registration error estimate (in meters unless otherwise noted) for the 1992 Alaskan AVHRR data set....................................................................................... 74

Table 18. Registration error estimate (in meters unless otherwise noted) for the 1993 Alaskan AVHRR data set........................................................................................... 75

Table 19. Registration error estimate (in meters unless otherwise noted) for the 1994 Alaskan

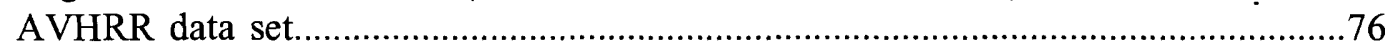

Table 20. Registration error estimate (in meters unless otherwise noted) for the 1995 Alaskan AVHRR data set....................................................................................... 77

Table 21. Registration error estimate (in meters unless otherwise noted) for the 1996 Alaskan AVHRR data set................................................................................ 78

Table 22. Registration error estimate (in meters unless otherwise noted) for the 1997 Alaskan AVHRR data set. 79 


\section{LIST OF FIGURES}

Figure 1. Satellite viewing angles used in processing the AVHRR data set...............................6

Figure 2. Solar zenith angles used in processing the AVHRR data set........................................6

Figure 3. Relative zenith angles used in processing the AVHRR data set.................................7

Figure 4. Example of the compositing process for a 3 day composite period.............................10

Figure 5. Distribution of AVHRR acquisition dates used for the compositing process for

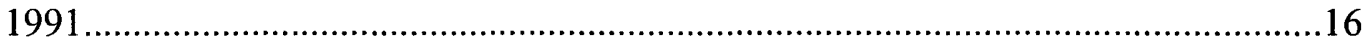

Figure 6. Distribution of AVHRR acquisition dates used for the compositing process for

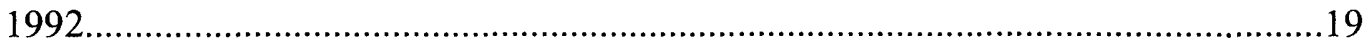

Figure 7. Distribution of AVHRR acquisition dates used for the compositing process for

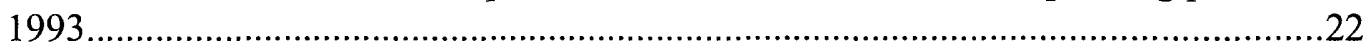

Figure 8. Distribution of AVHRR acquisition dates used for the compositing process for

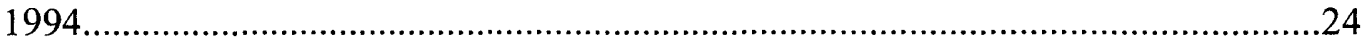

Figure 9. Distribution of AVHRR acquisition dates used for the compositing process for

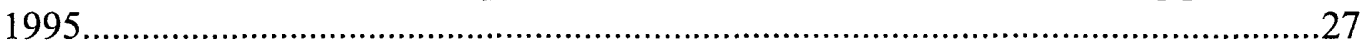

Figure 10. Distribution of AVHRR acquisition dates used for the compositing process for 1996.

Figure 11. Distribution of AVHRR acquisition dates used for the compositing process for

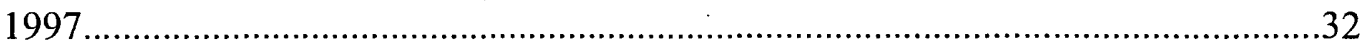

Figure 12. Distribution of AVHRR satellite scan angles for 1991............................................35

Figure 13. Distribution of AVHRR satellite scan angles for 1992 .............................................37

Figure 14. Distribution of AVHRR satellite scan angles for 1993 ..............................................40

Figure 15. Distribution of AVHRR satellite scan angles for 1994..............................................43

Figure 16. Distribution of AVHRR satellite scan angles for 1995 ..............................................46

Figure 17. Distribution of AVHRR satellite scan angles for 1996............................................48

Figure 18. Distribution of AVHRR satellite scan angles for 1997..............................................50

Figure 19. Distribution of solar zenith angles for 1991 AVHRR data set....................................54

Figure 20. Distribution of solar zenith angles for 1992 AVHRR data set....................................56

Figure 21. Distribution of solar zenith angles for 1993 AVHRR data set..................................58

Figure 22. Distribution of solar zenith angles for 1994 AVHRR data set....................................60

Figure 23. Distribution of solar zenith angles for 1995 AVHRR data set....................................62

Figure 24. Distribution of solar zenith angles for 1996 AVHRR data set....................................64

Figure 25. Distribution of solar zenith angles for 1997 AVHRR data set.....................................66

Figure 26. Estimates of cloud cover for the Alaskan AVHRR data sets.......................................71

Figure 27. Registration error estimates (in meters) for the Alaskan AVHRR data sets.................80 


\title{
CHARACTERISTICS OF THE ALASKAN 1 KM ADVANCED VERY HIGH RESOLUTION RADIOMETER DATA SETS USED FOR ANALYSIS OF VEGETATION BIOPHYSICAL PROPERTIES
}

\author{
Carl J. Markon ${ }^{1}$
}

\begin{abstract}
In this study, data characteristics for composited, multitemporal Advanced Very High Resolution Radiometer data sets for Alaska were assessed for a 7-year period from 1991 to 1997. This involved consideration of the satellite sensors used, data processing performed, and data set compilation, along with an analysis of acquisition date, solar zenith angle, satellite viewing angle, presence of clouds, and registration accuracy for each year.

Each year's worth of data are available on CD-ROM in byte format. All data sets have an initial start date of April 1, but had varying ending dates (mid-September to late October) because of satellite sensor malfunction or the presence of clouds or snow; no data set extended beyond October 31. Satellite scan angles were summarized in seven categories: data obtained at nadir, data within 30,40, and 55 degrees of nadir, data greater than 55 degrees off nadir, and proportions of the data representing east or west look angles. Minimum, maximum, and average solar zenith angles were provided for each period. Estimates of cloud cover for each period were based on three tests: reflectance gross cloud test, channel 3 minus channel 4, and channel 4 minus channel 5. Registration accuracy was estimated using a gray-level autocorrelation technique.

Results of this investigation indicate that the composited data available on CD-ROM should be useful for a number of different regional assessments of Earth cover properties. However, caution is advised when using these data because (1) loss in precision from the conversion to a byte format, (2) low sun angles and high viewing angles in the September and October data, and (3) registration inaccuracies of 2 to 8 pixels.
\end{abstract}

\section{INTRODUCTION}

The Advanced Very High Resolution Radiometer (AVHRR) is a passive sensor placed onboard the National Oceanic and Atmospheric Administrations's (NOAA) Tiros-N polarorbiting, Sun-synchronous satellites (Tucker, 1996). Used first in 1979 this sensor was originally designed for meteorological purposes. However, since the early 1980's it has been increasingly used for Earth biophysical studies(D'Souza and others, 1996) because of its frequent repeat cycle around the world (one to four or more times per day, depending on latitude and ascending and (or) descending mode), optical and thermal recording capabilities, relative low data volume to area covered ratio, and inexpensive cost (D'Souza and others, 1996). As the privatization of

${ }^{1}$ Raytheon Corp. USGS/EROS Alaska Field Office, 4230 University Drive, Anchorage, AK 99508-4664. Email: markon@usgs.gov. Work conducted under contract \#1434-CR-97-CN40274. 
Earth resource satellites increased during the 1980's, numerous studies were initiated to explore the usefulness of the AVHRR sensor for biophysical research (Tucker, 1996; D'Souza and others, 1996). In recognition of the demand for AVHRR data for local, regional, and global research, the Earth Resources Observation Systems (EROS) Data Center of the U.S. Geological Survey, began producing standardized, composited AVHRR data sets for the continental United States, Alaska, and the world (Eidenshink and Faundeen, 1994; Loveland and others, 1991). Production of these data sets was based on specifications developed by the International Geosphere Biosphere Programme (IGBP; Zhu and Yang, 1996).

Those data derived by the AVHRR sensor used that are used in most biophysical studies involve the red and near-infrared channels (reflected light energy) of the satellite sensor. The amount and quality of information recorded by the sensor are determined by the interaction of incident light energy with the following:

(a) plant community species composition

(b) vegetation form, vigor, and structure

(c) vegetation density in vertical and horizontal directions

(d) reflection, absorption, and transmission within and on the surface of the vegetation or ground

(e) reflection, absorption, and transmission by the atmosphere, clouds, and atmospheric contaminants

(f) amount and moisture content of barren ground or areas with snow and ice present

(g) soil color and brightness.

Leaf properties that determine reflection, absorption, and transmission in the visible and near-infrared light spectrum may be linked to photosynthesis, stomatal resistance, and evapotranspiration. This linkage can be inferred from measurements of reflected light energy (Tucker and Sellers, 1986). Healthy green leaves (deciduous and evergreen) absorb solar radiation in a wavelength region referred to as "photosynthetically active radiation" (the visible range or 0.4 to $0.7 \mu \mathrm{m}$ ). These wavelengths play a dominant role in carbon dioxide assimilation, with the absorbed light energy being converted to chemical energy. Leaf chlorophyll has strong absorption in the blue $(0.4-0.5 \mu \mathrm{m})$ and red $(0.62-0.7 \mu \mathrm{m})$ parts of the visible spectrum and reduced absorption in the green $(0.5-0.62 \mu \mathrm{m})$, which is why vegetation appears green to the human eye.

In the far-red to near-infrared region $(0.74$ to $1.1 \mu \mathrm{m})$, the green foliage of vegetation typically exhibits low absorption and high reflectance, which are dependent on leaf area, structure and water content. This wavelength region provides a strong reflectance from vegetation and good spectral contrast from most background materials (for example, soil). Spectral data from this region have been used to infer biophysical properties of plant canopies, such as chlorophyll density, which can provide information about photosynthesis and evapotranspiration (Tucker and Sellers, 1986). It has also been shown that chlorophyll density

$$
S R \cdot \frac{N I R}{R 1}
$$


can be related to a simple ratio of plant reflected near-infrared (NIR) energy divided by reflected red (R) energy (equation 1; Tucker and Sellers, 1986). Low values of this simple ratio represent areas of sparse vegetation or non-green areas and high values represent areas of lush or dense live vegetation.

\section{Normalized Difference Vegetation Index}

At any given time of the day, the atmosphere contains a certain amount of aerosols (for example, various chemical gases and water vapor). Electromagnetic radiation from the Sun has to pass through the atmosphere, reflect off the Earth's surface, and pass through the atmosphere again before being recorded by the satellite sensor. As satellite swath widths increase, light reaching the sensor has to pass through more atmosphere at the edges of the swath than at the point directly below the sensor (that is, at nadir). To help compensate for the effects of this atmospheric interaction, the data are "normalized" by the Normalized Difference Vegetation Index (NDVI) equation shown in equation 2.

$$
N D V I \cdot \frac{N I R 2 \cdot V I S 1}{N I R 2 \cdot V I S 1}
$$

In terms of the AVHRR sensor, NIR2 represents channel 2 and VIS1 represents channel 1 from the near-infrared and visible spectral channels, respectively. Using equation 2 , one should find that (1) negative values indicate nonvegetative surfaces, (2) positive values indicate vegetated surfaces, and (3) high positive values indicate high vegetation density or vigor (Goward and others, 1985).

The reason for using a NDVI, as summarized by Cracknell (1997), include its (1) simplicity for use in techniques for reducing clouds (that is, multidate compositing), (2) ability to enhance differences between healthy and senescent or unhealthy vegetation, and (3) use for minimizing the effects of extraneous factors, such as variations in atmospheric conditions, optical path length of the atmosphere, and surface reflectivity.

As the use of these data become more widespread, an increasing knowledge of the sensor data characteristics is being required. Many types of physical and biological research (for example, bidirectonal reflectance function, leaf area index, phenology) are affected by the data processing, compositing interval, date of acquisition, viewing and illumination geometry, and registration. This is especially true for data that are obtained in northern boreal and arctic regions where data availability may be limited owing to excessive cloudiness, shortened growing season, low sun angles, and a paucity of prominent features for registration. Therefore, the objective here is to analyze the Alaskan AVHRR data sets by (1) briefly describing the AVHRR sensors used, (2) explaining how the data were processed, and (3) summarizing some of the intrinsic qualities of the data that are made available for public use. Not mentioned here are problems associated with sensor calibration caused be degradation over time, and the effects of such problems on the resulting data sets, and aspects of the thermal channels. Also, the data characteristics described pertain only to the State of Alaska and do not include those areas of Canada and Russia that are part of the overall data sets. 


\section{The AVHRR Sensors}

The AVHRR sensors used in the Alaskan data sets are housed on NOAA TIROS 11 and 14 series satellites operating in a near-polar, Sun-synchronous orbit at approximately $833 \mathrm{~km}$. An orbital inclination of 98.9 degrees gives a period of 102 minutes or 14.1 orbits per day. NOAA 11 data (launched in 1988) were used for the 1991, 1992, 1993, and 1994 data sets; the AVHRR instrument subsequently failed in September 1994. NOAA 14 (launched in 1994) data were used for the 1995, 1996, and 1997 data sets. In both cases, data from afternoon (ascending node, daylight period) overpasses were used. The time of overpass was set to 2:30 p.m. (local solar time) at launch for both NOAA 11 and 14; however, by March of 1995, the NOAA 11 satellite platform overpass time had slipped to 5:30 p.m., and it is assumed that the 1994 data acquisitions were later than the 2:30 p.m. local solar time (Kidwell, 1997).

The AVHRR sensor collects reflected and thermal radiation data over a 2,500-km-wide swath with a nominal picture element (pixel) resolution of $1.1 \mathrm{~km}$ at nadir. Off-nadir viewing angles up to $+/-55$ degrees are possible and may produce pixel dimensions of $2.4 \mathrm{~km}$ (along track) by $6.9 \mathrm{~km}$ (across track). Although the data are coarse compared to the Landsat series of satellites (30- to 80-meter nominal resolution), or the French SPOT satellites (10- to 20-meter nominal resolution), the satellite has a repeat cycle two to four times per day over Alaska, providing a greater possibility of obtaining cloud free data.

The AVHRR sensor is capable of collecting information in five spectral bands or channels (table 1). The first two channels record information in the visible and near-infrared part of the electromagnetic spectrum, while the last two channels record information from the thermal or emitted part. The middle channel (channel 3) records information in both the reflected and thermal regions.

Table 1. Spectral characteristics and common uses of the NOAA AVHRR sensor

\begin{tabular}{cl}
\hline Channel & Spectral Response Common Uses \\
\hline 1 & $0.58-0.68 \cdot$ mChlorophyll density, daytime cloud, snow, ice mapping \\
2 & $0.72-1.10 \cdot$ mGreen leaf density, surface water delineation \\
3 & $3.55-3.93 \cdot$ mNighttime cloud mapping, detection of hot spots (fires \\
& volcanic activity), sea surface temperature, land/water distinction \\
4 & $10.3-11.3 \cdot \mathrm{mDay} /$ nigh cloud mapping, sea and land surface temperature \\
& measurements, soil moisture, volcanic eruptions \\
5 & $11.5-12.5 \cdot$ mSea surface temperature measurements, soil moisture \\
\hline
\end{tabular}

\section{Data Processing Flow}

The processing of the Alaskan AVHRR data sets is similar to that of the data sets produced for the Contiguous United States (Loveland and others, 1991; Eidenshink, 1992) and the global land data set (Loveland and Belward, 1997; Eidenshink and Faundeen, 1994). The major differences include the map projection used and the time period involved. The Alaskan data sets are mapped to a standard Alaskan Albers Conic Equal-Area projection (Snyder, 1982), as opposed to an Albers projection for the contiguous United States (Eidenshink, 1992) or the 
Interrupted Goode Homolosine projection of the global data set (Steinwand, 1994). Also, the Alaskan data sets cover a 6- to 7-month period for each year, whereas the other data sets cover 12-month periods.

There were seven basic steps in the production of the Alaskan data sets: (1) scene selection, (2) computation of solar illumination and satellite viewing geometry, (3) calibration, (4) geometric registration, (5) computation of the NDVI, (6) maximum value compositing, and (7) product generation. Each step is briefly described below.

\section{$\underline{\text { Scene selection }}$}

One of the prerequisites for producing the Alaskan data sets was that only the most cloudfree data available be used. On average, two to four afternoon scenes may be available per day over Alaska for possible use in the final data set. Each day, two or three afternoon scenes were selected and visually evaluated for cloud cover over the near-nadir viewing area. Afternoon scenes were used to ensure daylight conditions throughout the year. Scenes containing extensive cloud cover were not selected. Selected scenes were archived for later use.

\section{Computation of solar illumination and satellite viewing geometry}

Solar and satellite viewing geometries are useful for studying the effects of off-nadir viewing on the amount of ground area covered and surface reflectance (Curran, 1981; Teillet, 1998; Stoms and others, 1997; Leblanc and others, 1997; Li and others, 1996), bidirectional reflectance and illumination (Cihlar and others, 1994; Li and others, 1997; Myneni and Williams, 1994), data compositing (Cihlar and others, 1994), and potential data correction techniques (Eidenshink, 1992; Cracknell, 1997). Solar and satellite viewing angles also may have significant effects on models using the linear relationship between NDVI and absorbed photosynthetic radiation of plants (Prince, 1991). For the Alaskan data sets, three viewing angles were derived: satellite zenith, solar zenith, and relative azimuth. The satellite viewing angle (fig. 1) is computed in degrees from nadir, which is static at 90 degrees to a line tangent to the Earth's surface directly below the satellite. Computed values do not exceed 180 degrees. Although the maximum scan angle of the AVHRR sensor is $+/-55$ degrees, satellite zenith angles may exceed 55 degrees owing to the curvature of the Earth. Values less than 90 degrees represent view angles in a westerly direction, and those greater than 90 degrees represent view angles in an easterly direction. These angles are commonly represented as negative (up to -90 , westerly) or positive (up to +90 , easterly).

Solar zenith angles (fig. 2) are determined by calculating the angle between the Sun's rays and a line perpendicular to the ground at the viewing point of the satellite. These angles are computed between 0 and 90 degrees and are always positive. Very low angles (high solar elevation) show less shadow and result in more of the soil surface being observed and may be more prone to cause hot spots in the data (Curran, 1981; Leblanc and others, 1997). High zenith angles show more shadowing, depending on the roughness and density of the vegetation canopy, pass through more atmosphere, and will often increase the amount of red light to the sensor.

Relative zenith angles are computed as the absolute difference between the satellite viewing and solar zenith angles (fig. 3). Computed angles are between 0 and 180 degrees and are useful in atmospheric correction algorithms (Eidenshink, 1992). 


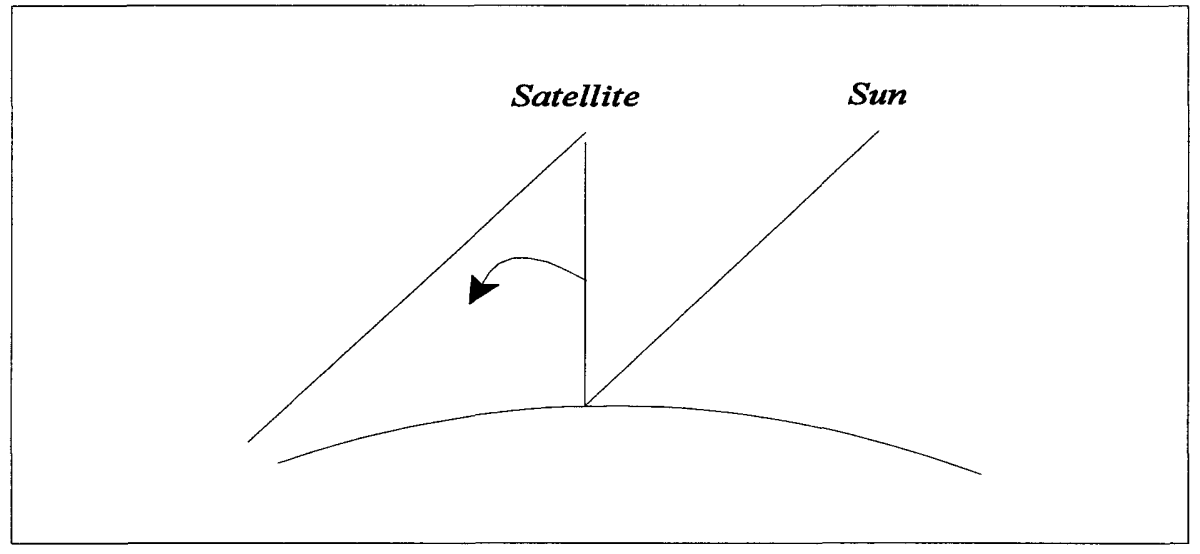

Figure 1. Satellite scan angle. the angle between the satellite look direction and a line perpendicular to the Earth's surface at the view point

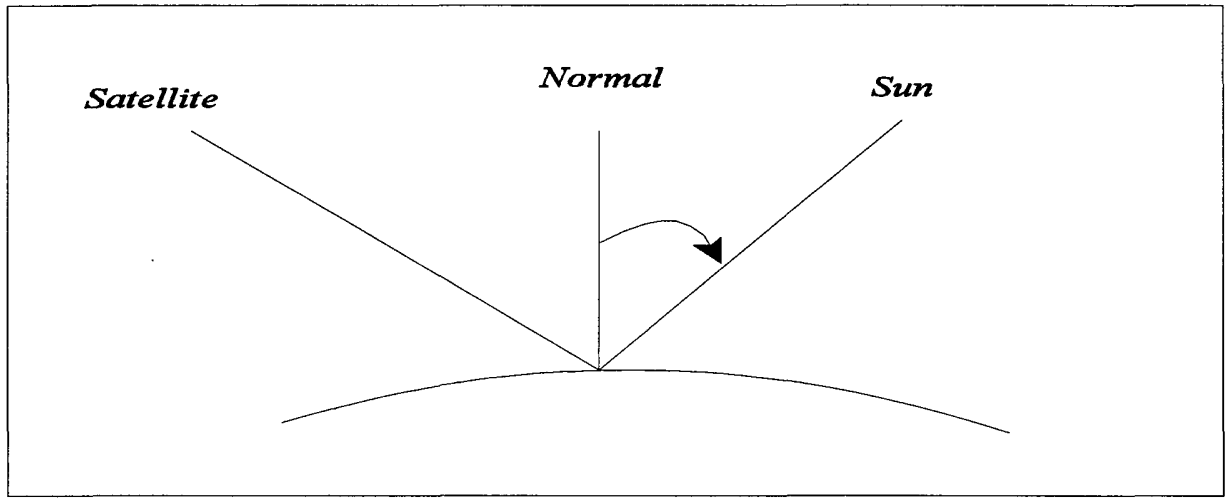

Figure 2. Solar zenith angle: the angle between the Sun and a line perpendicular to the Earth's surface at the view point 


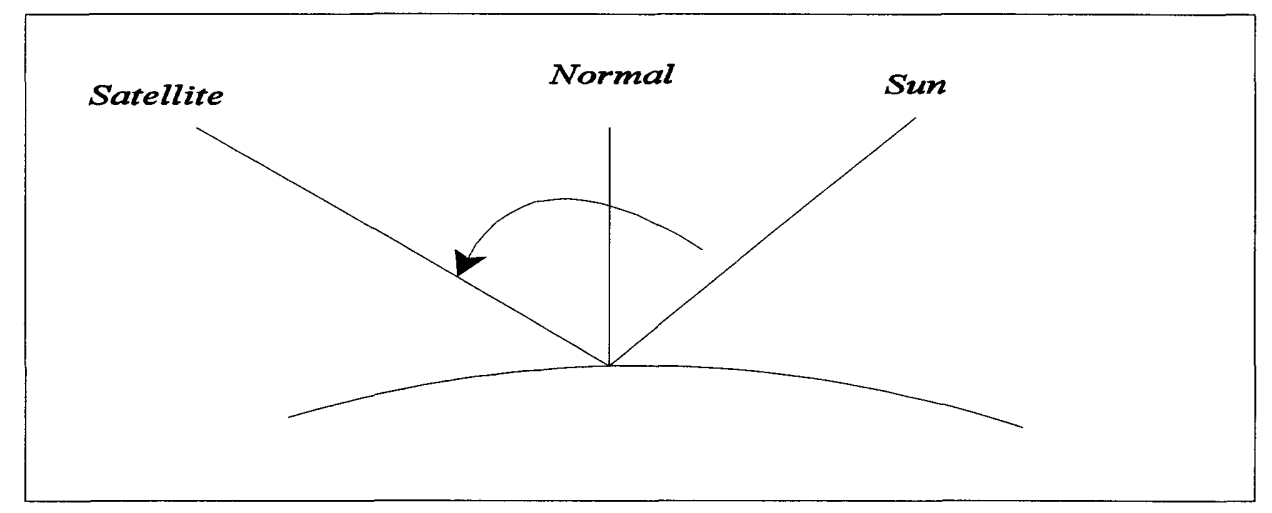

Figure 3. Relative zenith angle: the angle between the Sun and the satellite view angle.

\section{Radiometric Calibration}

Data calibration for the Alaska AVHRR data sets began with the processing of 10-bit data, which were ultimately converted to a byte range $(0-255)$. Channels 1 (red) and 2 (infrared) were calibrated for sensor degradation and changes in solar illumination to percentage reflectance. The visible and near-infrared channels of the AVHRR sensor do not have any onboard calibration capability and were adjusted using prelaunch sensor coefficients provided by NOAA and postlaunch adjustments using signal output obtained over desert sites (Binnian and Ohlen, 1992). A 0.25-percent scaling factor was applied to the calibrated reflectance values to maintain as much data precision as possible. Data converted to byte resulted in reflectance ranges of $0-63.5$ percent equaling bit values of $0-254$; reflectance values greater than 63.5 percent were grouped at a value of 255 .

The thermal channels were calibrated in-flight using views of a stable blackbody and deep space as references (Kidwell, 1997). Digital numbers for channels 3, 4, and 5 were converted to radiance using the following formula:

where: $\mathrm{R}$ is radiance

$$
R=a+b c
$$

$\mathrm{a}$ is the intercept

$\mathrm{b}$ is the gain coefficient

$\mathrm{c}$ is the digital number

Radiance was then converted to brightness temperature using an inverse of Planck's radiation function, represented in degrees Kelvin ${ }^{2}$. Brightness temperatures were then scaled to a byte range while attempting to maintain one-half degree of accuracy. This was achieved by

\footnotetext{
${ }^{2}$ Planck's radiation formula states that a blackbody must absorb and convert all incident radiant energy into heat energy. The inverse assumes that radiant energy leaving the surface is proportional to the temperature of the surface (Reeves and others, 1975).
} 
subtracting 202.5 from the brightness temperature values and multiplying the difference by 2 (for example, 250.5 becomes 96 ). This process tended to lump low brightness temperatures while providing sensitivity to high brightness temperatures.

\section{Geometric registration}

Historically, geometric registration of the Alaskan data sets proceeded through a series of changes, ultimately culminating in a process that is used for both the Alaska data and the global data. Specific requirements in all cases involved (1) efficient digital processing techniques, (2) full coverage of Alaska and surrounding land masses, (3) sufficient registration point distribution, and (4) desired geometric accuracy of less than 1 pixel $\left(1 \mathrm{~km}^{2}\right)$ root mean square error (RMSE). To accomplish this, seven, near-nadir, cloud free, channel 2 AVHRR images were acquired from archival data and composited to produce a base image. Each segment of the base image was georeferenced using 1:2,000,000 - scale digital line graph hydrology (rivers, water bodies, shorelines) provided by the Defense Mapping Agency. The final base image was projected to a standard geographic reference in the Albers Conic Equal-Area projection (Snyder, 1982) as shown in table 2.

Table 2. Projection parameters for the Alaska AVHRR data sets

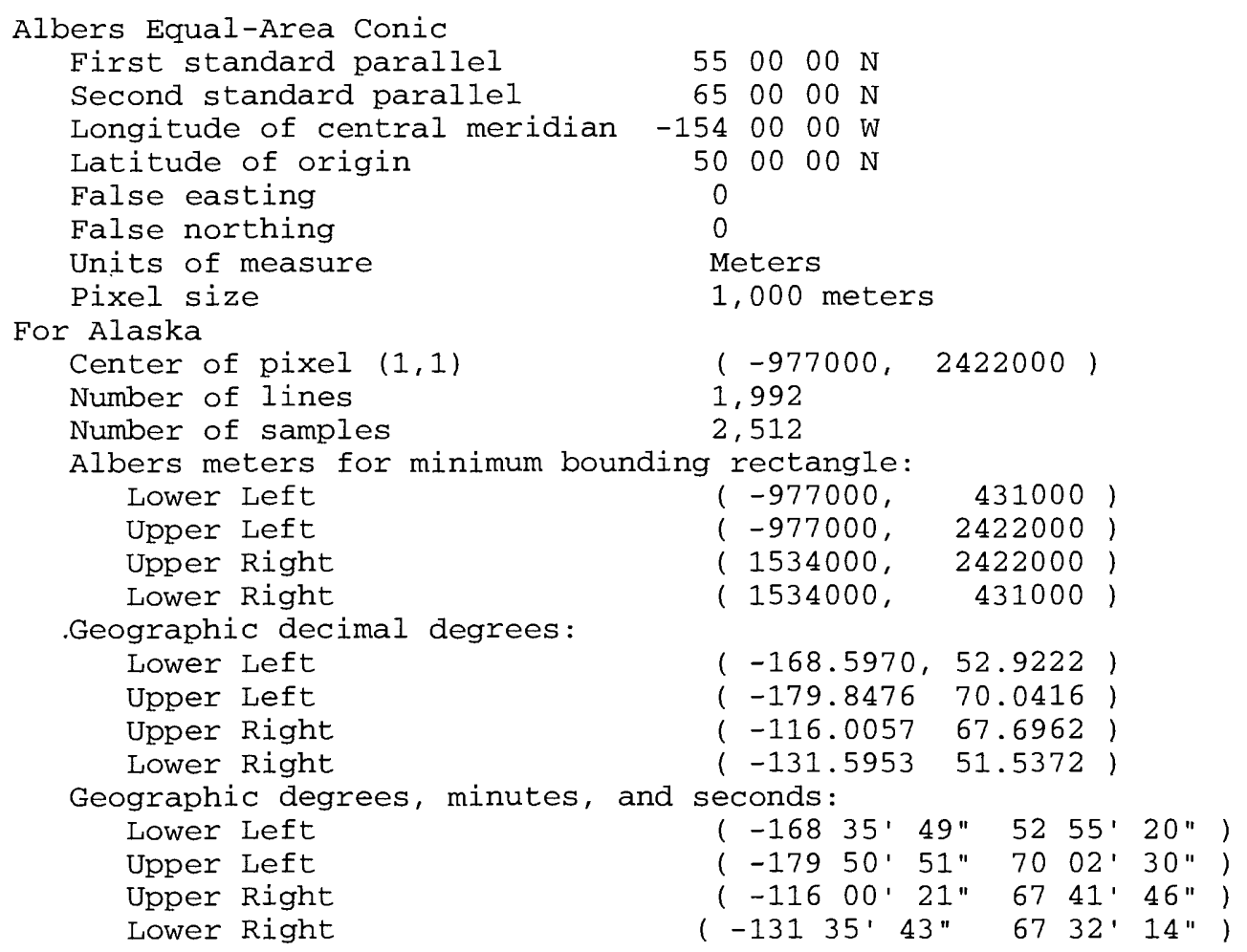

From June 1991 through September 1994, image data were georeferenced using 180 control points scattered along shorelines and inland water bodies. As new data were acquired throughout the years, new points were added to the original 180 points. Beginning in 1995 , a 
new technique of using systematically selected (gridded) points and gray-level correlation was used to georeference the unregistered data to the georeferenced base image (Ailts and others, 1990). Data for April through May 1991 also were georeferenced using the gray-level correlation because the two monthly data sets were not produced until 1997.

In brief, the gray-level correlation process begins with a series of 32 pixel kernels (subimage sections) extracted along a grid established over each AVHRR image being georeferenced. The 32 pixel kernels are then used as input to an autocorrelation routine that is based on the maximum gray-level computed over a set of relative offsets between the input image and the base image. Those areas with high gray level correlation (differences in pixel location of 1 pixel or less) are used as control point locations, with the line and sample of the base image (and corresponding latitude/longitude) used to produce a transformation equation relating line and sample of the unregistered input image to latitude and longitude of the base image.

Initially, channel 2 was used for the registration process, with the transformation equation applied to all other associated channels (one red, three thermal, solar zenith, and satellite viewing geometry) so that all data were georeferenced to the common Albers projection.

\section{Computation of the normalized difference vegetation index}

Following the georeferencing, the NDVI was calculated using channels 1 and 2 (as described earlier). Output may range from -1.0 to +1.0 . However, the data are scaled from 0 to 200 to allow a byte output format. Values from -1.0 to 0 are scaled from 0 to 100 , and values from 0 to 1 are scaled from 100 to 200; each unit is equal to 1-percent NDVI. Values between 0 and 100 normally indicate nonvegetated surfaces (water, clouds, ice, barren ground), and values between 100 and 200 indicate potentially vegetated surfaces (Lloyd, 1990; Reed and others, 1994), with high values indicating vegetation of high density and vigor.

\section{Maximum value compositing}

For most biophysical research of the Earth's surface, cloud-free data are needed. However, daily cloud-free data are normally not available, especially in northern latitudes. Therefore, a series of images is often collected over a set time period, with those images containing the least cloud cover being used in a compositing process (Holben, 1986; Eidenshink, 1992). For the Alaskan data sets, this time period varied between 14 and 16 days. The 1991-94 data sets are based on bimonthly ( 15 or 16 day) periods, dictated by the original production protocols and whether a particular month contained 30 or 31 days. The 1995-97 data sets are based on a 14-day period to match the processing flow of global data sets currently being produced. For different periods, the number of AVHRR scenes used to produce a composite varied from 10 to 16 .

The makeup of AVHRR scenes used during the composite period was based on the maximum NDVI value within any particular scene (fig 4). It should be noted that the purpose of the compositing process is to create minimum residual clouds, not to obtain maximum NDVI (Cihlar and Huang, 1994). Those scenes or parts of scenes with the highest NDVI values were selected during the compositing process to be used in the final composited data set. Each pixel 


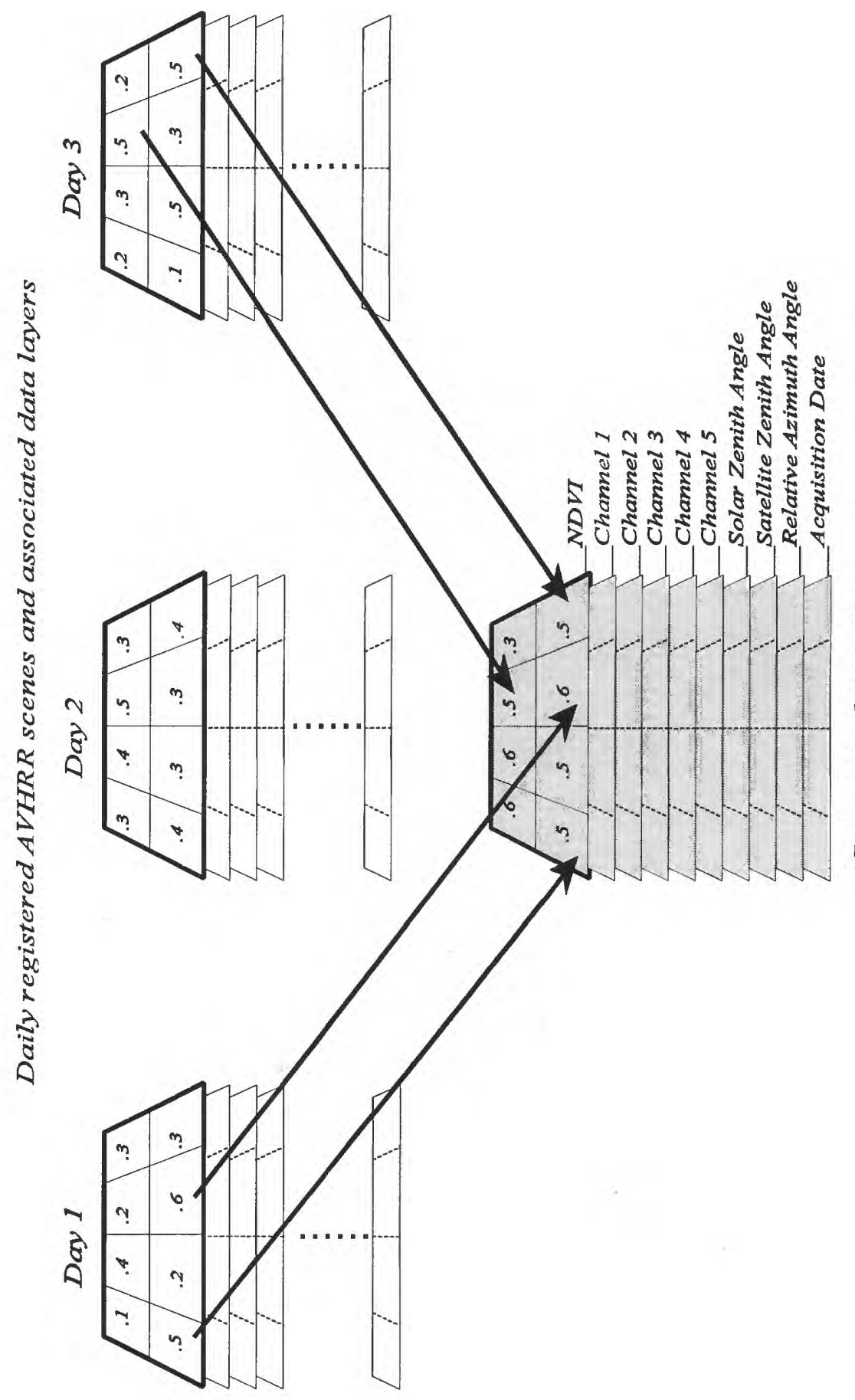

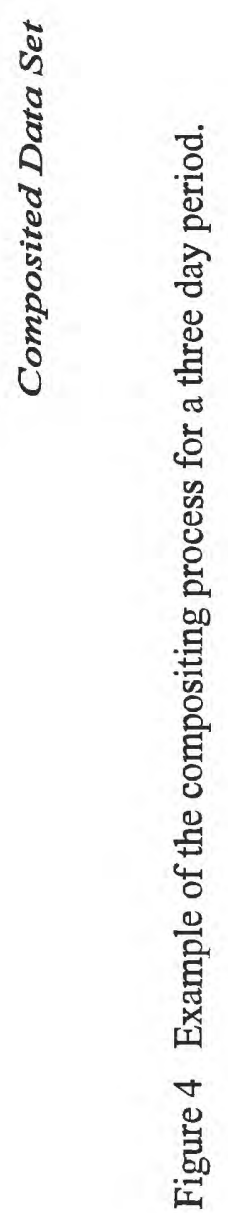


used in the final composite image was identified by a scene identification number and date. Corresponding pixels from all AVHRR channels $(1-5)$ and solar and satellite viewing geometry were included, along with a date of observation identifier, to create a 10-layer data set (table 3). A date attribute table listing the date identifiers and scene identification numbers also was produced.

\section{Product generation}

Following the compositing process and the compilation of the 10 different data layers, the entire data set was put onto CD-ROM for distribution to research scientists and the general public. The CD-ROM also contained a readme file (for example, Binnian and Ohlen, 1992) and ancillary data, such as cultural features (roads) and rudimentary viewing software. These data sets are currenlty available on CD-ROM from the U.S. Geological Survey, EROS Data Center, Sioux Falls, SD, U.S.A.

Table 3. Data layers making up the final AVHRR composite data sets

Band Description

1. NOAA channel 1

2. NOAA channel 2

3. NOAA channel 3

4. NOAA channel 4

5. NOAA channel 5
Band Description
6. NDVI
7. Satellite zenith
8. Solar zenith
9. Relative azimuth
10. Date

\section{METHODS}

The types of characteristics analyzed for the Alaskan data sets include acquisition date, satellite viewing angle, solar zenith angle, cloud cover, and registration. The data described are based on the individual 14-16 day composite periods produced for the 1991 through 1997 data sets.

\section{Acquisition Date}

Satellite data acquisition dates can be useful for looking at changes in seasonality between years and may indicate instances of cloud occurrence during any given composite period. They also indicate how representative the data are for any period. Data for the Alaskan acquisition dates were extracted from scene identification numbers for each AVHRR scene found in the date attribute file. Data identification consists of a 16-digit number representing the satellite number (NOAA 11 for 1991-94, NOAA 14 for 1995-97), date (month, day, year), and scene identification (Binnian and Ohlen, 1992). For this study, calendar dates were converted to Julian dates (tables 4 and 5 ) for use in intrayear and interyear comparisons (for example, distribution of dates for scene acquisition).

Each recorded date within a 2-week period indicates the most cloud-free pixel obtained for that period on the basis of maximum value compositing process. This does not mean that the day was necessarily cloud free, only that the day was the most cloud free or had the highest NDVI 
Table 4. Biweekly time periods, corresponding Julian dates and time period abbreviation for 1991 through 1994 (one day was added to the 1992 Julian days to account for leap year)

\begin{tabular}{|c|c|c|}
\hline Time Period & Julian Date & Abbreviated ID \\
\hline April $01-15$ & $091-105$ & PD1 \\
\hline April $16-30$ & $106-120$ & PD2 \\
\hline May $01-15$ & $121-135$ & PD3 \\
\hline May $16-31$ & $135-151$ & PD4 \\
\hline June $01-15$ & $152-166$ & PD5 \\
\hline June $16-30$ & $167-181$ & PD6 \\
\hline July $01-15$ & $182-196$ & PD7 \\
\hline July $16-31$ & $197-212$ & PD8 \\
\hline August $1-15$ & $213-227$ & PD9 \\
\hline August $16-31$ & $228-243$ & PD10 \\
\hline September $01-15$ & $244-258$ & PD11 \\
\hline September $16-30$ & $259-273$ & $\mathrm{PD} 12$ \\
\hline October $01-15$ & $274-288$ & PD13 \\
\hline October $16-31$ & $289-304$ & PD14 \\
\hline
\end{tabular}

value out of the 14 to 16 day period. However, if a preponderance of dates occurs at the beginning of the period, one may assume that cloudy conditions occurred during the latter part of the 2-week period.

The resulting NDVI values from the compositing process are often affected by the AVHRR satellite view angle (Zhu and Yang, 1996; Goward and others, 1991; Moody and Strahler, 1994; Cihlar and Huang, 1994). Through the compositing process, many multiday coverages are achievable with off-nadir view angles. Per pixel view angle values for each bi-weekly composite and for each year as a whole were derived from the satellite scan angle band of the Alaska AVHRR data sets.

\section{Satellite Scan Angles}

Satellite scan angles do not exceed 180 degrees. West (-) and east $(+)$ satellite view directions were calculated by subtracting 90 degrees from each of the values in the satellite view data layer (Baglio, Jr. and Holroyd, 1989).

Solar Zenith Angle

Goward and others (1991) reported that the precision of AVHRR measurements decreases to levels below $+/-1$ percent at solar zenith angles above 80 degrees for northern latitudes greater than 45 degrees. Longer path lengths can potentially lower NDVI values through increased atmospheric scattering and lower surface backscatter (Moody and Strahler, 1994; Liu and others, 1997). Solar zenith values were extracted directly from that respective data layer.

\section{Cloud Cover}

Cloud cover was estimated using a 10-percent systematic sample of the data sets as input to three different cloud detection algorithms following procedures described by Zhu and Yang (1996) that were based on work by Baglio and Holroyd (1989) and Stowe and others (1991). 
Table 5. Biweekly time periods, corresponding Julian dates and time period abbreviation for 1995 and 1997 (one day was added to the 1996 Julian days to account for leap year)

\begin{tabular}{lcl}
\hline Time Period & Julian Date & Abbreviated ID \\
\hline & & \\
April 01 - 14 & $091-104$ & PD1 \\
April 15 - 28 & $105-118$ & PD2 \\
April 29 - May 12 & $119-132$ & PD3 \\
May 13 - 26 & $133-146$ & PD4 \\
May 27 - June 09 & $147-160$ & PD5 \\
June 10 - 25 & $161-176$ & PD6 \\
June 26 - July 07 & $177-188$ & PD7 \\
July 08 - July 21 & $189-202$ & PD8 \\
July 22 - August 04 & $203-216$ & PD9 \\
August 05 - 18 & $217-230$ & PD10 \\
August 19- Sept. 01 & $231-244$ & PD11 \\
Sept. 02 - 15 & $245-258$ & PD12 \\
Sept. 16 - 29 & $259-272$ & PD13 \\
Sept. 30 - Oct. 13 & $273-286$ & PD14 \\
\hline
\end{tabular}

Inorder for the sample to be considered cloud free, the data had to pass every test ${ }^{3}$. Since the data were scaled to byte as part of the production and distribution process, they had to be converted back to their original reflectance value (or as close as possible). Channels 1, 3, 4, and 5 (red through thermal) were used for the cloud tests, and their conversion factors from byte to original reflectance radiance values are shown in table 6 using the general formula:

$$
\text { actual }=(\text { scaled }- \text { offset }) / \text { scale }
$$

Table 6. Conversion factors used to translate the byte AVHRR reflectance and thermal data back to actual reflectance and thermal data

\begin{tabular}{llc}
\hline Field & Scale & Offset \\
\hline Satellite Zenith & 1 & 90 \\
Solar Zenith & 1 & 0 \\
Reflectance & 4 & 0 \\
Radiance & 0.766 & 0 \\
Thermal & 2 & -405 \\
NDVI & 100 & 100 \\
\hline
\end{tabular}

\footnotetext{
${ }^{3}$ Results from the tests were binary in nature so that if a 1 was detected, then the test failed and a cloud was assumed. If the outcome was 0 the test passed. If the sum from all tests was 0 , then the pixel was considered to be cloud free.
} 
Although some of the dynamic range is lost owing to the conversion, these tests should provide good representation of the presence of clouds.

The first test was based on the gross reflectiveness of clouds (reflective gross cloud test [RGCT]; Stowe and others, 1991). This test assumes that if the reflectance of channel 1 (red) is greater than 0.44 , then the pixel in question is either a cloud, snow, or other bright surface (for example, barren ground). The threshold value was based on literature (Stowe and others, 1991) and manual comparison of test results with hard-copy output products.

The second test, which used the difference in brightness temperatures between channel 3 and channel 4 (TMF), separates clouds from snow-covered land (Baglio and Holroyd, 1989). Top-of-cloud emission in channels 4 and 5 is similar to snow-covered surfaces. Channel 3 , however, is in the midinfrared and has qualities of both reflected and emitted energy (3.55 - 3.93 - $m$ ), and Baglio and Holroyd (1989) reported that cloud and snow are spectrally different in this region. At this wavelength, snow is strongly absorptive, but opaque clouds and some cirrus have greater reflectance; however, thin cirrus clouds can be difficult to discriminate because they are optically thin (Baglio, Jr. and Holroyd, 1989). Because channel 3 is calibrated using cold space and a sensor-mounted blackbody, clouds and other similar reflective surfaces have warmer than actual temperatures. Therefore, a more accurate representation of cloud/snow separation was performed by using channel 3 minus channel 4, channel 4 having a more definitive estimate of the true temperature. For this study, a value exceeding $40 \mathrm{~K}$ would cause the test to fail (that is., cloud detected).

The third test subtracted the brightness temperatures of channel 4 (mid-infrared) from channel 5 (thermal; FMF). This test was based on the idea that water and ice have different emissivity in the two channels, and it was primarily used to detect thin cirrus clouds and clouds in polar latitudes (Stowe and others, 1991; Zhu and Yang, 1996). The threshold for this test was based on results from a fourth degree polynomial in channel 4 temperatures and the maximum value from of channel 4 minus channel 5 (Stowe and others, 1991).

\section{Geographic Registration}

Correct registration of any space-borne data set is important in any type of data extraction project. The Alaskan data sets create a special problem in that there is a paucity of surface features that can be used to georeference the data set. This is especially true for larger resolution data such as $1 \mathrm{~km}$ pixels where surface features must be large enough to be discernible in the data. The composited images (based on NDVI) are formed by merging individual images or image sections that had been georeferenced to a common base image. To assess how well the resulting composited images compare to the base image, autocorrelation and verification routines were performed. First, a grid of tie-points was systematically sampled from the base image. Spacing for each point was at every 64th line and sample, producing 1,209 points. These points were then supplied to an autocorrelation routine that extracts $32-$ by 32 - pixel image chips from both the base image and the composite image. The two sets of image chips were then used in a gray-level (normalized) cross correlation using fast Fourier transformation, which determined the translation alignment of the base image chips relative to the composite image chips. Maximum alignments were then found within each image chip pair and assessed as to location of correlation peaks. If two or more peaks wee found within a 9- by 9- pixel window that had correlation strengths within a given tolerance, then the image chip was not used because of the possibility 
that the same feature was represented in the two image chips. If only one peak was found, then it was assumed that the peaks within the two image chips represented the same surface feature. Statistics were then computed on the residuals between accepted pair peaks from the correlation (that is, average, minimum, and maximum line and sample error or offset, line, and sample root mean squared error). The gray-level correlation was performed between the base image and each channel 2 (NIR) composite image from each year.

\section{RESULTS}

\section{Distribution of Acquisition Dates}

Data acquisition for each of the seven temporal data sets was initiated on April 1 of each year. At this time, over 90 percent of the State is snow covered. However, ending dates range from September 13 to October 31 owing to excessive cloudiness, the demise of NOAA 11 in late 1994, excessively low sun angles late in the year, or cessation of visible channel acquisition over higher latitudes during the winter months (Holben, 1986; Kidwell, 1997; J. Eidenshink, EROS Data Center, Sioux Falls, S. Dak., personal comm.). The seasonal period of data recording is shorter than it is for similar products produced for the contiguous United States (Loveland and others, 1991; Eidenshink, 1992; Reed and others, 1994). Figures 5 through 11 show the distribution of data acquired using Julian date (as percentage of total pixels) and indicate which days AVHRR data were kept and used for compositing. A short synopsis for each year follows.

1991

Compositing periods for 1991 were based on 15- or 16-day intervals (16 days for the second half of months with 31 days). During the first two periods, 50 percent to 70 percent of the data were acquired during the first 2 days (figs. $5 \mathrm{a}$ and $5 \mathrm{~b}$ ), the remaining 50 percent to 30 percent being distributed throughout the remaining days. Period 2 is especially interesting because close to 70 percent of the data were composited from 1 day (Julian day 107, April 17). The first part of period 3 (beginning in May) was somewhat trimodal with significant amounts of data acquired midmonth. A spike in data acquisition occurred the last day of the period, which seemed to start a trend that continued into the first week of period 4 (fig. $5 \mathrm{~d}$; beginning in May), indicating that parts of period 3 may be more representative of the beginning of period 4 than of period 3. This may be a significant factor in certain applications, especially for the interior areas of Alaska, where this is the beginning of green-up. No data were acquired during the last week of period 4.

Acquisition dates for periods 5 and 6 (June) were spread throughout the month, with a slight increase in acquisition toward the last week of period 5 and a slight bimodal shape to period 6 (figs. 5e and 5f). Periods 7 and 8 (figs. $5 \mathrm{~g}$ and $5 \mathrm{~h}$ ) are interesting in that no data were acquired during the second and third weeks of July, indicating total or near total cloudy skies over all of the State for those 2 weeks. This is of some concern for greenness studies because July is often at or close to the peak of greenness for much of Alaska.

Periods 9 and 10 (August, figs. 5i and 5j) indicate that AVHRR data were obtained throughout each biweekly period, with a slightly larger number of scenes kept from the first half 

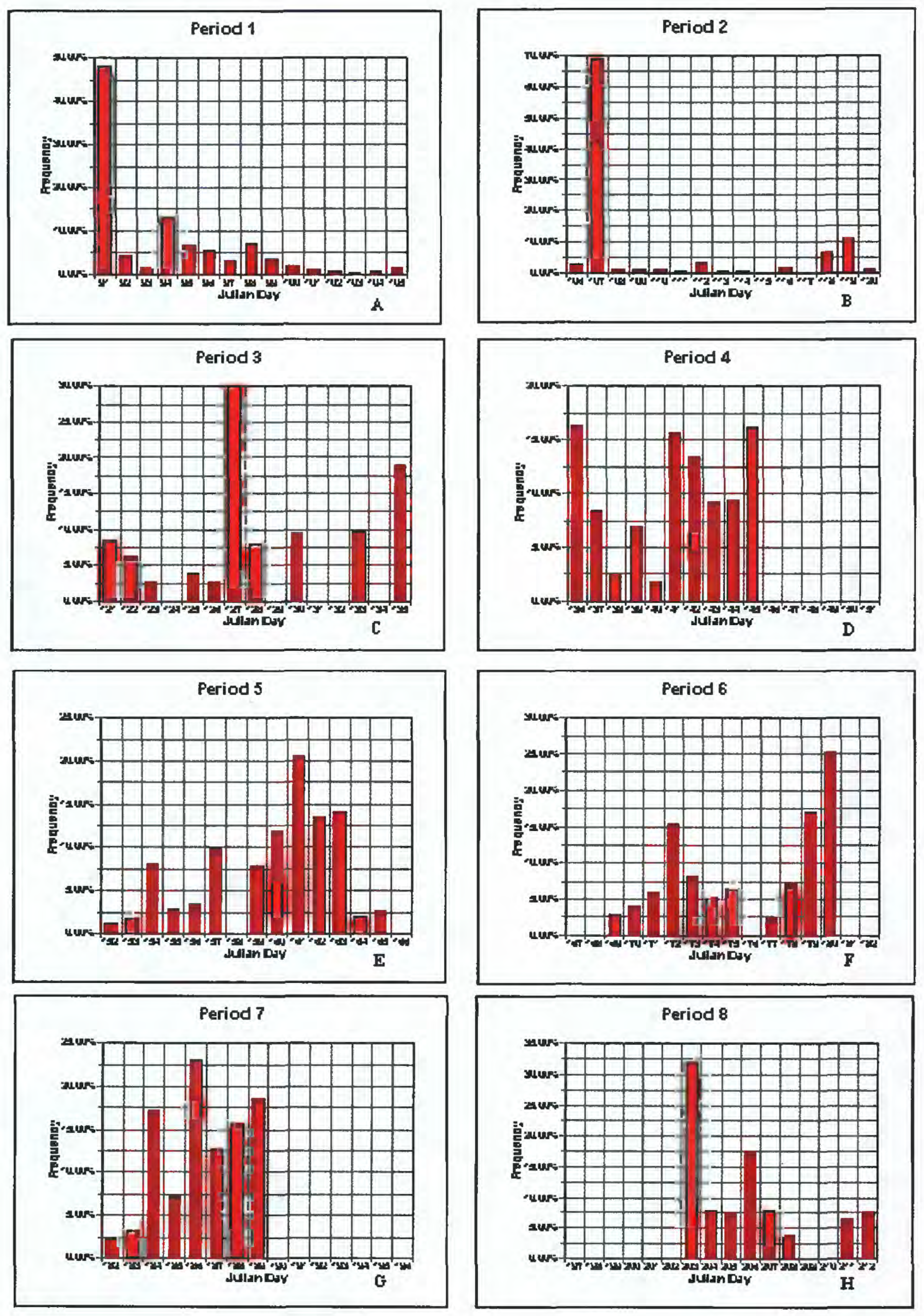

Figure 5. Distribution of AVHRR acquisition dates used for the compositing process for 1991 

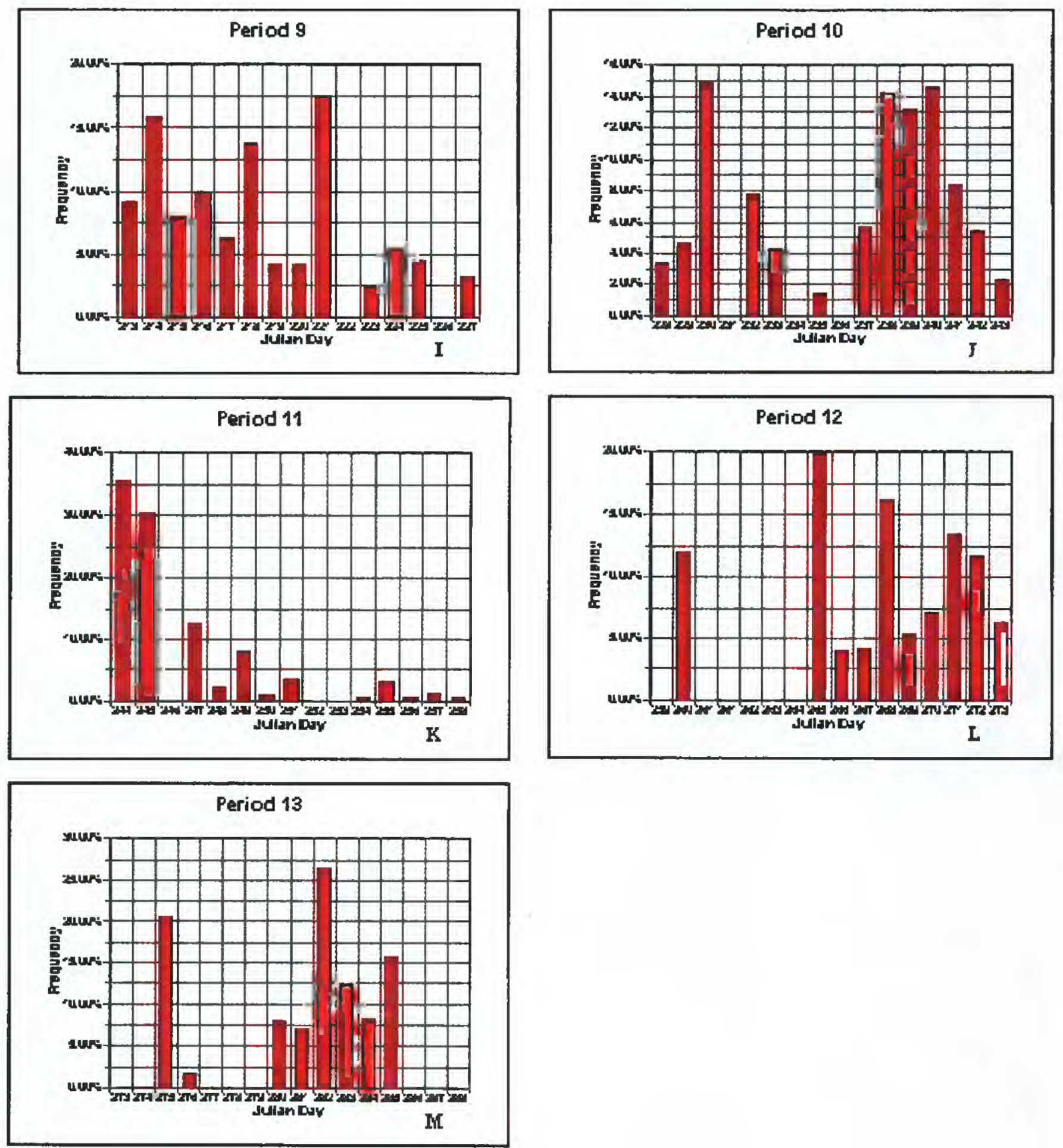

Figure 5. Distribution of AVHRR acquisition dates used for the compositing process for 1991 (continued) 
of period 9 and the second half of period 10. For period 11 (first half of September, fig. 5k), most of the scenes were obtained during the first week, in contrast to periods 12 (last 2 weeks of September, fig. 5l) and 13 (first 2 weeks in October, fig. $5 \mathrm{~m}$ ), when most of the data were acquired during the later part of the period. This could be expected since vegetation senescence is beginning or has already occurred over much of the State and autumn rains and snow have begun.

\section{2}

In comparison to 1991, the 1992 acquisition dates were more spread out over each biweekly period. During period 1 (first part of April, fig. 6a), over one-third of the scenes were kept from the second day of the month, with roughly one-half of the data obtained during the first 5 days; fewer data were obtained during the later part of the period. For period 2 (last 2 weeks in April, fig. 6b), over 80 percent of the data used were acquired the first 2 days of the period, with the remaining 20 percent of the data collected over the rest of the period.

Data acquisitions for period 3 (first part of May, fig. 6c) were primarily from the first 4 days, whereas data for period 4 (last half of May, fig. 6d) were bimodal, with one-fourth of the data acquired the first day of the period and most of the remainder during the last week of the period.

During period 5 (first half of June, fig. 6e), most of the data were acquired toward the end of the period, whereas in period 6 (last half of June, fig. 6f), the acquisition was spread out over the 2 -week period. The trend shown in the last 2 weeks of period 6 continued through period 7 (first 2 weeks of July, fig. $6 \mathrm{~g}$ ) and into the first 2 weeks of period 8 (first 2 weeks of August, fig. $6 \mathrm{~h}$ ). Although there were two spikes in data acquisition during period 8 , they were relatively minor as far as actual data used during the composite period; data were predominately acquired throughout the entire 2-week interval. However, there appeared to be a trend in data acquisition toward the end of period 8 that continued into the first day of period 9 (first 2 weeks in August), when slightly over 35 percent of the data were acquired.

Period 10 (the last 2-week period in August, fig. 6j) was slightly different from the previous three biweekly periods because for the first 8 days data acquired for compositing occurred in 1- to 3-day intervals, which continued into period 11 (first 2-week period in September, fig. 6k), although most of the data for this period were acquired from the later part of the period. The remainder of September acquisitions (period 12) were spread throughout the 2week period except for a spike on the first day (day 260, fig. 61).

In period 13 (first 2 weeks in October, fig. $6 \mathrm{~m}$ ), most of the data were acquired during the middle and last parts of the time period, in contrast to period 14 (last 2-week period of the data set) when over 50 percent of the data were acquired on 2 days that were 4 days apart during the last half of October (fig. 6n).

1993

During the first period of 1993, over 60 percent of the data were acquired during the first 4 days (first week of April, fig. 7a), with the remainder being acquired primarily during the last week. Period 2 (fig. $7 \mathrm{~b}$ ) was somewhat similar in that almost 40 percent of the data were acquired during 1 day at the start of the period, with the remainder being distributed throughout the rest of the 2 weeks. 

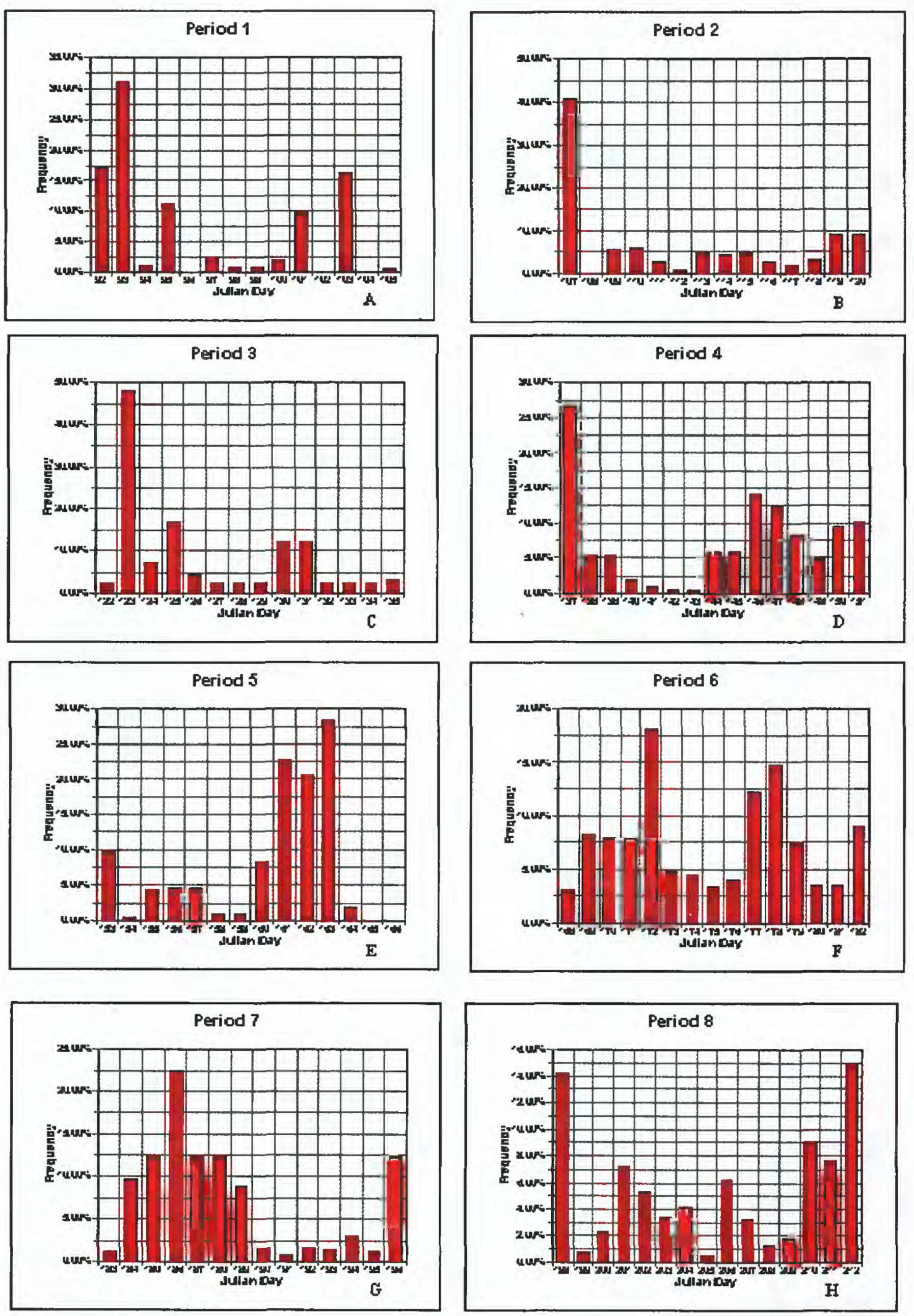

Figure 6. Distribution of AVHRR acquisition dates used for the compositing process for 1992 

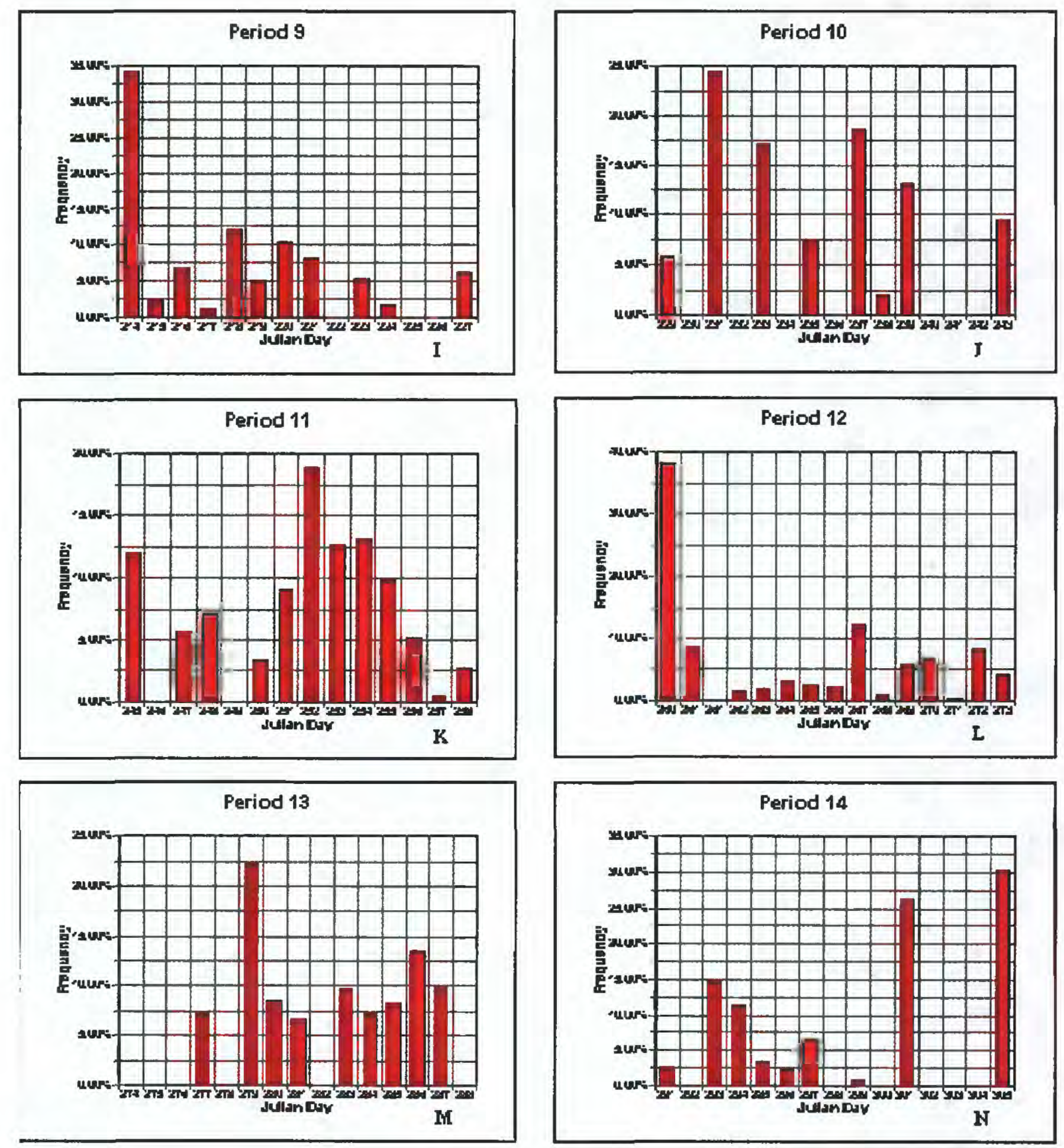

Figure 6. Distribution of AVHRR acquisition dates used for the compositing process for 1992 (continued) 
In period 3 (first 2 weeks in May, fig. 7c), most of the data (over 65 percent) were acquired during the first week of the period, with a strong spike on the last day of the period. This contrasts sharply with the fourth period (last 2-week period in May, fig. 7d) when most of the data came at the end of the 2-week period.

Period 5 (first 2 weeks in June, fig. 7e) was distinctly bimodal, with many of the acquisitions coming on the first 4 and last 4 days; no data were acquired from the middle 5 days of the biweekly period. Again, the last few days of the period received an increase in acquisitions, a time period of either less cloudy conditions and (or) higher NDVI, which extended into the first week of period 6 (fig. 7f). Period 6 (last 2 weeks of June, fig. 7f) was different in that most of the data were acquired from the first 8 days. A general trend for June 1993 was that most of the data were acquired during midmonth, dropping off toward the end of the month. During period 7 (first 2 weeks in July, fig. $7 \mathrm{~g}$ ) there was a paucity of data acquired the first week, with most data being acquired during the last 6 days, a feature which seemed to extend into the first week of period 8 (fig. $7 \mathrm{~h}$ ), although data acquisition extended throughout the 2 -week period for the rest of the month of July. Again, this may be of some concern for greenness studies that look at peak of greenness.

The first 2 weeks of period 9 (first half of August, fig. 7i) were bimodal, with most of the data being acquired in the second week. The trend of (more or less) peak acquisition every 10 days continued somewhat into period 10. The last two periods (11 and 12, September, fig. $7 \mathrm{k}$ and 71) were interesting because in period 11 , most of the data were acquired on 2 days (the first and seventh days of the month) and in period 12 , most of the data were acquired during midmonth. This pattern is probably due to increasing inclement weather during this time of year.

1994

All of the periods in 1994 displayed some sort of bimodal or Poisson shape in the date acquisition histograms. In period 1 (first part of April, fig. 8a), most of the data were acquired during midperiod, in contrast to period 2 (last half of April, fig. 8b), when most of the data were acquired during the first 2 days, with a minor amount acquired during the latter part of the period. Periods 3 and 4 (first and last half of May, respectively, figs. 8c and 8d) were distinctly bimodal, with most of the data being acquired during the first or latter parts of the periods. In contrast, period 5 ( first 2 weeks in June, fig. 8e) showed a Poisson shape with over 60 percent of the data being acquired 3 consecutive days at the end of the period. The second period in June (period 6 , fig. 8f) also was bimodal, with no data acquired on days 4 through 7 , and most of the data being acquired later in the 2 week period. During period 7 (first 2 weeks of July, fig. 8g), roughly onehalf of the data were acquired during the first 2 days, a possible extension of good weather from the previous period, with the other half being acquired primarily during the second week. In contrast, data for period 8 (last 2 weeks in July, fig. $8 \mathrm{~h}$ ) were acquired predominately during the last 7 days.

Periods 9 and 10 (first and second half of August, figs. 8i and 8j) were similar in that most of the data came from the first week in the time period, with a 4-day gap in the middle of period 10.

Period 11, the last period for this year (first 2 weeks in September, fig. 8k) was slightly bimodal, with 8 percent of the data coming from the first day of the period (probably a continuation of the trend from period 10) and then the rest being acquired during the second 

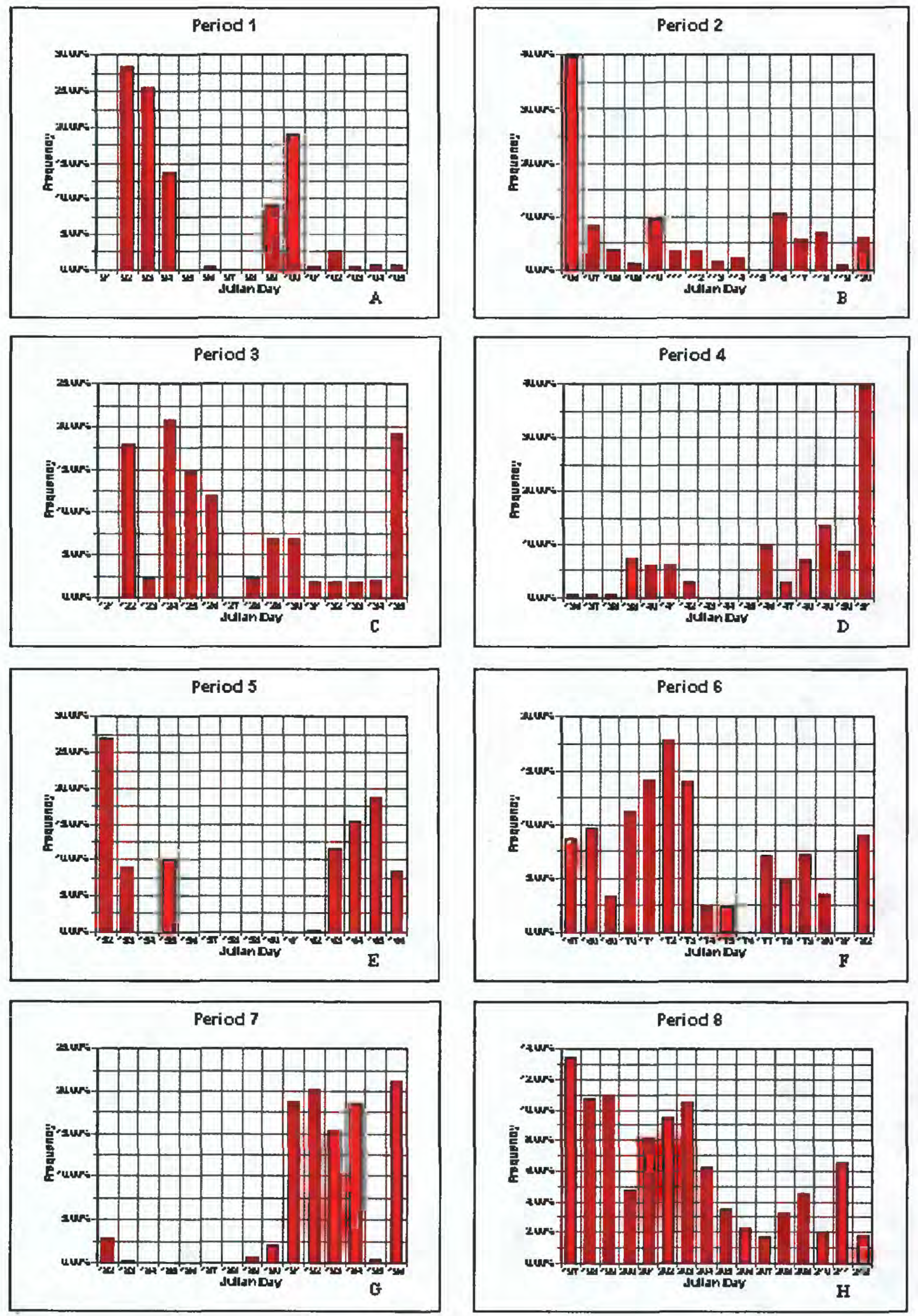

Figure 7. Distribution of AVHRR acquisition dates used for the compositing process for 1993 

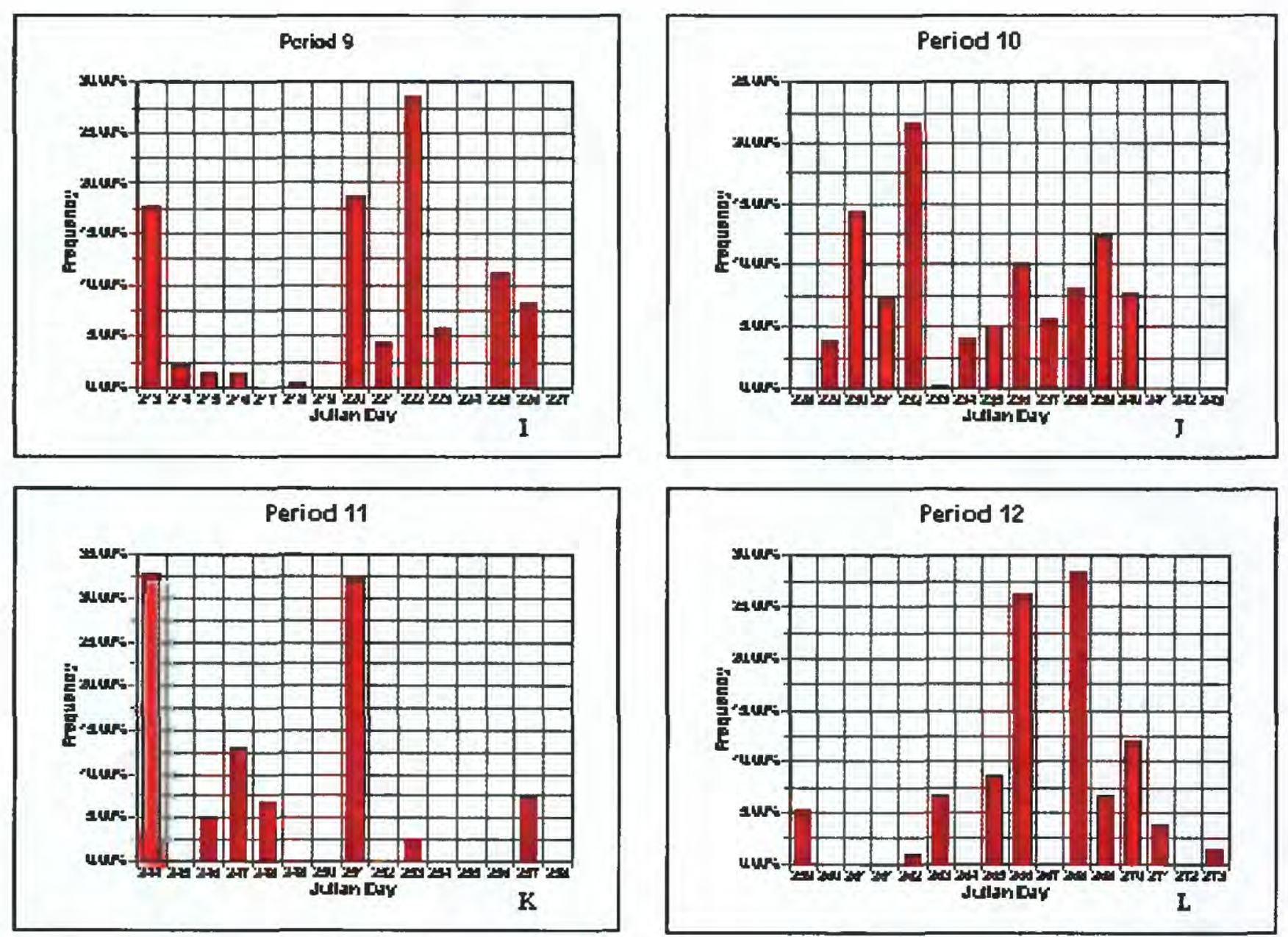

Figure 7. Distribution of AVHRR acquisition dates used for the compositing process for 1993 

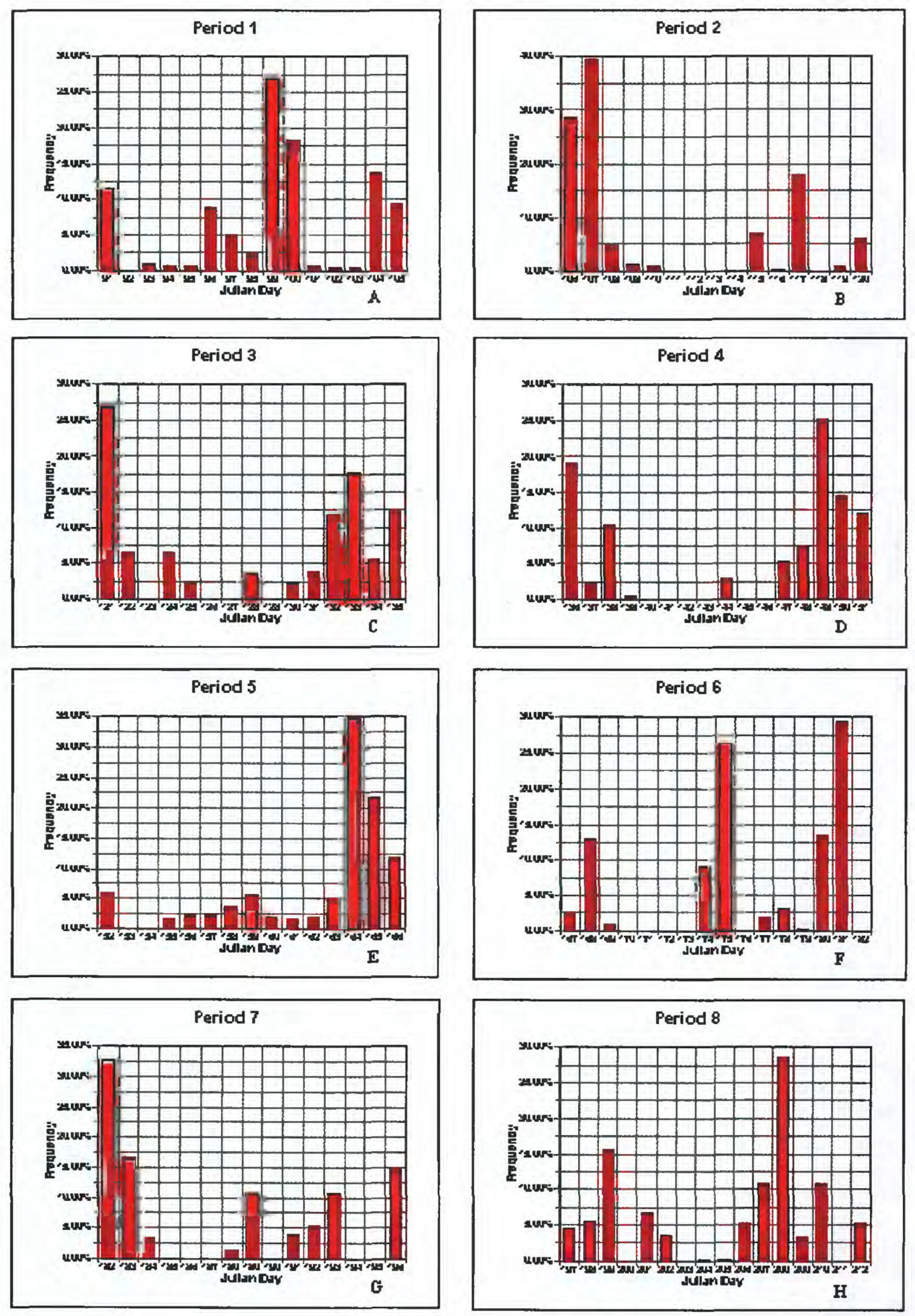

Figure 8. Distribution of AVHRR acquisition dates used for the compositing process for 1994 

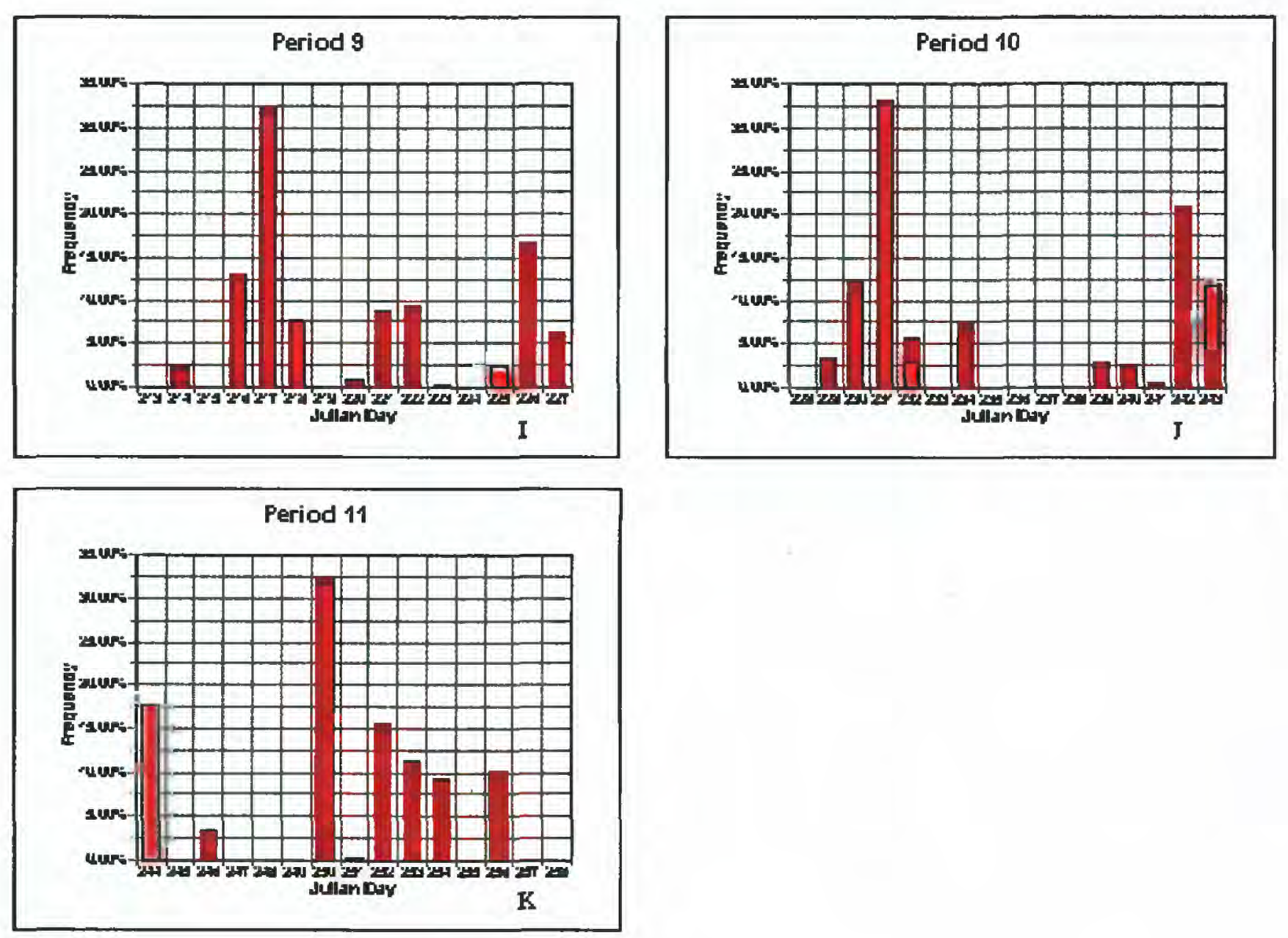

Figure 8. Distribution of AVHRR acquisition dates used for the compositing process for 1994 (continued) 
week of the period.

1995

Beginning in 1995, data were based on a 14-day period instead of the 15- or 16-day periods of the 1991-94 data sets. During 1995, the data were more spread out across the 14-day period than they were in the previous years' 15 - or 16-day periods.

During periods 1 and 2 (April $1-28$, figs.9a and 9b), most of the data were acquired during the first few days of the period, with almost 40 percent of the data for period 2 being acquired the first day. Period 3 (April 29 - May 12, fig. 9c) was distinctly bimodal, although most of the data were acquired the last 4 days of the period.

Data acquisitions for periods 4 and 5 (May 13 - 26 and May 27 - 9 June, respectively, figs. 9c and 9d) were spread throughout the two periods, with the trend extending into the first part of period 6 (June $10-23$, fig. 9f). Period 6 was slightly bimodal, with much of the data being acquired during the early and later parts of the period.

Most of the data for period 7 (June 24 - 7 July, fig. 9g) were acquired toward the end of the compositing period, whereas data acquired during period 8 (July $8-21$ July, fig. 9h) were somewhat distributed throughout the 14-day period.

During period 9 (July 22 - 4 August, fig. 9i), most of the data were acquired within the first 7 days, compared to period 10 (August 5 - 18, fig. 9j), when the data were distributed within two peak times, and period 11 (August 19 - 1 September, fig. 9k), with data acquisition scattered throughout the time period.

Data for period 12 (September 2 - 13, fig. 91) were acquired primarily during the first 5 days, perhaps indicating the onset of wetter autumn conditions; however, this condition repeated itself for period 13 (fig. $9 \mathrm{~m}$ ). Fully one-fourth of the composited data used for period 13 came from the first day of the period (September 16), with the remainder coming from midperiod. Most of the composite data acquired for the first week of 14 period (September 30 - October 13, fig. 9n) were obtained from the first week.

1996

Periods 1 and 2 (figs. 10a and 10b) for 1996 were similar to previous early season acquisitions in that over 50 percent of the data were acquired in a 2- to 4-day period, first around Julian days 91-94 (April 1-4) and next around Julian days 105-108 (April 15-18). On the other hand, period 3 (fig. 10c) was more similar to 1995 than to the other years in that a little over half of the data were acquired during 2 days (Julian days 119 and 132, fig. 10c). Data acquisitions for the remainder of May (period 4, fig. 10d) were fairly well distributed throughout the time period.

During period 5 (fig. 10e), most of the acquisitions were made in the first week of June (Julian dates 154-157), a time when green-up is progressing, whereas in period 6 (fig. 10f), the acquisitions were again distributed throughout most of the period. During beginning of peak of greenness for much of the State, period 7 (June 24 - July 7, fig. $10 \mathrm{~g}$ ) data were acquired primarily from the middle to the end of the period. During the peak of greenness, data acquisitions for periods 8 (July 8-21, fig. 10h) and 9 (July 22 - 4 August, fig. 10i), were distributed throughout the time.

Data acquisitions for period 10 (August 5-18, fig.10j) were bimodal, with roughly half of the data composited from the first 3 days of the period and the rest from the last 8 days. The low 

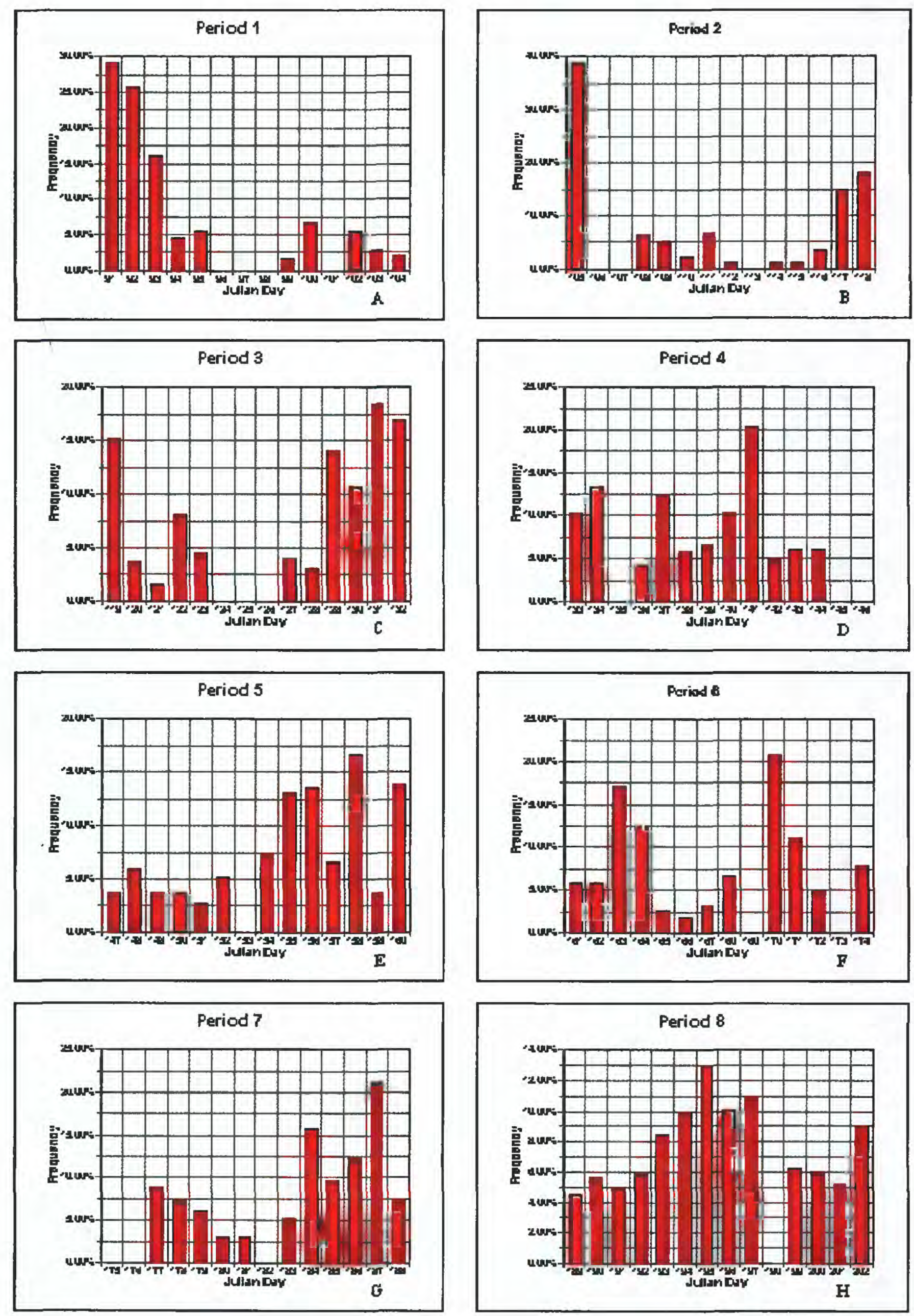

Figure 9. Distribution of AVHRR acquisition dates used for the compositing process for 1995 

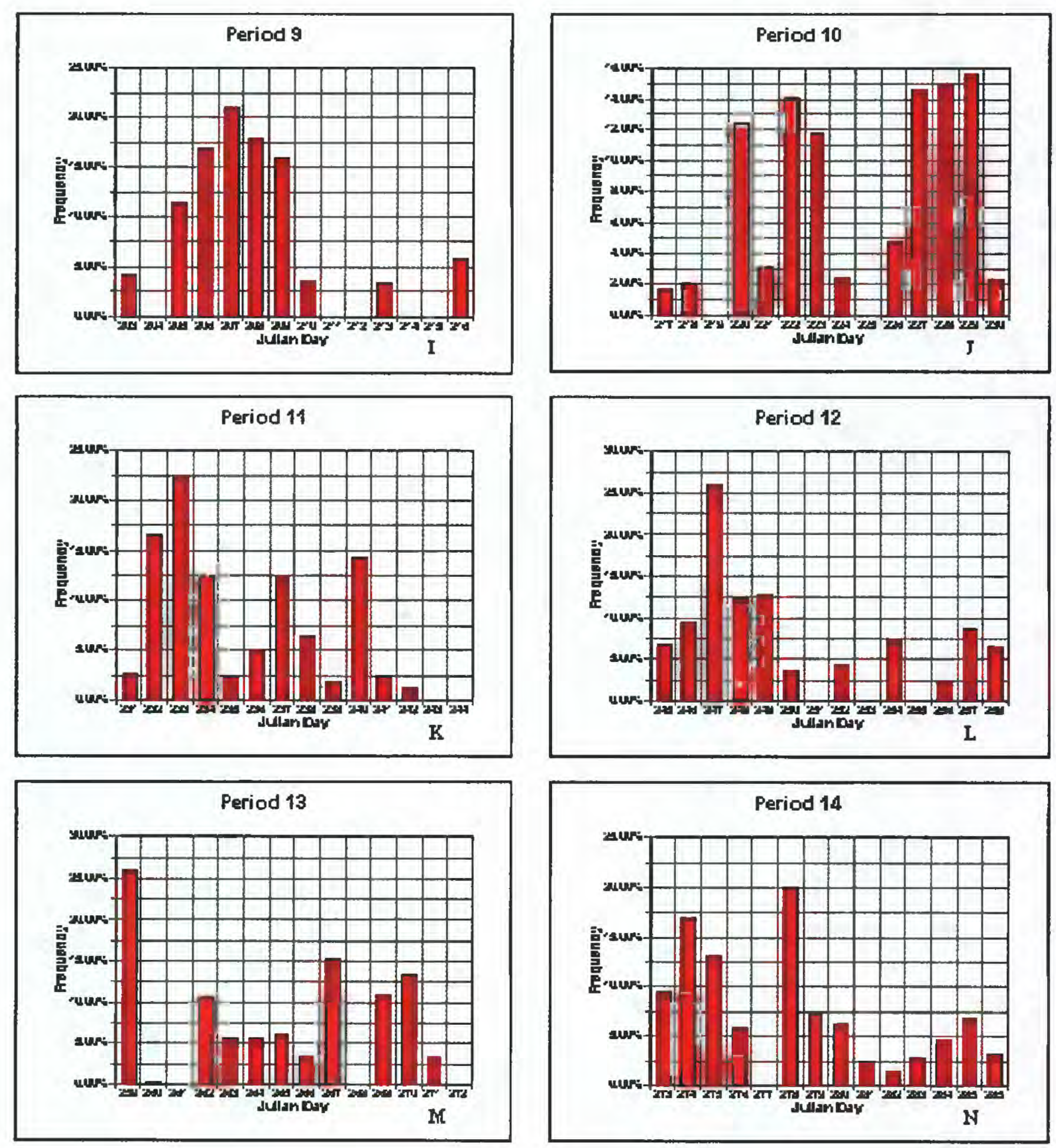

Figure 9. Distribution of AVHRR acquisition dates used for the compositing process for 1995 (continued) 

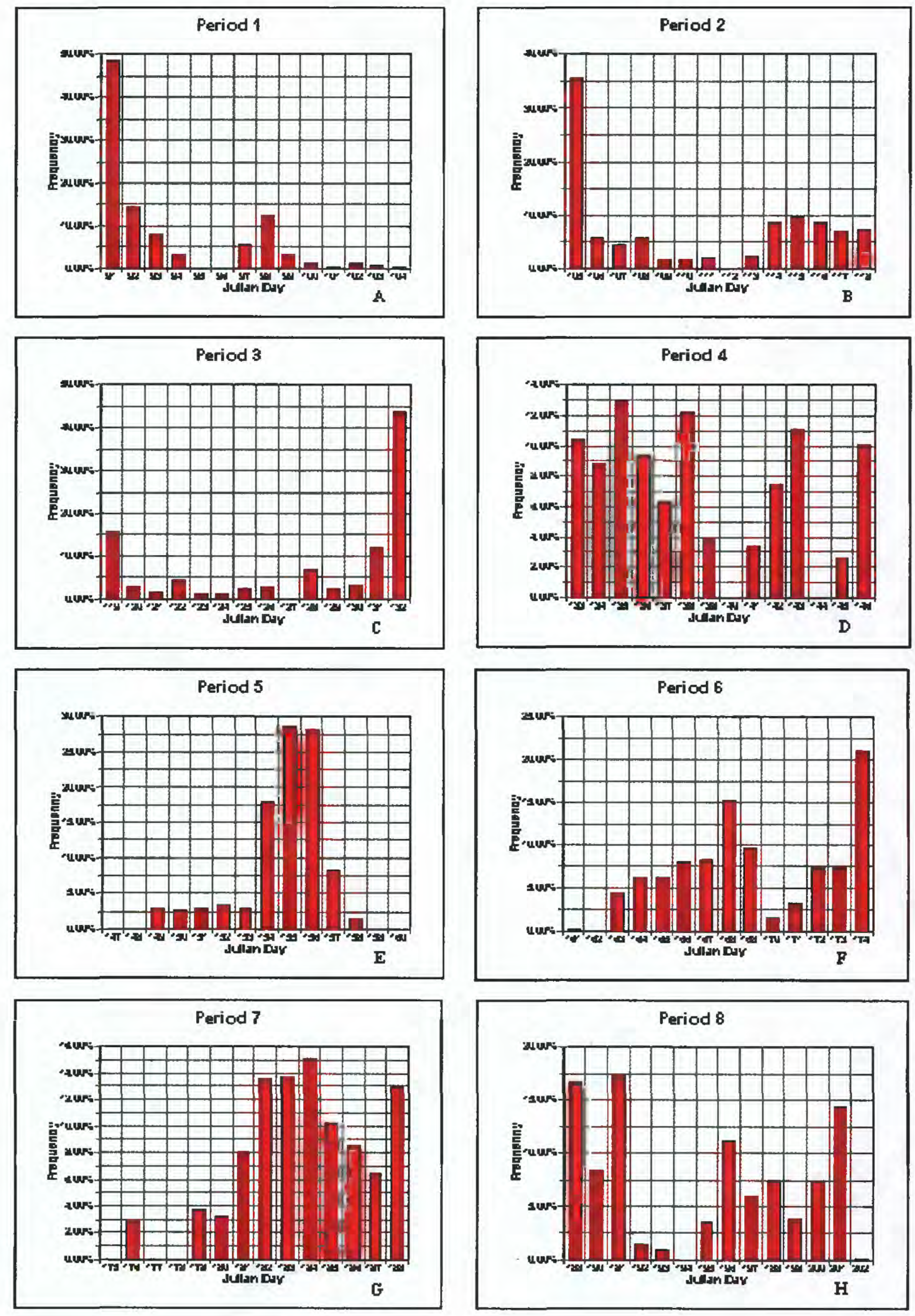

Figure 10. Distribution of AVHRR acquisition dates used for the compositing process for 1996 

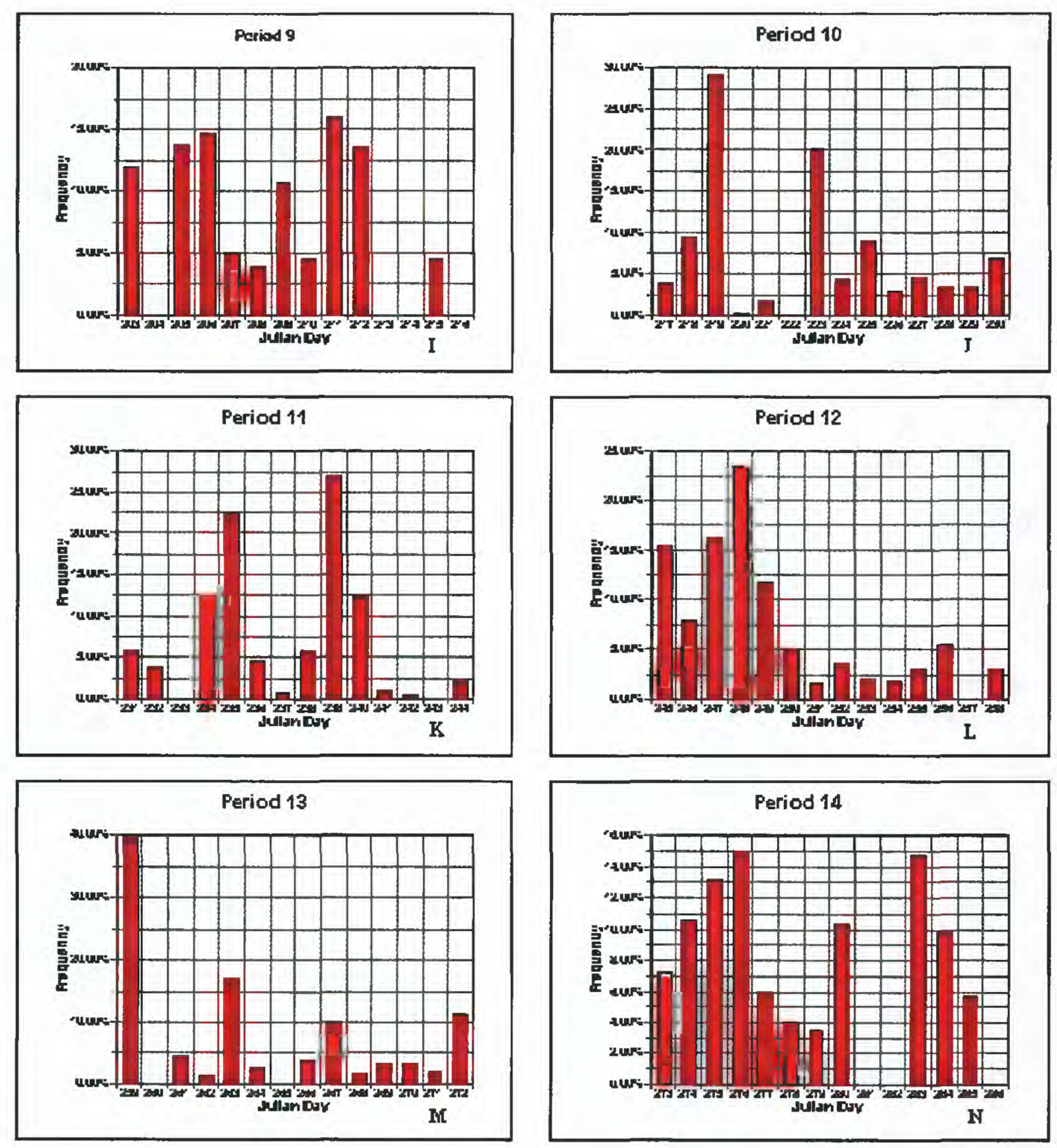

Figure 10. Distribution of AVHRR acquisition dates used for the compositing process for 1996 (continued) 
acquisition during the later days of period 10 continued into period 11 (August 19 - September 1); most data acquisitions occurred midperiod with two small peaks during an 8-day time sequence.

During period 12 (September 2-13, fig. 101), most of the data were acquired in the first 5 days, a time period when leaf senescence had started. Period 13 (fig. $10 \mathrm{~m}$ ) was similar to period 13 for 1995 because the bulk of the data (close to 40 percent in this case) came from the first day of the period, with the rest being accessed during the following 13 days. Period 14 (fig. 10n) was also similar to 1995, although over half of the data were obtained during the first 8 days.

1997

The first period in 1997 (fig. 11a) was similar to 1995 and 1996 in that the bulk of the data used for the composite came from the first 3 days of the period. In contrast, the bulk of data in period 2 (fig. 11b) came from days 105 (the first day of the period, April 15 ) and 110 (April 20).

During period 3 (fig. 11c), most of the data were acquired midperiod, as compared to period 4 (May $13-26$, fig. 11d) when most of the data came from the last 2 days (May 25-26). This is of some concern because most of the green-up in Alaska occurs during May. In period 5 (fig. 11e), the data were collected throughout the 14-days, with a slight increase in data acquisitions at the end of the period. The increase in data acquisitions did not continue into period 6 (fig. 11f), however, when the bulk of the data was obtained during the last 5 days.

Most of the data acquired for period 7 (fig. 11g) were obtained during the first 8 days, with only 1 day not contributing to the data set. During period 8 (fig. $11 \mathrm{~h}$ ), the data were distributed fairly evenly throughout the 14-days, with 2 days not contributing to the data.

For period 9 (fig. 11i), the bulk of the data was acquired midperiod (toward the end of July) when greenness is at or near its peak throughout Alaska. This is in contrast to period 10 (fig. 11j) when the distribution of data collected was bimodal, with the bulk collected toward the end of the period. This trend seemed to continue somewhat into period 11 (fig. $11 \mathrm{k}$ ), when almost 35 percent of the data used during the composite period came from the first day of the period (Julian day 231, or August 19), with most of the rest being acquired at the start of senescence.

In period 12 (fig. 111), data acquisition was somewhat distributed throughout 2 weeks, although the majority of the data came toward the end.

For the last two periods, data acquisition was trimodal for period 13 (fig. $11 \mathrm{~m}$ ) and somewhat bimodal for period 14 (fig. $11 \mathrm{n}$ ). Such patterns are not surprising because these two periods are at the end of the growing season, when greenness data are scarce and inclement weather begins to set in.

\section{Satellite Scan Angle Distribution}

Figures 12 through 18 show frequency of satellite scan angles obtained for each composite period. Tables 7 through 13 summarize the data into seven categories: data obtained at nadir, data within 30, 40, and 55 degrees of nadir, data greater than 55 degrees off nadir, and percentages of the data that represent west and east look angles. 

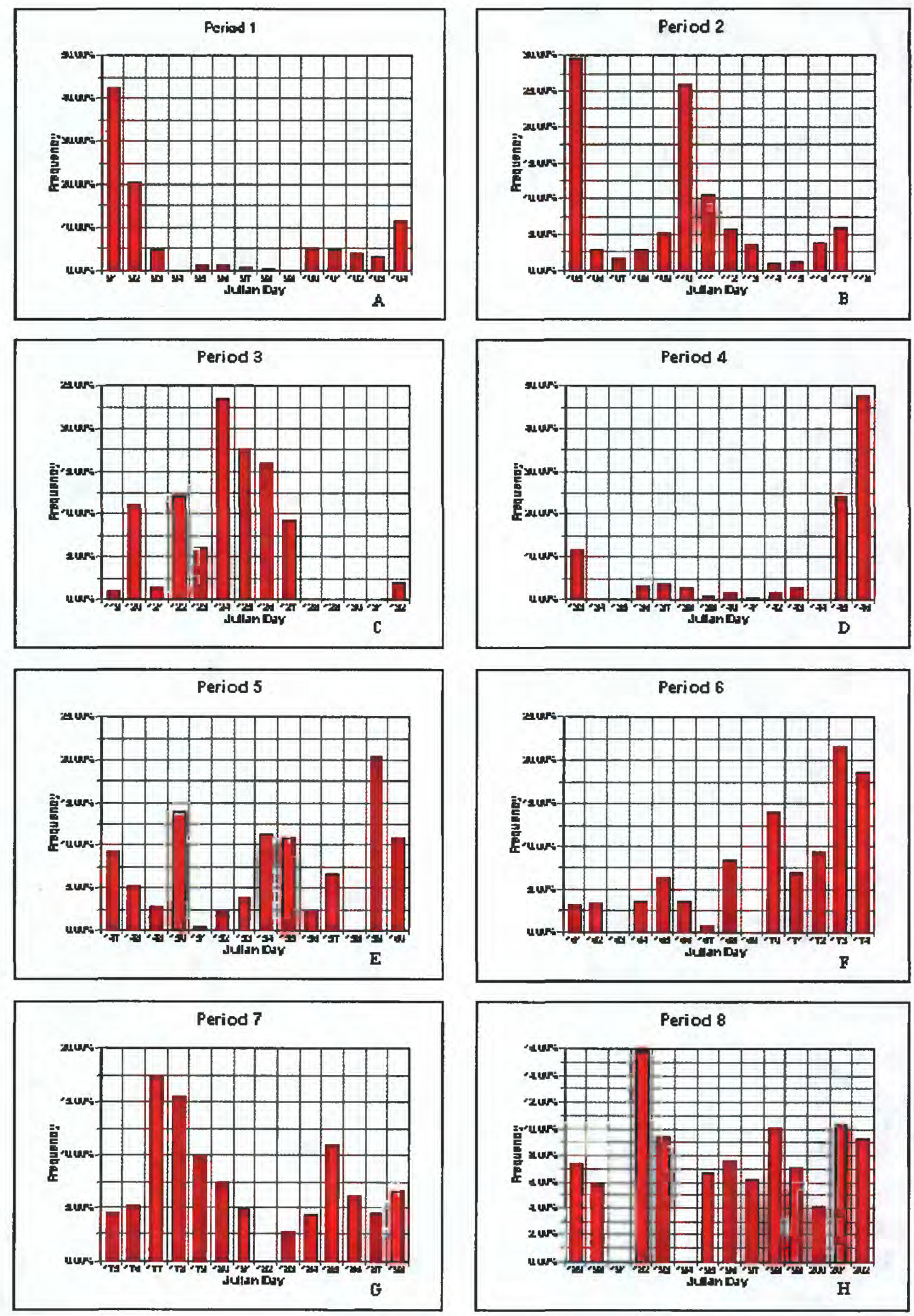

Figure 11. Distribution of AVHRR acquisition dates used for the compositing process for 1997 

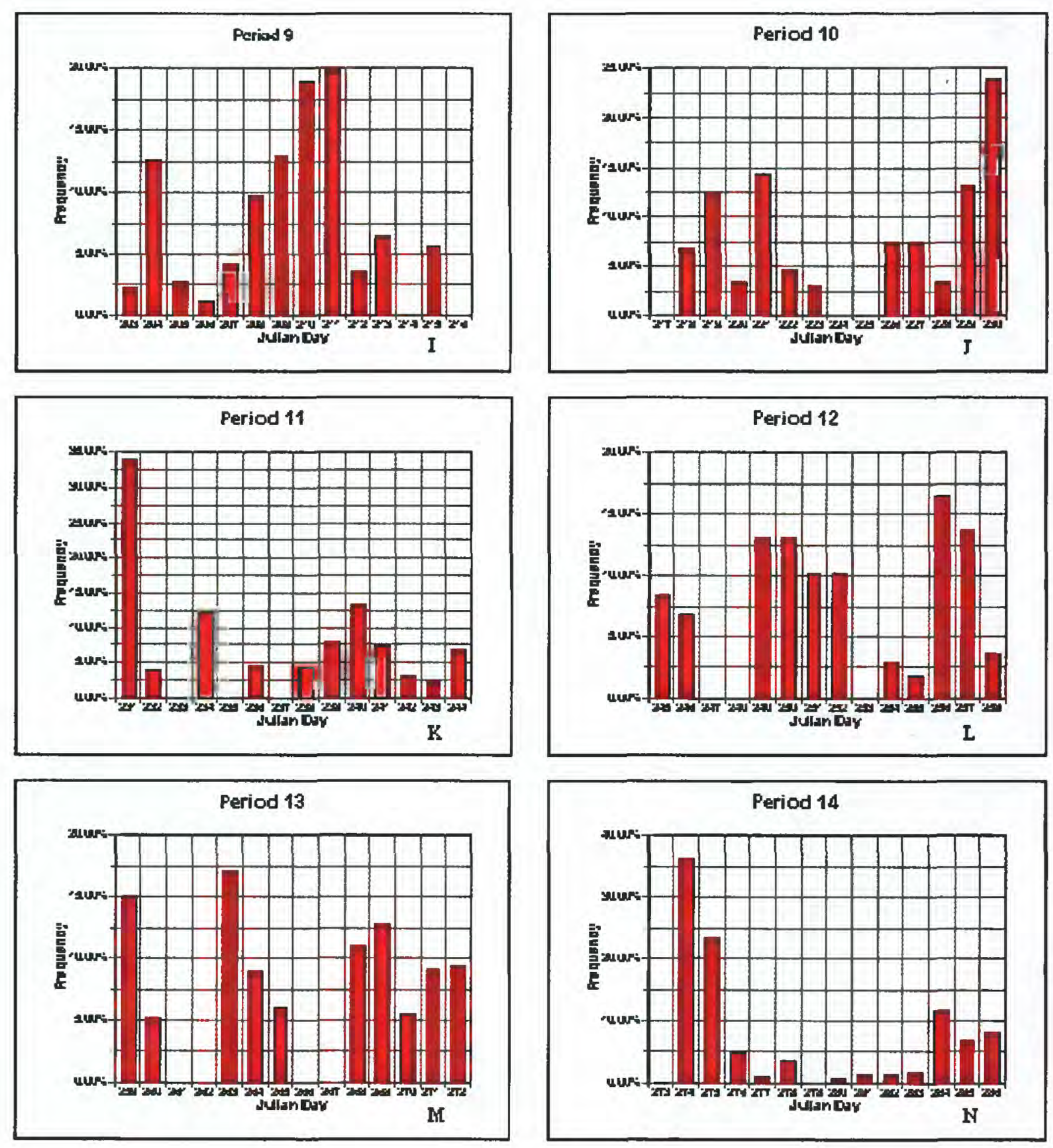

Figure 11. Distribution of AVHRR acquisition dates used for the compositing process for 1997 (continued) 
1991

Scan angle values for 1991 (fig. 12, table 7) were predominantly less than $+/-55$ degrees (nominal view of the satellite) for the core months of the growing season (late May to late August). Period 1 (April 1-15) had a small spike greater than -55 degrees, but it amounted to less than 6 percent of the total pixels. Period 3 (May 15-31) had the greatest number of pixels with off-nadir viewing, with over 13 percent of the data being greater than $+/-55$ degrees. Other periods with view angles greater than $+/-55$ degrees were less than 2 percent, except for early and late in the year (periods 1 and 2, and 12 and 13; table 7). As a whole, less than 1.5 percent of the total pixels in the 13 different periods had viewing angles at nadir, although, in most cases, 50 - 70 percent of the data were within $+/-30$ degrees view angle.

Table 7 Summary of satellite scan angle distribution for 1991

\begin{tabular}{cccccrrr}
\hline Period & Nadir & $+/-30$ & $+/-40$ & $+/-55$ & $>+/-55$ & West (-) & East (+) \\
\hline 1 & $0.35 \%$ & $42.25 \%$ & $58.91 \%$ & $93.72 \%$ & $5.93 \%$ & $67.40 \%$ & $32.24 \%$ \\
2 & $0.58 \%$ & $51.56 \%$ & $71.78 \%$ & $96.84 \%$ & $2.59 \%$ & $48.56 \%$ & $50.86 \%$ \\
3 & $0.63 \%$ & $41.23 \%$ & $58.13 \%$ & $85.57 \%$ & $13.80 \%$ & $31.79 \%$ & $67.58 \%$ \\
4 & $1.05 \%$ & $62.25 \%$ & $78.99 \%$ & $97.30 \%$ & $1.65 \%$ & $53.57 \%$ & $45.37 \%$ \\
5 & $1.14 \%$ & $63.02 \%$ & $\mathbf{8 1 . 0 9 \%}$ & $97.79 \%$ & $1.07 \%$ & $53.89 \%$ & $44.97 \%$ \\
6 & $0.91 \%$ & $60.65 \%$ & $\mathbf{8 2 . 0 3 \%}$ & $98.54 \%$ & $0.55 \%$ & $32.04 \%$ & $67.04 \%$ \\
7 & $1.16 \%$ & $56.83 \%$ & $74.39 \%$ & $97.65 \%$ & $1.19 \%$ & $65.42 \%$ & $33.42 \%$ \\
8 & $1.24 \%$ & $67.50 \%$ & $83.96 \%$ & $97.80 \%$ & $0.96 \%$ & $33.04 \%$ & $65.72 \%$ \\
9 & $1.06 \%$ & $65.18 \%$ & $84.06 \%$ & $97.77 \%$ & $1.17 \%$ & $60.10 \%$ & $38.84 \%$ \\
10 & $1.49 \%$ & $70.64 \%$ & $86.34 \%$ & $97.36 \%$ & $1.14 \%$ & $41.83 \%$ & $56.68 \%$ \\
11 & $0.72 \%$ & $56.26 \%$ & $80.02 \%$ & $97.67 \%$ & $1.62 \%$ & $44.14 \%$ & $55.14 \%$ \\
12 & $1.27 \%$ & $70.04 \%$ & $81.97 \%$ & $94.74 \%$ & $3.99 \%$ & $51.74 \%$ & $46.99 \%$ \\
13 & $1.09 \%$ & $65.10 \%$ & $77.13 \%$ & $95.75 \%$ & $3.16 \%$ & $58.52 \%$ & $40.39 \%$ \\
\hline
\end{tabular}

Look direction varied between periods, with no prominent orientation for the year (table 7). Some periods showed a greater than average orientation toward one direction; however, these tendencies did not appear to be seasonally oriented.

1992

The 1992 data set was somewhat similar to 1991 because 2 percent or less of the pixels within the composite period were within the nadir view angle. However, all periods except the last three contained more than 4 percent of the pixels in excess of $+/-55$ degrees, with four periods exceeding 10 percent (table 8 ). The number of pixels within $+/-30$ degree view angle was slightly less than in 1991, but not substantially. Also, most of the periods contained pixels with the majority of the view angles ( 90 percent or better) within $+/-55$ degrees of nadir.

Look angles favored a slightly easterly direction for 1992 data (table 8), for 9 of the 14 periods. An interesting note is that the last three periods of 1992 were strongly skewed to the west (figs. $131,13 \mathrm{~m}$, and $13 \mathrm{n}$ ) with period 14 having a very strong westerly orientation ( 83 percent of the pixels, table 8).

1993

View angles for 1993 (fig. 14) were better than for the previous years because generally 

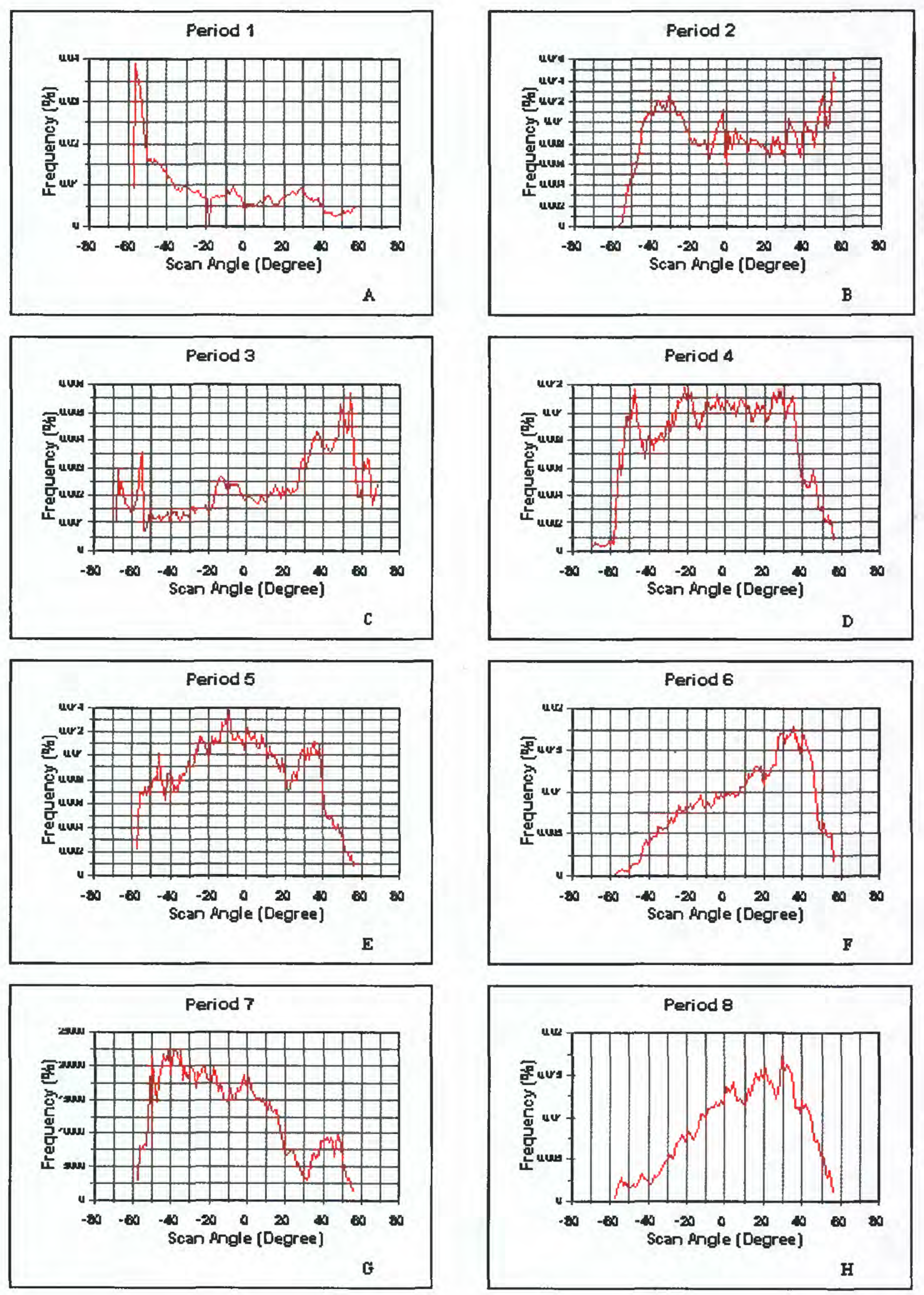

Figure 12. Distribution of AVHRR satellite scan angles for 1991 

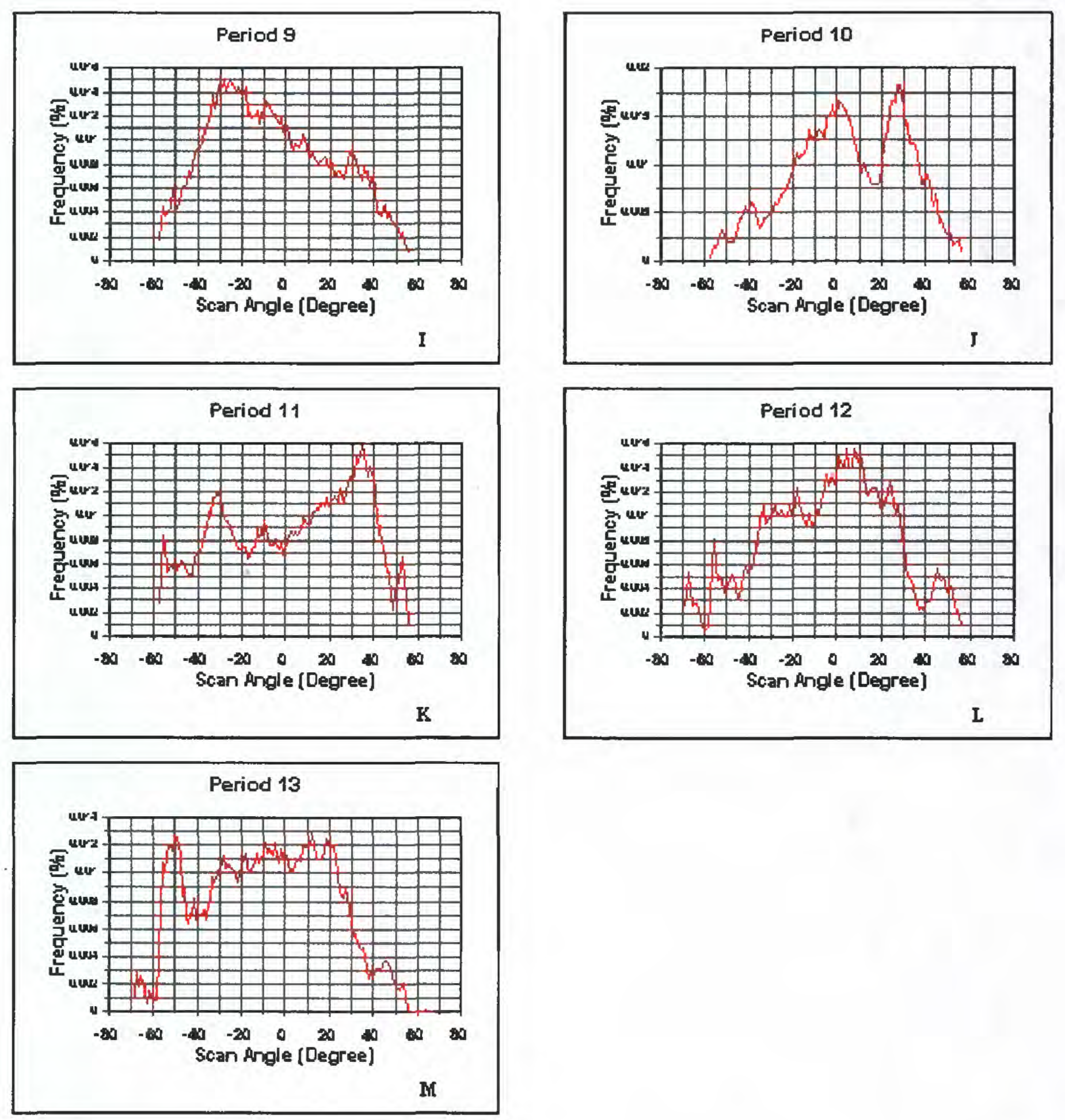

Figure 12. Distribution of AVHRR satellite scan angles for 1991 (continued) 

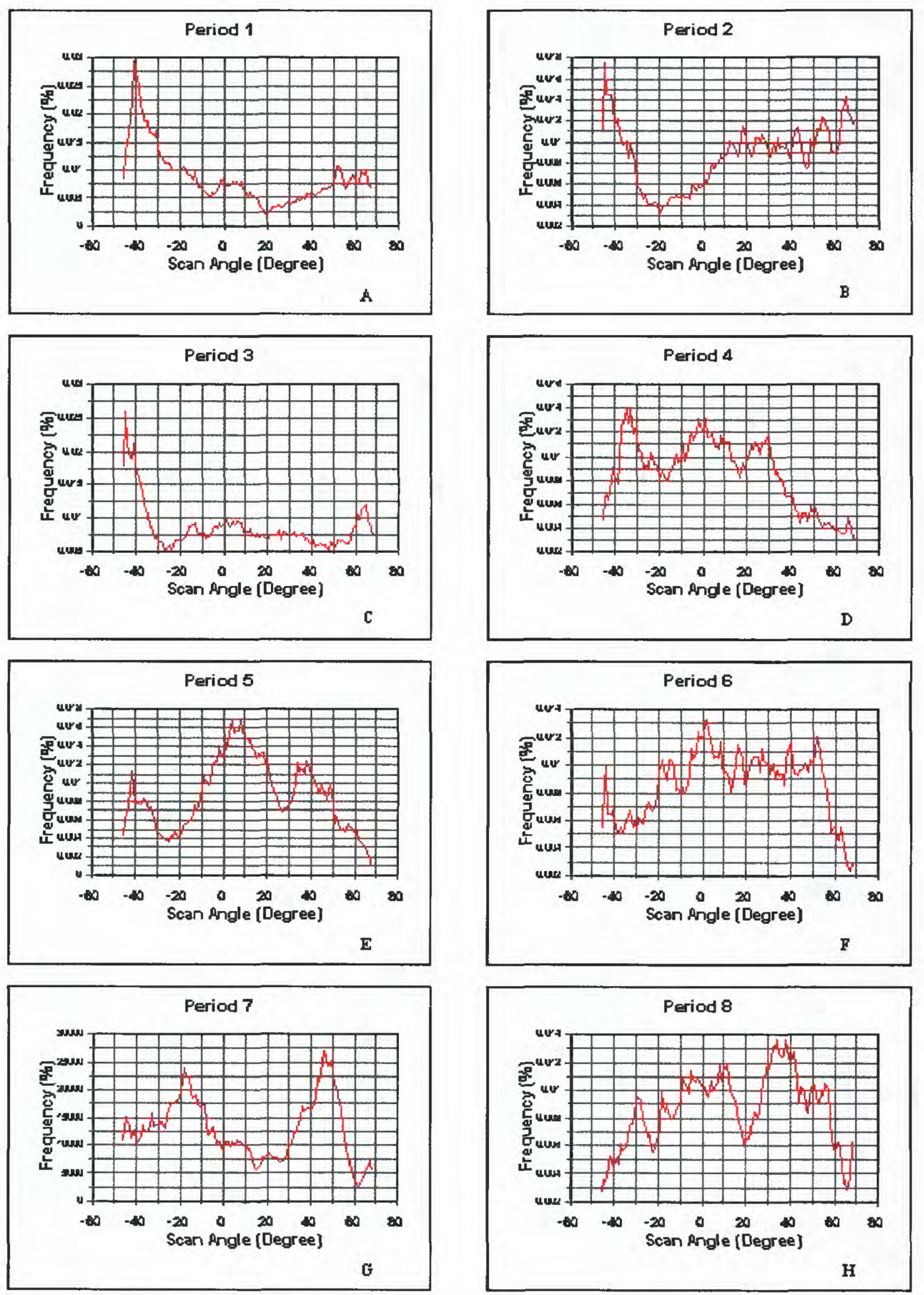

Figure 13. Distribution of AVHRR satellite scan angles for 1992 

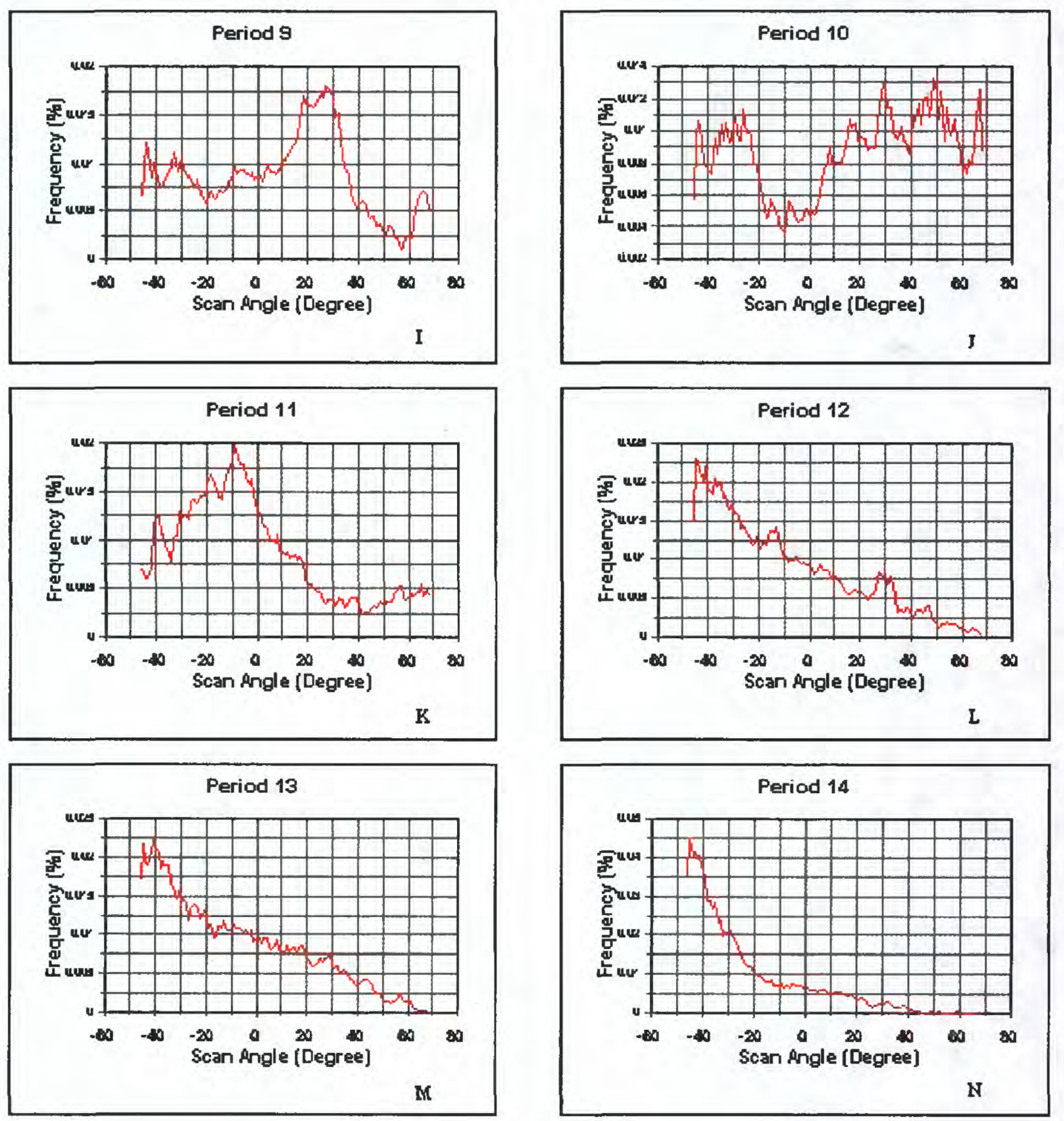

Figure 13. Distribution of AVHRR satellite scan angles for 1992 (continued) 
Table 8 Summary of satellite scan angle distribution for 1992

\begin{tabular}{clllrrrr}
\hline Period & Nadir & $+/-30$ & \multicolumn{1}{l}{$/-40$} & \multicolumn{1}{c}{$/-55$} & $>+/-55$ & West (-) & East (+) \\
\hline 1 & $0.79 \%$ & $41.96 \%$ & $66.82 \%$ & $88.61 \%$ & $10.60 \%$ & $57.39 \%$ & $41.82 \%$ \\
2 & $0.58 \%$ & $41.52 \%$ & $60.98 \%$ & $84.72 \%$ & $14.70 \%$ & $32.81 \%$ & $66.61 \%$ \\
3 & $0.93 \%$ & $46.45 \%$ & $65.39 \%$ & $87.20 \%$ & $11.87 \%$ & $46.62 \%$ & $52.46 \%$ \\
4 & $1.21 \%$ & $62.26 \%$ & $81.93 \%$ & $93.68 \%$ & $5.11 \%$ & $45.92 \%$ & $52.87 \%$ \\
5 & $1.29 \%$ & $59.03 \%$ & $77.16 \%$ & $93.77 \%$ & $4.95 \%$ & $33.65 \%$ & $65.06 \%$ \\
6 & $1.21 \%$ & $57.34 \%$ & $73.00 \%$ & $92.53 \%$ & $6.27 \%$ & $36.17 \%$ & $62.63 \%$ \\
7 & $0.63 \%$ & $49.99 \%$ & $68.22 \%$ & $94.62 \%$ & $4.75 \%$ & $46.31 \%$ & $53.06 \%$ \\
8 & $1.02 \%$ & $54.64 \%$ & $73.60 \%$ & $91.08 \%$ & $7.90 \%$ & $34.84 \%$ & $64.14 \%$ \\
9 & $0.86 \%$ & $63.57 \%$ & $82.17 \%$ & $93.84 \%$ & $5.30 \%$ & $38.88 \%$ & $60.26 \%$ \\
10 & $0.46 \%$ & $46.24 \%$ & $65.27 \%$ & $87.57 \%$ & $11.97 \%$ & $34.11 \%$ & $65.43 \%$ \\
11 & $1.31 \%$ & $69.20 \%$ & $83.35 \%$ & $92.80 \%$ & $5.89 \%$ & $61.55 \%$ & $37.14 \%$ \\
12 & $0.91 \%$ & $57.88 \%$ & $81.17 \%$ & $97.67 \%$ & $1.42 \%$ & $67.69 \%$ & $31.40 \%$ \\
13 & $0.93 \%$ & $58.63 \%$ & $81.65 \%$ & $97.75 \%$ & $1.32 \%$ & $65.18 \%$ & $33.89 \%$ \\
14 & $0.62 \%$ & $45.29 \%$ & $74.47 \%$ & $99.22 \%$ & $0.16 \%$ & $83.50 \%$ & $15.87 \%$ \\
\hline
\end{tabular}

less than 3 percent of the pixels exceeded $+/-55$ degrees off nadir (table 9). Except for late June and early July (periods 6 and 7), less than 1 percent of the pixels were at nadir, with periods 6 and 7 barely achieving 1 percent. In 1993, look angles were predominantly eastward, although only periods 2, 5, 8, and 11 (late April, early June, late July, and early September, respectively) seemed to be skewed significantly (figs. $14 \mathrm{~b}, 14 \mathrm{e}, 14 \mathrm{~h}$, and $14 \mathrm{k}$ ).

Table 9 Summary of satellite scan angle distribution for 1993

\begin{tabular}{clllllll}
\hline Period & Nadir & $+/-30$ & $+/-40$ & $+/-55$ & $>+/-55$ & West (-) & East (+) \\
\hline 1 & $0.45 \%$ & $43.57 \%$ & $60.29 \%$ & $96.85 \%$ & $2.70 \%$ & $44.10 \%$ & $55.45 \%$ \\
2 & $0.45 \%$ & $52.14 \%$ & $71.93 \%$ & $97.75 \%$ & $1.79 \%$ & $30.37 \%$ & $69.17 \%$ \\
3 & $0.42 \%$ & $42.09 \%$ & $59.23 \%$ & $96.60 \%$ & $2.98 \%$ & $58.73 \%$ & $40.85 \%$ \\
4 & $0.72 \%$ & $67.36 \%$ & $83.36 \%$ & $98.70 \%$ & $0.58 \%$ & $38.06 \%$ & $61.22 \%$ \\
5 & $0.56 \%$ & $60.85 \%$ & $80.18 \%$ & $98.10 \%$ & $1.34 \%$ & $27.86 \%$ & $71.58 \%$ \\
6 & $1.01 \%$ & $59.57 \%$ & $76.02 \%$ & $97.74 \%$ & $1.25 \%$ & $38.25 \%$ & $60.75 \%$ \\
7 & $1.01 \%$ & $70.45 \%$ & $84.56 \%$ & $97.96 \%$ & $1.04 \%$ & $44.49 \%$ & $54.50 \%$ \\
8 & $0.56 \%$ & $72.51 \%$ & $88.84 \%$ & $98.35 \%$ & $1.08 \%$ & $27.78 \%$ & $71.65 \%$ \\
9 & $0.70 \%$ & $67.40 \%$ & $83.83 \%$ & $98.17 \%$ & $1.12 \%$ & $49.45 \%$ & $49.84 \%$ \\
10 & $0.54 \%$ & $68.58 \%$ & $87.01 \%$ & $98.33 \%$ & $1.12 \%$ & $45.61 \%$ & $53.84 \%$ \\
11 & $0.38 \%$ & $60.70 \%$ & $80.18 \%$ & $99.00 \%$ & $0.61 \%$ & $24.58 \%$ & $75.04 \%$ \\
12 & $0.68 \%$ & $63.28 \%$ & $86.13 \%$ & $99.04 \%$ & $0.28 \%$ & $54.90 \%$ & $44.42 \%$ \\
\hline
\end{tabular}



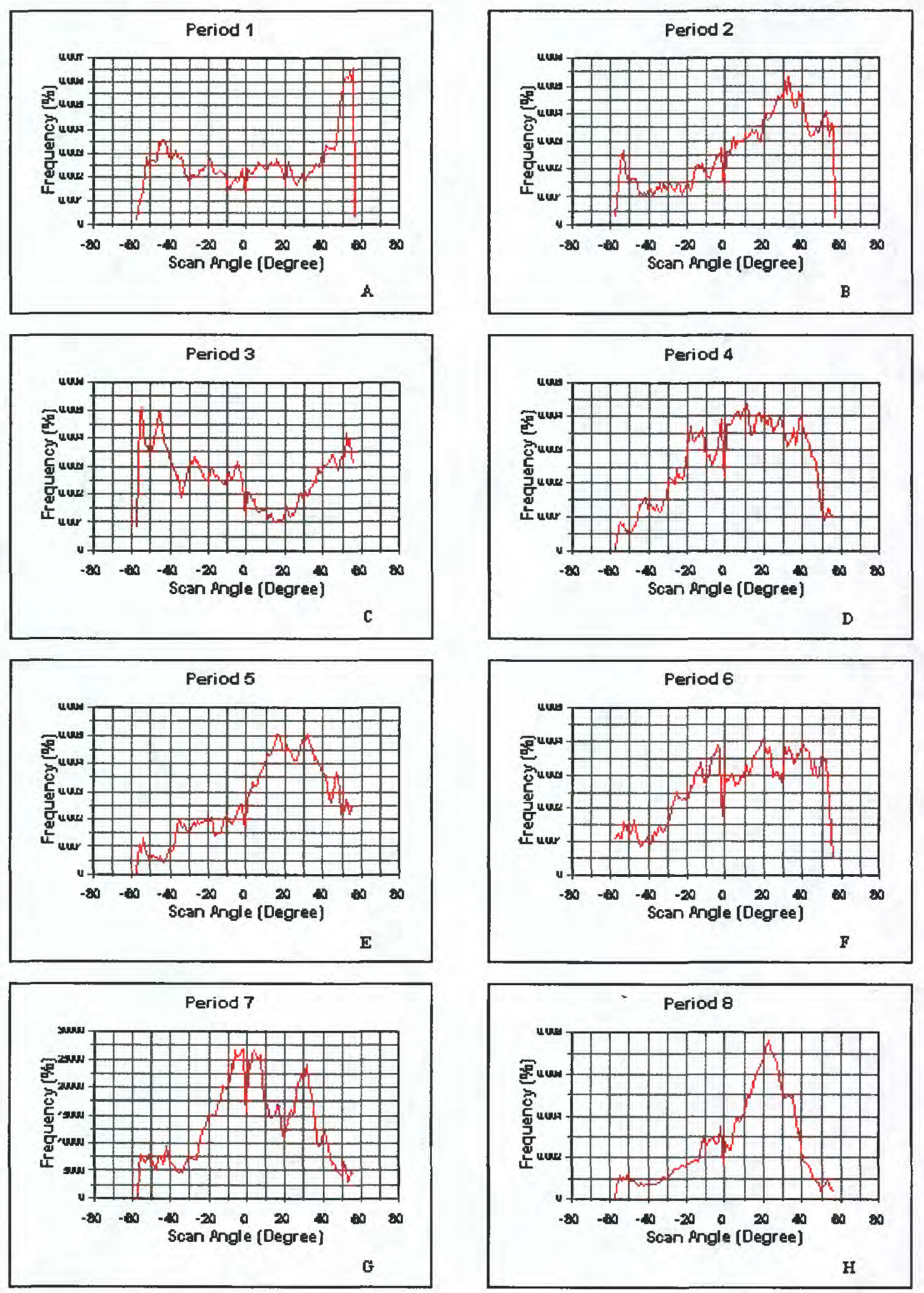

Figure 14. Distribution of AVHRR satellite scan angles for 1993 

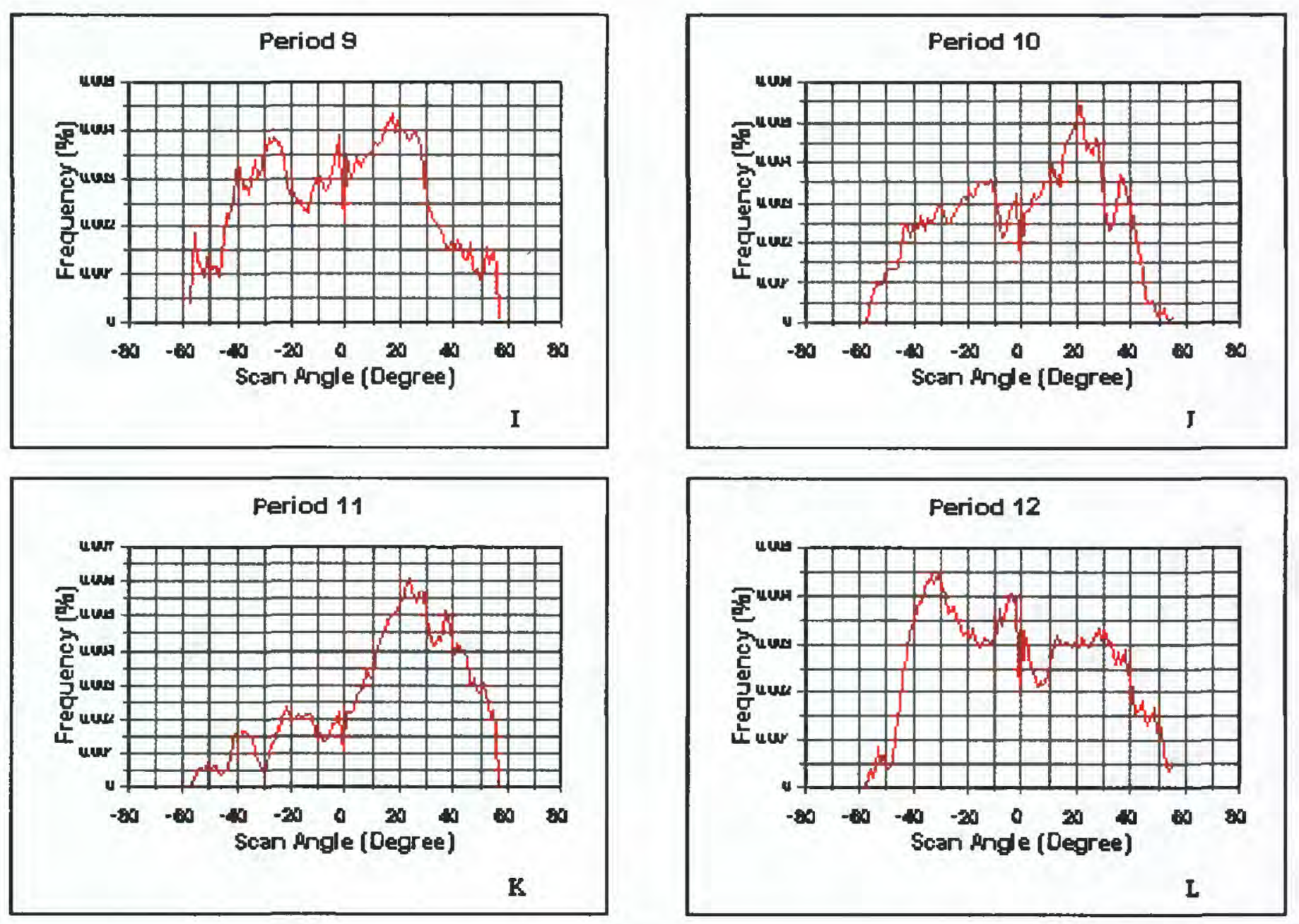

Figure 14. Distribution of AVHRR satellite scan angles for 1993 (continued) 
1994

View angles for 1994 (fig. 15) were similar to those for the previous years, although there were slightly less pixels with look angles near nadir (table 10). View angles within $+/-30$ degrees ranged from 31 to 75 percent, and in most cases better than 98 percent of the pixels were within $+/-55$ percent. Look directions were about equal, although a westerly aspect occurred during the first half of the year and an easterly during the second half of the year; only periods 1 , 2, and 10 (early and late April and late August, respectively) seemed to be skewed toward any one direction.

Table 10 Summary of satellite scan angle distribution for 1994

\begin{tabular}{clllllll}
\hline Period & Nadir & $+/-30$ & $+/-40$ & $+/-55$ & $>+/-55$ & West (-) & East (+) \\
\hline 1 & $0.18 \%$ & $31.09 \%$ & $55.17 \%$ & $95.91 \%$ & $3.92 \%$ & $69.57 \%$ & $30.25 \%$ \\
2 & $0.40 \%$ & $35.08 \%$ & $55.74 \%$ & $96.17 \%$ & $3.43 \%$ & $68.96 \%$ & $30.64 \%$ \\
3 & $0.52 \%$ & $59.65 \%$ & $78.01 \%$ & $98.29 \%$ & $1.20 \%$ & $43.41 \%$ & $56.07 \%$ \\
4 & $0.31 \%$ & $42.55 \%$ & $63.09 \%$ & $96.87 \%$ & $2.83 \%$ & $60.53 \%$ & $39.16 \%$ \\
5 & $0.51 \%$ & $48.33 \%$ & $68.57 \%$ & $97.17 \%$ & $2.33 \%$ & $50.97 \%$ & $48.52 \%$ \\
6 & $0.35 \%$ & $50.00 \%$ & $72.20 \%$ & $98.36 \%$ & $1.29 \%$ & $51.33 \%$ & $48.32 \%$ \\
7 & $0.25 \%$ & $52.43 \%$ & $76.02 \%$ & $98.91 \%$ & $0.84 \%$ & $48.22 \%$ & $51.53 \%$ \\
8 & $0.64 \%$ & $67.41 \%$ & $81.37 \%$ & $98.69 \%$ & $0.67 \%$ & $39.94 \%$ & $59.42 \%$ \\
9 & $1.03 \%$ & $79.18 \%$ & $90.95 \%$ & $98.64 \%$ & $0.33 \%$ & $43.35 \%$ & $55.62 \%$ \\
10 & $1.03 \%$ & $75.58 \%$ & $89.38 \%$ & $98.58 \%$ & $0.39 \%$ & $29.28 \%$ & $69.69 \%$ \\
11 & $0.90 \%$ & $75.09 \%$ & $93.07 \%$ & $98.85 \%$ & $0.26 \%$ & $43.83 \%$ & $55.28 \%$ \\
\hline
\end{tabular}

1995

Table 11 summarizes view angle results for 1995 along with figure 16. Except for period 9 (July 22 - August 4), less than 1 percent of the pixels were obtained at nadir, with roughly 60 percent or less of the pixels occurring within +/-30 degrees of nadir. However, 97 percent or more of the pixels were obtained within nominal view angles, except during period 1 (with 94 percent). All but two periods favored an easterly look angle, with period 10 highly favoring an eastward look angle and period 13 being favoring a westward look angle.

1996

Look angles for 1996 were similar to those for 1995 in that they favored an easterly look direction. Only period 14 (September 30 - October 13) favored a westerly look direction (fig. 17). Most pixels in each composite period (94 percent or more) occurred within $+/-55$ degrees of nadir. As with other years, very few pixels occurred at nadir (table 12). Those periods with the most pixels occurring at look angles greater than $+/-55$ degrees from nadir had minimal differences in look directions (for example, period 2).

1997

View angles were similar to those for the previous years in that the majority (greater than 96 percent) of the pixels were within $+/-55$ degrees (table 13) and less than 2 percent of the 

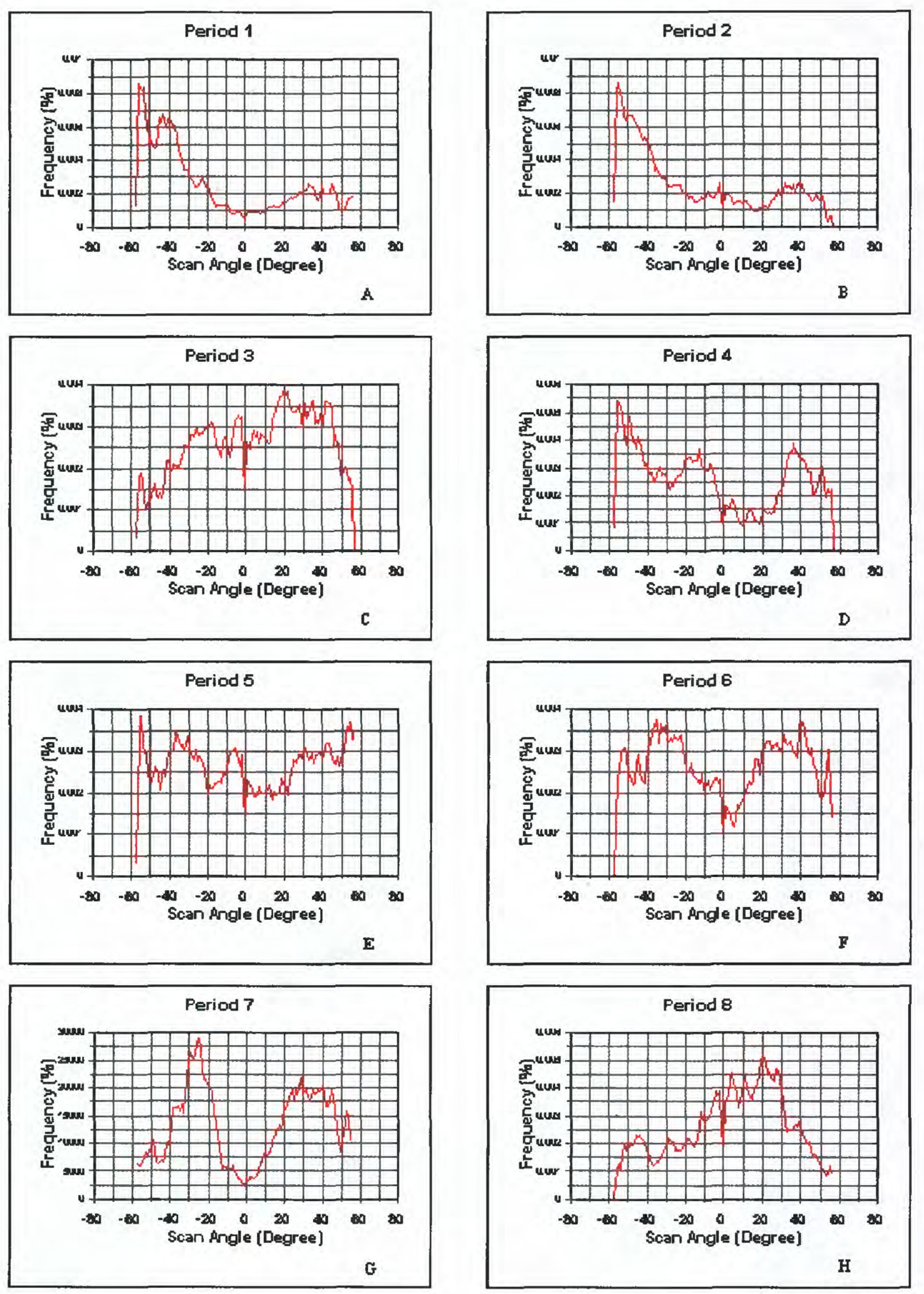

Figure 15. Distribution of AVHRR satellite scan angles for 1994 

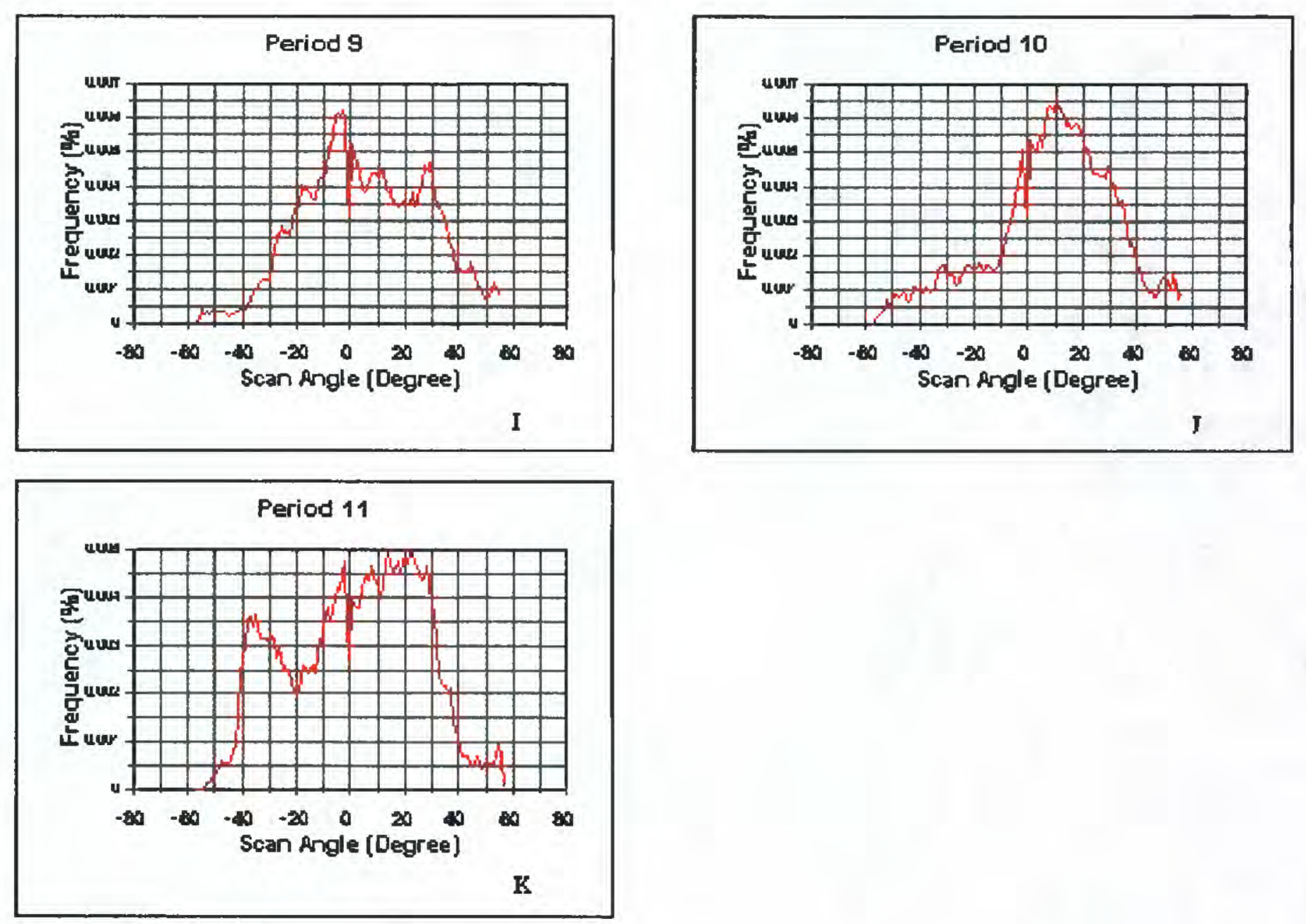

Figure 15. Distribution of AVHRR satellite scan angles for 1994 (continued) 
Table 11 Summary of satellite scan angle distribution for 1995

\begin{tabular}{cccccccc}
\hline & Nadir & $+/-30$ & $+/-40$ & $+/-55$ & $>+/-55$ & West (-) & East (+) \\
Period & & & & & & & \\
\hline 1 & $0.62 \%$ & $37.92 \%$ & $52.97 \%$ & $94.80 \%$ & $4.59 \%$ & $37.58 \%$ & $61.80 \%$ \\
2 & $0.86 \%$ & $52.60 \%$ & $72.34 \%$ & $97.49 \%$ & $1.65 \%$ & $57.70 \%$ & $41.44 \%$ \\
3 & $0.88 \%$ & $61.40 \%$ & $79.73 \%$ & $98.14 \%$ & $0.99 \%$ & $42.26 \%$ & $56.87 \%$ \\
4 & $0.71 \%$ & $56.83 \%$ & $77.70 \%$ & $98.19 \%$ & $1.10 \%$ & $38.41 \%$ & $60.88 \%$ \\
5 & $0.66 \%$ & $58.21 \%$ & $77.54 \%$ & $97.61 \%$ & $1.72 \%$ & $40.35 \%$ & $58.99 \%$ \\
6 & $0.82 \%$ & $59.91 \%$ & $80.48 \%$ & $98.51 \%$ & $0.67 \%$ & $39.52 \%$ & $59.67 \%$ \\
7 & $0.70 \%$ & $61.77 \%$ & $83.32 \%$ & $98.60 \%$ & $0.70 \%$ & $41.48 \%$ & $57.82 \%$ \\
8 & $0.90 \%$ & $61.98 \%$ & $82.93 \%$ & $98.53 \%$ & $0.58 \%$ & $39.24 \%$ & $59.86 \%$ \\
9 & $1.20 \%$ & $70.16 \%$ & $84.18 \%$ & $98.45 \%$ & $0.35 \%$ & $40.21 \%$ & $58.59 \%$ \\
10 & $0.86 \%$ & $63.27 \%$ & $80.10 \%$ & $98.34 \%$ & $0.80 \%$ & $28.77 \%$ & $70.37 \%$ \\
11 & $0.80 \%$ & $59.80 \%$ & $80.35 \%$ & $98.44 \%$ & $0.77 \%$ & $33.23 \%$ & $65.97 \%$ \\
12 & $0.97 \%$ & $60.67 \%$ & $81.34 \%$ & $98.43 \%$ & $0.60 \%$ & $39.47 \%$ & $59.56 \%$ \\
13 & $0.73 \%$ & $56.12 \%$ & $71.69 \%$ & $97.37 \%$ & $1.90 \%$ & $71.10 \%$ & $28.17 \%$ \\
14 & $0.90 \%$ & $66.74 \%$ & $83.20 \%$ & $97.88 \%$ & $1.22 \%$ & $45.77 \%$ & $53.33 \%$ \\
\hline
\end{tabular}

pixels were at nadir. In 1997, all periods were in an easterly direction, some substantially; in seven of the periods, over 70 percent of the pixels were east looking (figure 18, table 13).

Solar Zenith Angle

Solar zenith angles obtained from the Alaskan data set are shown in figures 19-25, with minimum, maximum, and average values for each period shown in table 14. As a whole, most of

Table 12 Summary of satellite scan angle distribution for 1996

\begin{tabular}{cccccccc}
\hline Period & Nadir & $+/-30$ & $+/-40$ & $+/-55$ & $>+/-55$ & West (-) & East (+) \\
\hline 1 & $0.35 \%$ & $34.28 \%$ & $57.00 \%$ & $98.02 \%$ & $1.63 \%$ & $28.33 \%$ & $71.32 \%$ \\
2 & $0.69 \%$ & $42.82 \%$ & $56.79 \%$ & $94.20 \%$ & $5.11 \%$ & $49.61 \%$ & $49.70 \%$ \\
3 & $0.54 \%$ & $44.54 \%$ & $68.36 \%$ & $97.74 \%$ & $1.72 \%$ & $49.75 \%$ & $49.71 \%$ \\
4 & $0.95 \%$ & $61.70 \%$ & $80.29 \%$ & $97.97 \%$ & $1.08 \%$ & $40.07 \%$ & $58.98 \%$ \\
5 & $0.62 \%$ & $65.49 \%$ & $84.91 \%$ & $98.89 \%$ & $0.50 \%$ & $44.56 \%$ & $54.83 \%$ \\
6 & $0.88 \%$ & $63.10 \%$ & $81.63 \%$ & $98.59 \%$ & $0.53 \%$ & $24.50 \%$ & $74.62 \%$ \\
7 & $0.78 \%$ & $59.96 \%$ & $78.89 \%$ & $98.51 \%$ & $0.72 \%$ & $38.37 \%$ & $60.86 \%$ \\
8 & $0.88 \%$ & $59.11 \%$ & $78.52 \%$ & $98.34 \%$ & $0.78 \%$ & $33.54 \%$ & $65.59 \%$ \\
9 & $1.13 \%$ & $64.43 \%$ & $81.94 \%$ & $98.45 \%$ & $0.42 \%$ & $39.19 \%$ & $59.68 \%$ \\
10 & $0.86 \%$ & $68.48 \%$ & $83.60 \%$ & $98.29 \%$ & $0.84 \%$ & $39.23 \%$ & $59.90 \%$ \\
11 & $1.75 \%$ & $78.31 \%$ & $88.98 \%$ & $97.64 \%$ & $0.60 \%$ & $39.54 \%$ & $58.71 \%$ \\
12 & $1.27 \%$ & $72.10 \%$ & $88.59 \%$ & $98.25 \%$ & $0.47 \%$ & $38.51 \%$ & $60.22 \%$ \\
13 & $0.89 \%$ & $55.46 \%$ & $73.54 \%$ & $97.65 \%$ & $1.46 \%$ & $41.70 \%$ & $57.42 \%$ \\
14 & $0.64 \%$ & $59.30 \%$ & $78.56 \%$ & $98.59 \%$ & $0.77 \%$ & $54.95 \%$ & $44.41 \%$ \\
\hline
\end{tabular}



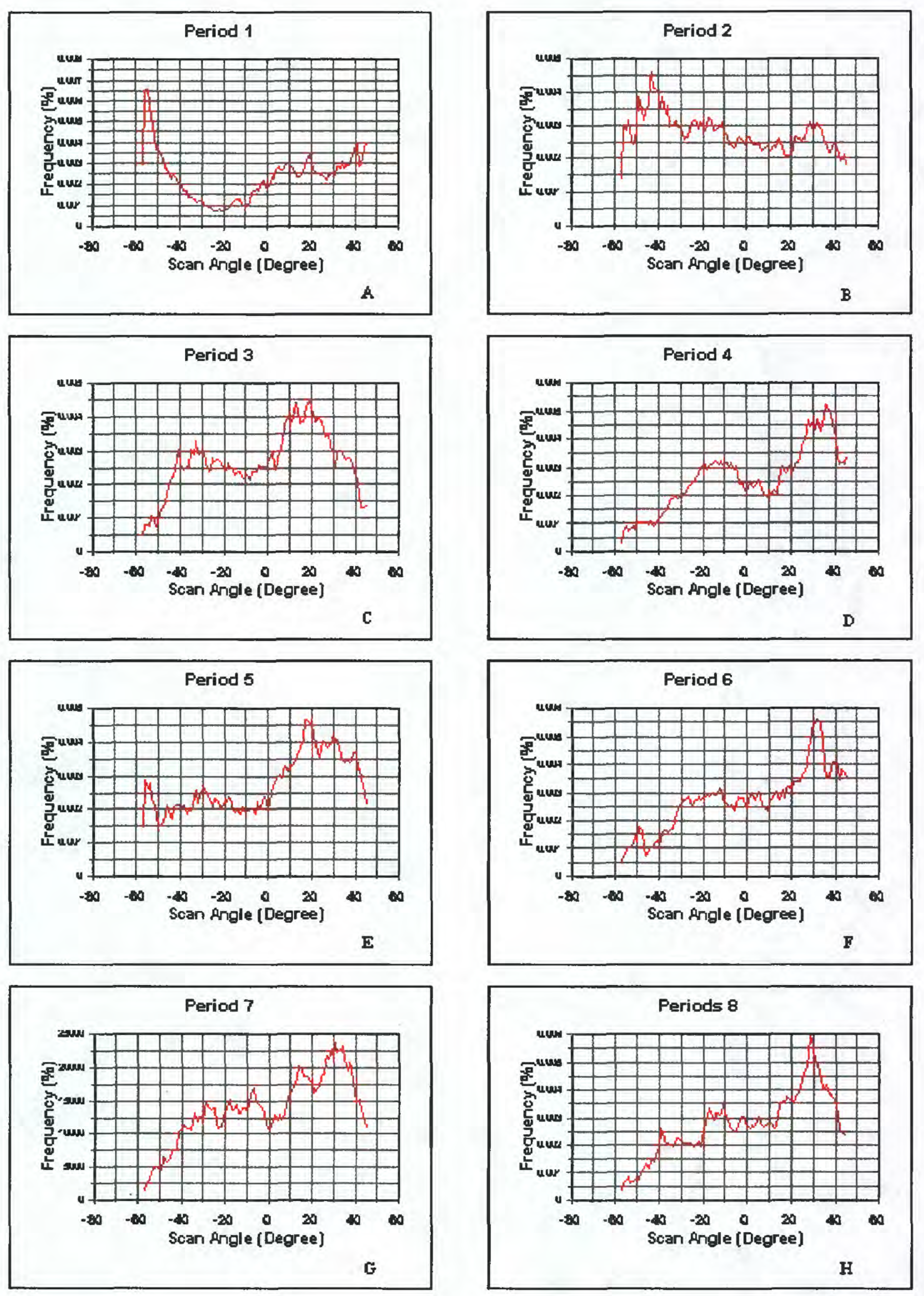

Figure 16. Distribution of AVHRR satellite scan angles for 1995 

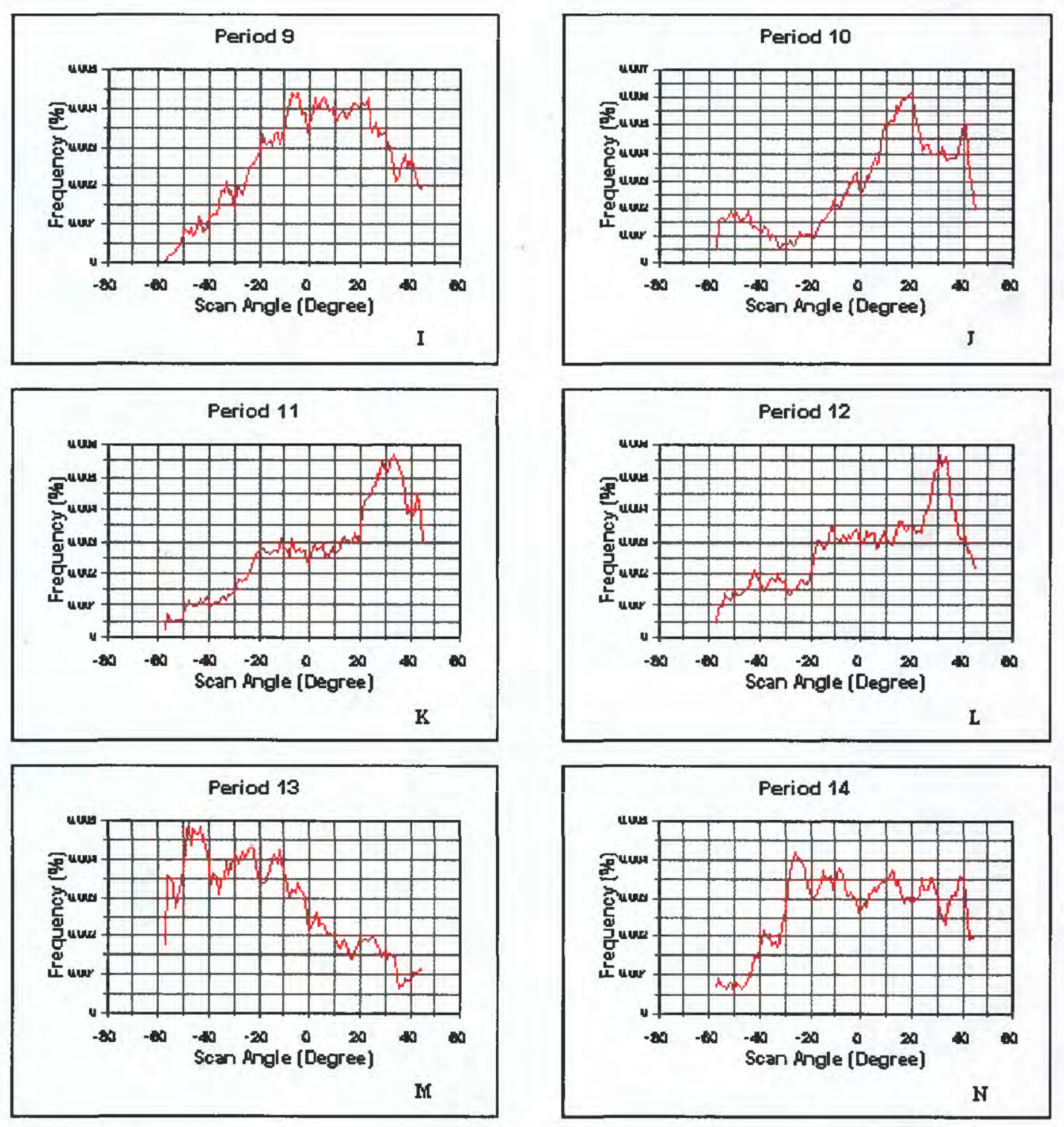

Figure 16. Distribution of AVHRR satellite scan angles for 1995 (continued) 

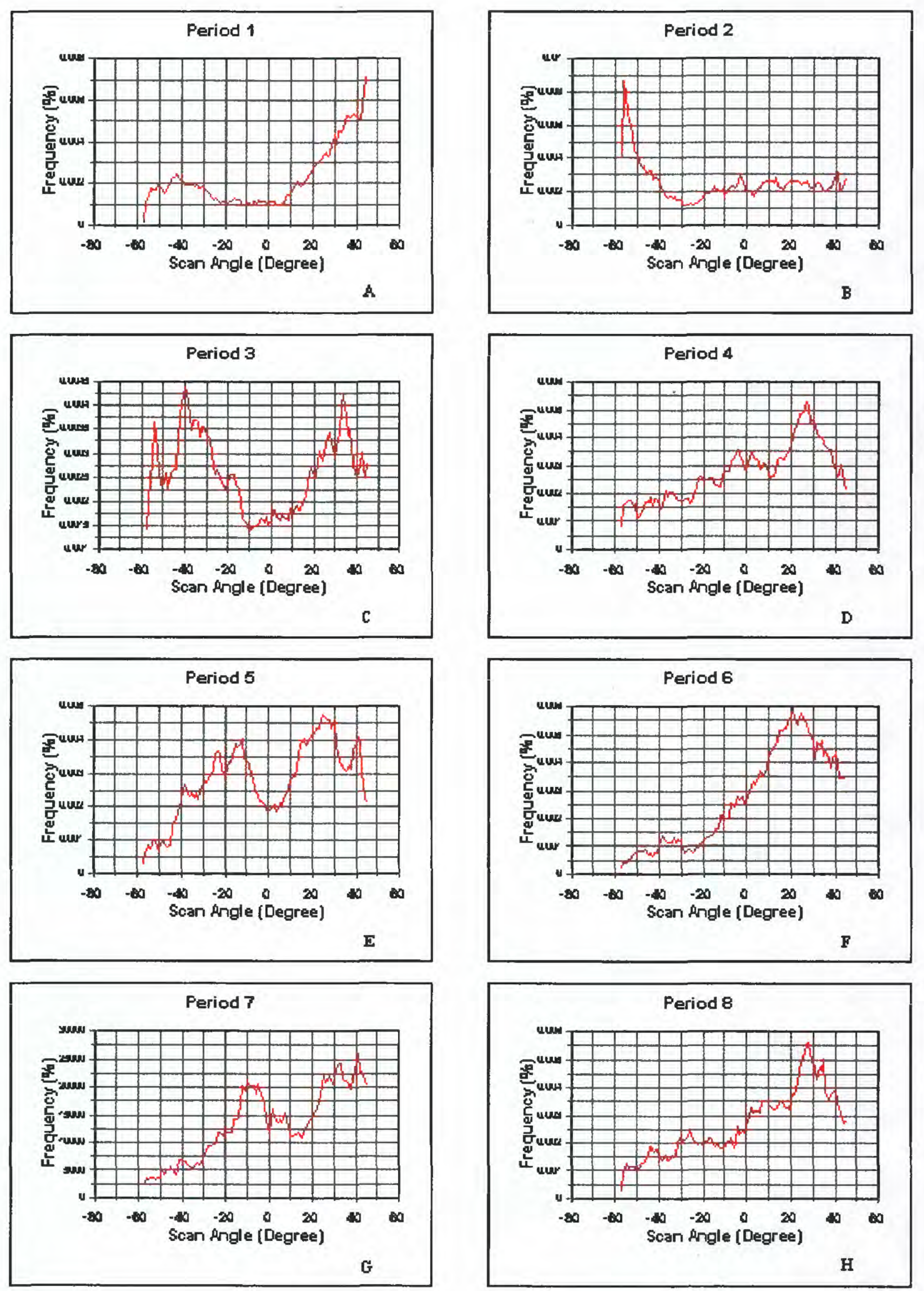

Figure 17. Distribution of AVHRR satellite scan angles for 1996 

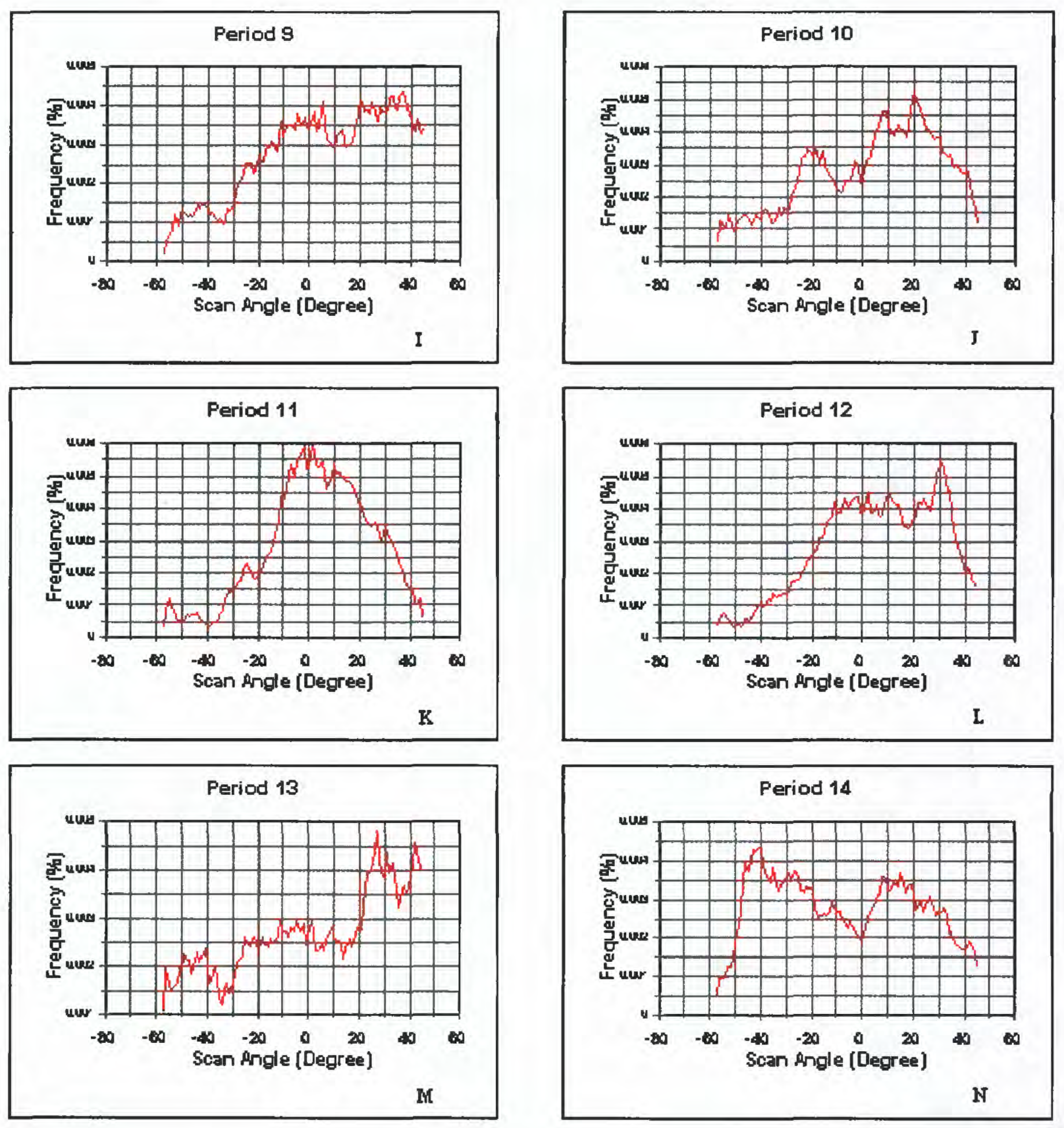

Figure 17. Distribution of AVHRR satellite scan angles for 1996 (continued) 

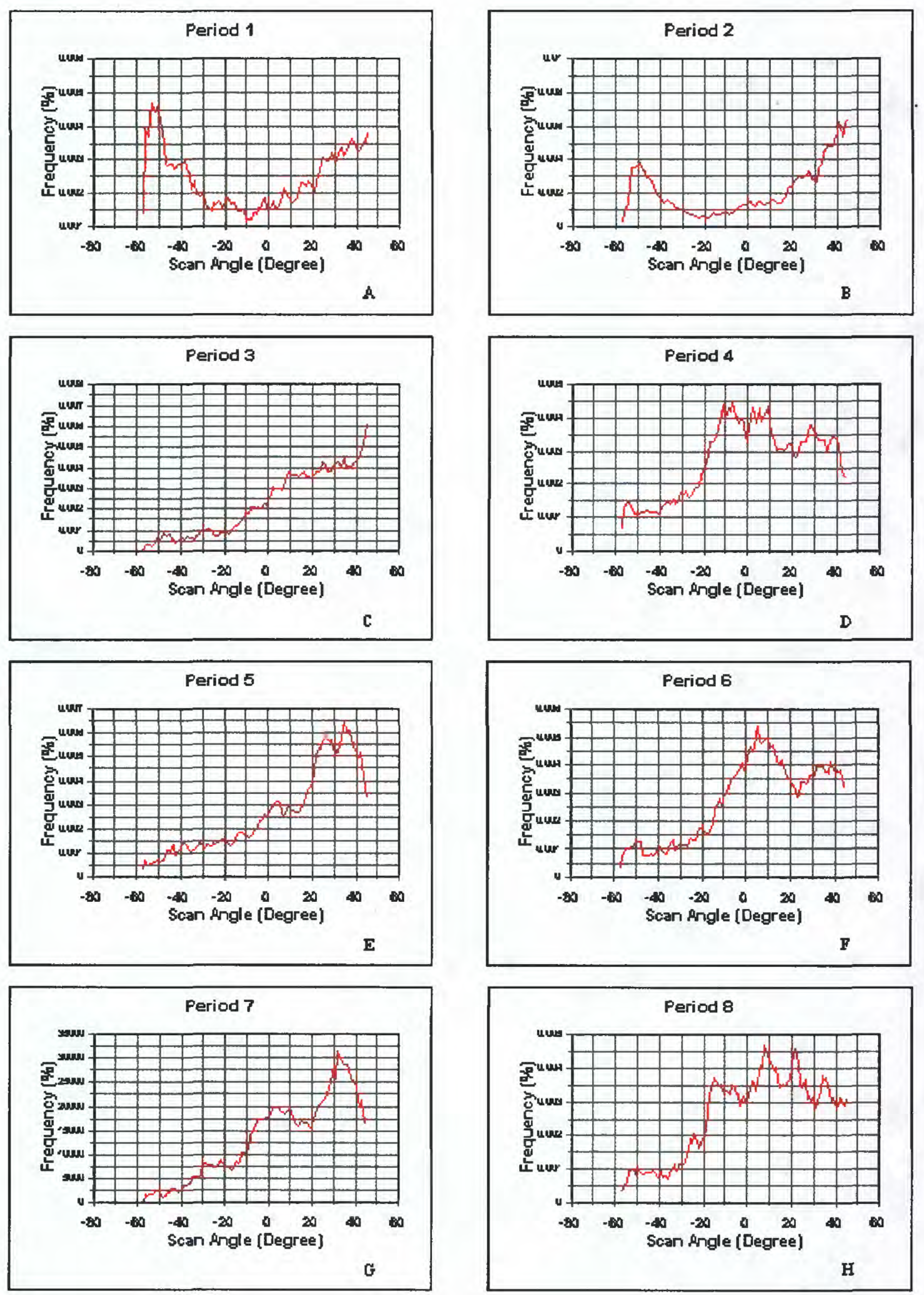

Figure 18. Distribution of AVHRR satellite scan angles for 1997 

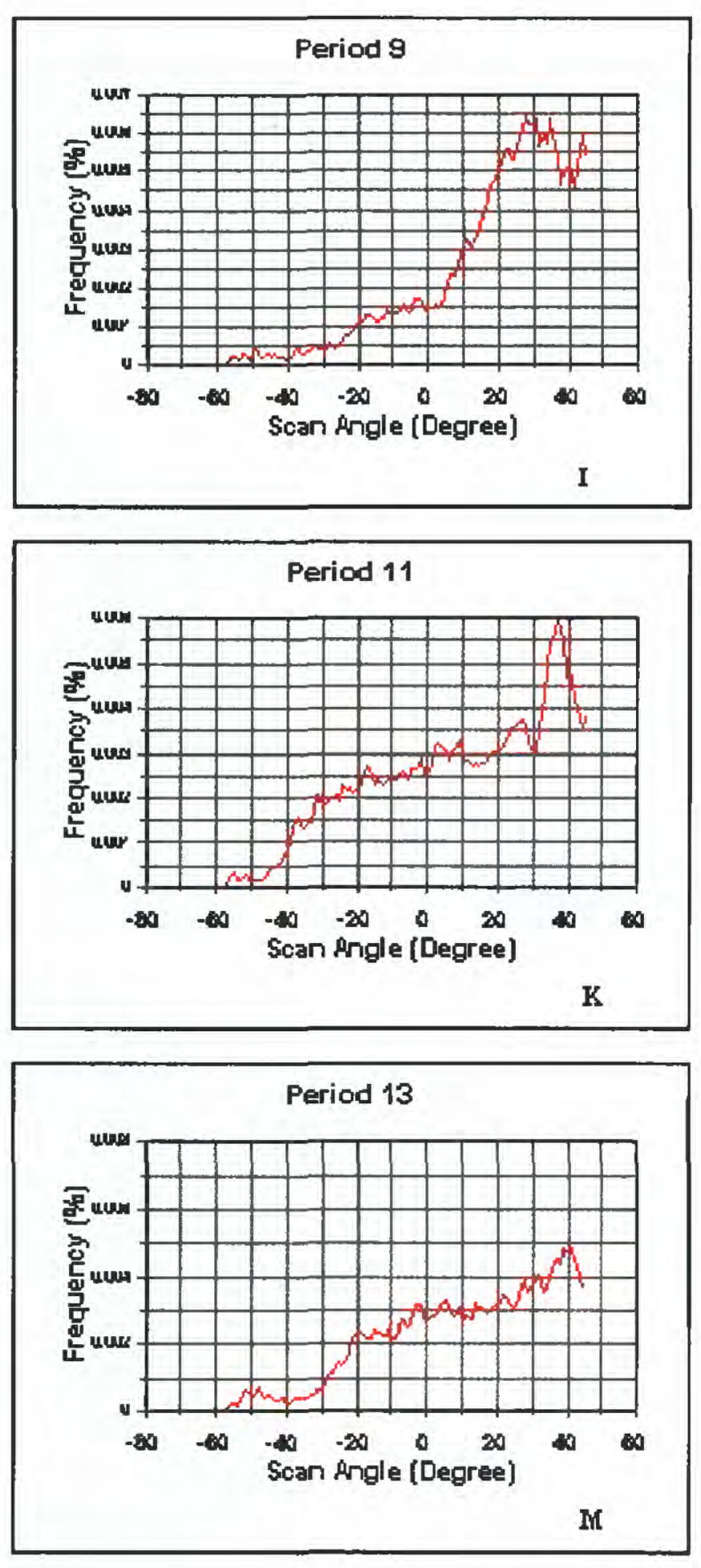
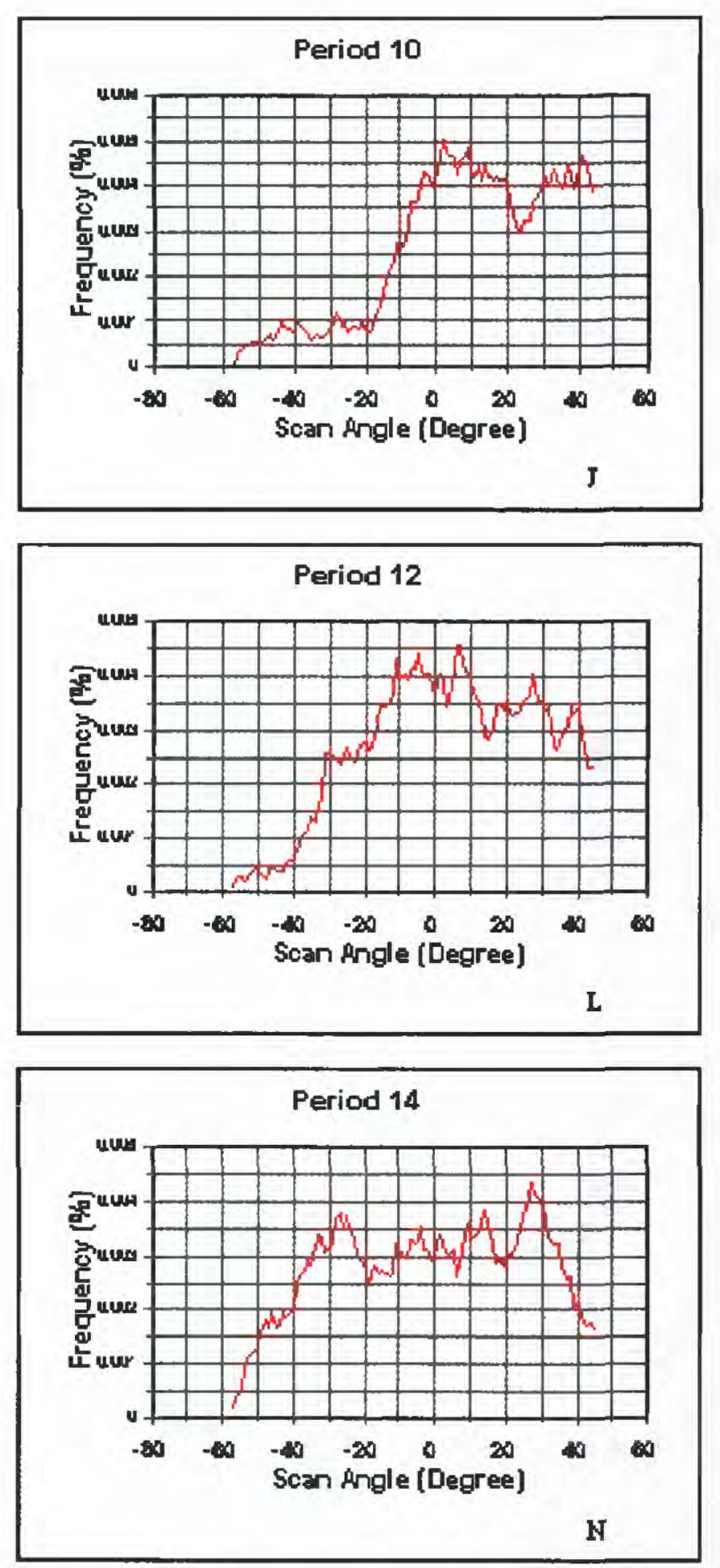

Figure 18. Distribution of AVHRR satellite scan angles for 1997 (continued) 
Table 13 Summary of satellite scan angle distribution for 1997

\begin{tabular}{rccccccc}
\hline \multicolumn{1}{c}{ Period } & Nadir & $+/-30$ & $+/-40$ & $+/-55$ & $>+/-55$ & West $(-)$ & East $(+)$ \\
\hline 1 & $0.48 \%$ & $38.23 \%$ & $57.41 \%$ & $96.59 \%$ & $2.92 \%$ & $43.54 \%$ & $55.97 \%$ \\
2 & $0.50 \%$ & $28.80 \%$ & $48.28 \%$ & $97.47 \%$ & $2.03 \%$ & $27.80 \%$ & $71.71 \%$ \\
3 & $0.80 \%$ & $49.44 \%$ & $65.75 \%$ & $98.03 \%$ & $1.17 \%$ & $19.03 \%$ & $80.17 \%$ \\
4 & $1.13 \%$ & $66.32 \%$ & $82.24 \%$ & $97.84 \%$ & $1.03 \%$ & $42.41 \%$ & $56.45 \%$ \\
5 & $0.85 \%$ & $54.66 \%$ & $77.94 \%$ & $98.24 \%$ & $0.91 \%$ & $25.41 \%$ & $73.74 \%$ \\
6 & $1.32 \%$ & $64.01 \%$ & $80.54 \%$ & $97.72 \%$ & $0.96 \%$ & $31.99 \%$ & $66.70 \%$ \\
7 & $1.17 \%$ & $59.58 \%$ & $81.05 \%$ & $98.29 \%$ & $0.53 \%$ & $26.16 \%$ & $72.67 \%$ \\
8 & $1.02 \%$ & $64.65 \%$ & $78.68 \%$ & $98.19 \%$ & $0.79 \%$ & $34.67 \%$ & $64.31 \%$ \\
9 & $0.47 \%$ & $50.66 \%$ & $70.64 \%$ & $98.47 \%$ & $1.06 \%$ & $13.57 \%$ & $85.96 \%$ \\
10 & $1.35 \%$ & $61.53 \%$ & $78.01 \%$ & $98.15 \%$ & $0.50 \%$ & $26.44 \%$ & $72.21 \%$ \\
11 & $0.85 \%$ & $54.95 \%$ & $75.90 \%$ & $98.62 \%$ & $0.53 \%$ & $30.15 \%$ & $69.00 \%$ \\
12 & $1.23 \%$ & $69.48 \%$ & $84.38 \%$ & $98.36 \%$ & $0.41 \%$ & $39.66 \%$ & $59.11 \%$ \\
13 & $0.90 \%$ & $52.61 \%$ & $67.91 \%$ & $98.01 \%$ & $1.09 \%$ & $24.63 \%$ & $74.47 \%$ \\
14 & $1.01 \%$ & $65.04 \%$ & $84.34 \%$ & $98.65 \%$ & $0.34 \%$ & $48.38 \%$ & $50.60 \%$ \\
\hline
\end{tabular}

the data had solar zenith angles below 70 degrees. Those periods that had angles above 70 degrees occurred primarily during early (April 1-15) or late (after September 1) season acquisitions. Overall percentages for these high angles were low, except for those periods occurring after August $(12,13$, and 14). Such percentages are not surprising since the solar elevations rapidly become lower owing to the onset of the fall equinox.

Mean solar angles for 1991 (table 14) ranged from 38 to 80 degrees, with the majority being in the 40- to 60- degree range. Periods 1 and 11 contained a few values greater than 70 degrees (fig. 19); however, periods 12,13 , and 14 contained significantly more, with averages greater than 70 degrees. Solar angles for 1992 and 1993 were similar to 1991, although the yearly average angles were somewhat higher for 1992 and 1993 than for 1991 (table 14). The pattern of periods $1,11,12,13$, and 14 having higher angles than the other parts of the year was also similar to 1991, except that period 10 in 1993 also contained some solar angles 70 degrees or higher, possibly because acquisitions were made in late August (fig. 13j). Figures 20 and 21 show that periods 12 through 14 in 1992 and 11 and 12 in 1993 were most affected by high solar angles.

High solar angles appeared to be most pronounced in 1994. Of the 11 periods, 5 contained angles in excess of 70 degrees (periods 1 , and 2, and 9 through 11, table 14), although the average for each period varied between 53 and 69 degrees. Those periods that were more strongly affected by high solar angles were 1, 2, 10, and 11 (fig. 22).

The remaining 3 years $(1995,1996$, and 1997) were very similar in the range and distribution of solar angles in the data sets (table 14, figs. 23, 24, and 25). Average solar angles varied between 40 and 69 degrees, with the higher angles occurring toward the end of the season (periods 12, 13, and 14). Minimum angle for each year was 29 degrees, lower than any of the first 4 years, and the highest angle (79 degrees) did not exceed the values for 1991 or 1992. 
Table 14 Summarized solar zenith angles by composite period for each year

\begin{tabular}{|c|c|c|c|c|c|c|c|c|c|c|c|c|c|c|}
\hline \multicolumn{15}{|l|}{$\overline{1991}$} \\
\hline Period & 1 & 2 & $\mathbf{3}$ & 4 & 5 & 6 & 7 & 8 & 9 & 10 & 11 & 12 & 13 & 14 \\
\hline Min & 45 & 40 & 37 & 22 & 34 & 33 & 34 & 36 & 39 & 44 & 50 & 58 & 61 & 69 \\
\hline $\operatorname{Max}$ & 71 & 65 & 61 & 58 & 56 & 54 & 56 & 59 & 63 & 69 & 74 & 82 & 87 & 90 \\
\hline Mean & 58 & 52 & 49 & 38 & 45 & 44 & 45 & 48 & 51 & 57 & 62 & 70 & 74 & 80 \\
\hline \multicolumn{15}{|l|}{1992} \\
\hline Period & 1 & 2 & 3 & 4 & 5 & 6 & 7 & 8 & 9 & 10 & 11 & 12 & 13 & 14 \\
\hline Min & 46 & 41 & 38 & 35 & 34 & 32 & 33 & 36 & 39 & 45 & 48 & 56 & $\overline{63}$ & 69 \\
\hline $\operatorname{Max}$ & 71 & 65 & 62 & 57 & 56 & 55 & 69 & 59 & 63 & 69 & 76 & 83 & 87 & 90 \\
\hline Mean & 59 & 53 & 50 & 46 & 45 & 44 & 51 & 48 & 51 & 57 & 62 & 70 & 75 & 80 \\
\hline \multicolumn{15}{|l|}{1993} \\
\hline Period & 1 & 2 & 3 & 4 & 5 & 6 & 7 & 8 & 9 & 10 & 11 & 12 & 13 & 14 \\
\hline Min & 51 & 45 & 42 & 38 & 37 & 37 & 38 & 39 & 43 & 47 & 53 & 61 & & \\
\hline $\operatorname{Max}$ & 73 & 67 & 65 & 60 & 58 & 58 & 59 & 62 & 66 & 71 & 77 & 79 & & \\
\hline Mean & 62 & 56 & 54 & 49 & 48 & 48 & 49 & 51 & 55 & 59 & 65 & 70 & & \\
\hline \multicolumn{15}{|l|}{1994} \\
\hline Period & 1 & 2 & 3 & 4 & 5 & 6 & 7 & 8 & 9 & 10 & 11 & 12 & 13 & 14 \\
\hline Min & 54 & 52 & 47 & 46 & 43 & 43 & 43 & 46 & 49 & 54 & 58 & & & \\
\hline $\operatorname{Max}$ & 76 & 74 & 68 & 64 & 63 & 62 & 64 & 67 & 70 & 74 & 79 & & & \\
\hline Mean & 65 & 63 & 58 & 55 & 53 & 53 & 54 & 57 & 60 & 64 & 69 & & & \\
\hline \multicolumn{15}{|l|}{1995} \\
\hline Period & 1 & 2 & 3 & 4 & 5 & 6 & 7 & 8 & 9 & 10 & 11 & 12 & 13 & 14 \\
\hline Min & 44 & 39 & 35 & 32 & 30 & 29 & 29 & 31 & 33 & 37 & 41 & 47 & 51 & 59 \\
\hline $\operatorname{Max}$ & 68 & 62 & 57 & 54 & 52 & 50 & 50 & 53 & 55 & 60 & 65 & 71 & 75 & 79 \\
\hline Mean & 56 & 51 & 46 & 43 & 41 & 40 & 40 & 42 & 44 & 49 & 53 & 59 & 63 & 69 \\
\hline \multicolumn{15}{|l|}{1996} \\
\hline Period & 1 & 2 & 3 & 4 & 5 & 6 & 7 & 8 & 9 & 10 & 11 & 12 & 13 & 14 \\
\hline Min & 45 & 38 & 35 & 32 & 30 & 29 & 29 & 30 & 34 & 36 & 42 & 47 & 53 & 57 \\
\hline $\operatorname{Max}$ & 68 & 62 & 57 & 54 & 52 & 50 & 50 & 53 & 55 & 60 & 65 & 71 & 77 & 79 \\
\hline Mean & 57 & 50 & 46 & 43 & 41 & 40 & 40 & 42 & 45 & 48 & 54 & 59 & 65 & 68 \\
\hline \multicolumn{15}{|l|}{1997} \\
\hline Period & 1 & 2 & 3 & 4 & 5 & 6 & 7 & 8 & 9 & 10 & 11 & 12 & 13 & 14 \\
\hline Min & 44 & 41 & 36 & 32 & 30 & 29 & 30 & 31 & 34 & 37 & 42 & 49 & 54 & 58 \\
\hline $\operatorname{Max}$ & 68 & 62 & 58 & 54 & 52 & 50 & 50 & 53 & 55 & 60 & 64 & 71 & 75 & 79 \\
\hline Mean & 56 & 52 & 47 & 43 & 41 & 40 & 40 & 42 & 45 & 49 & 53 & 60 & 65 & 69 \\
\hline
\end{tabular}



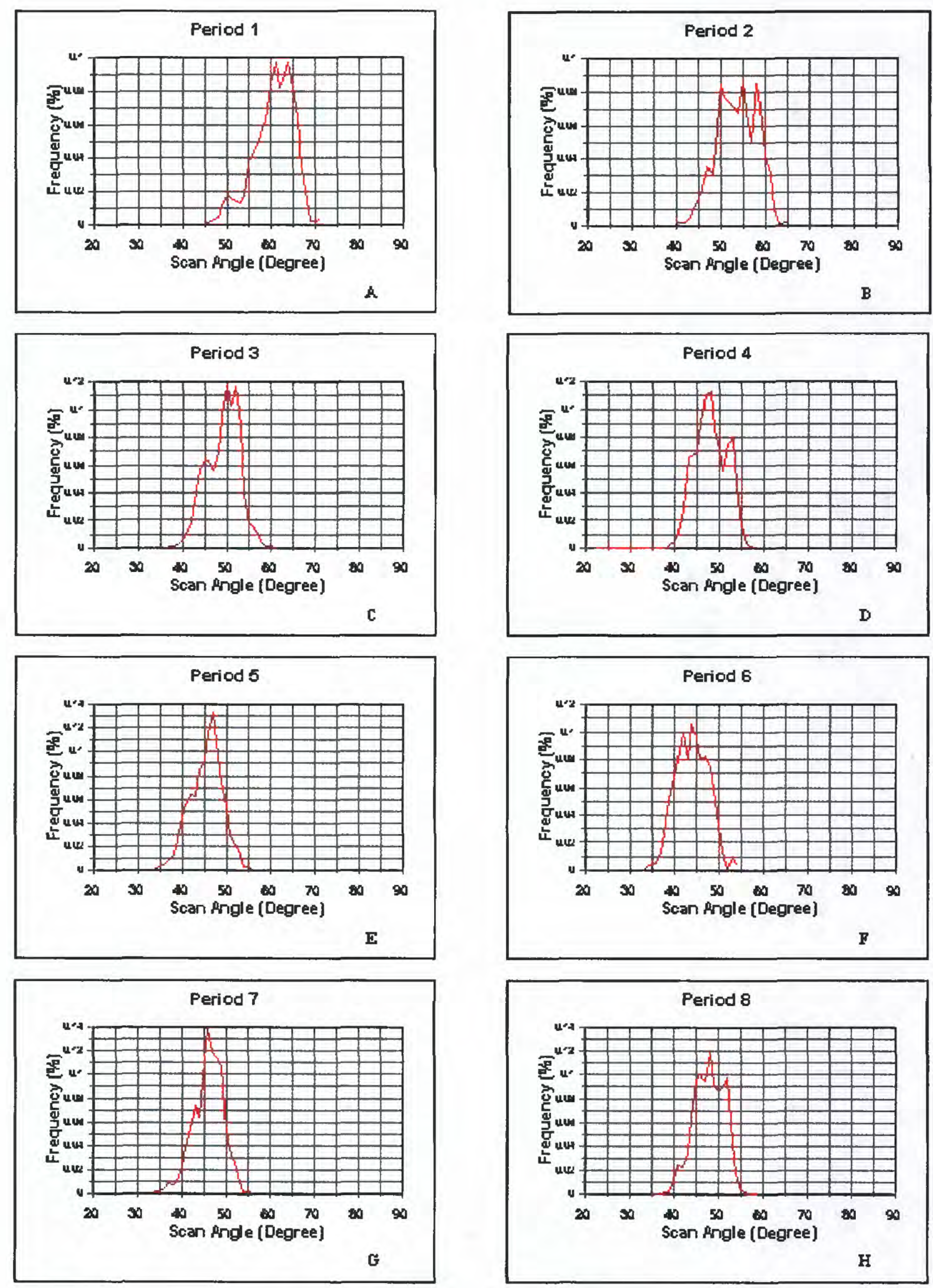

Figure 19. Distribution of solar zenith angles for 1991 AVHRR data set 

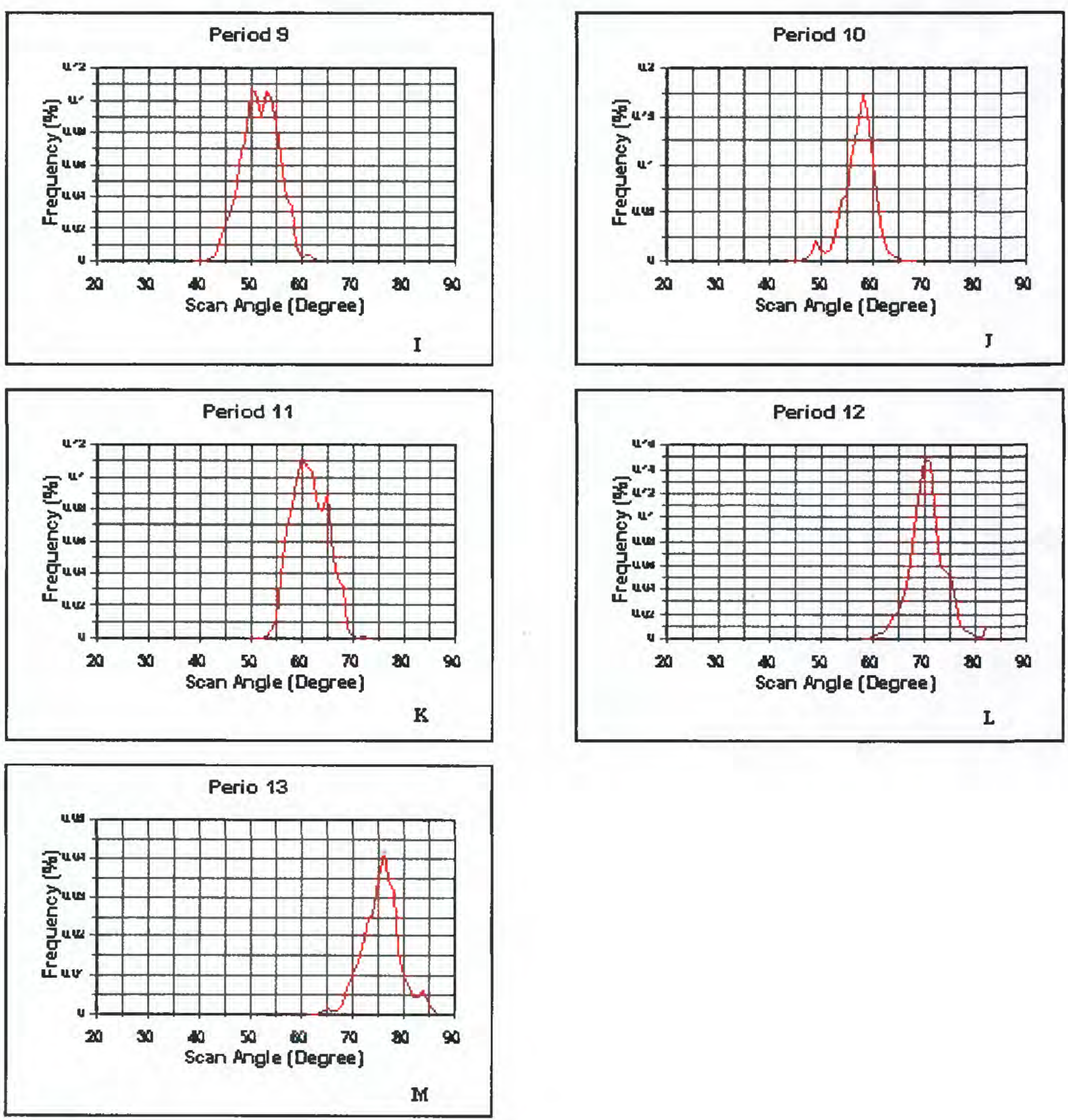

Figure 19. Distribution of solar zenith angles for 1991 AVHRR data set (continued) 

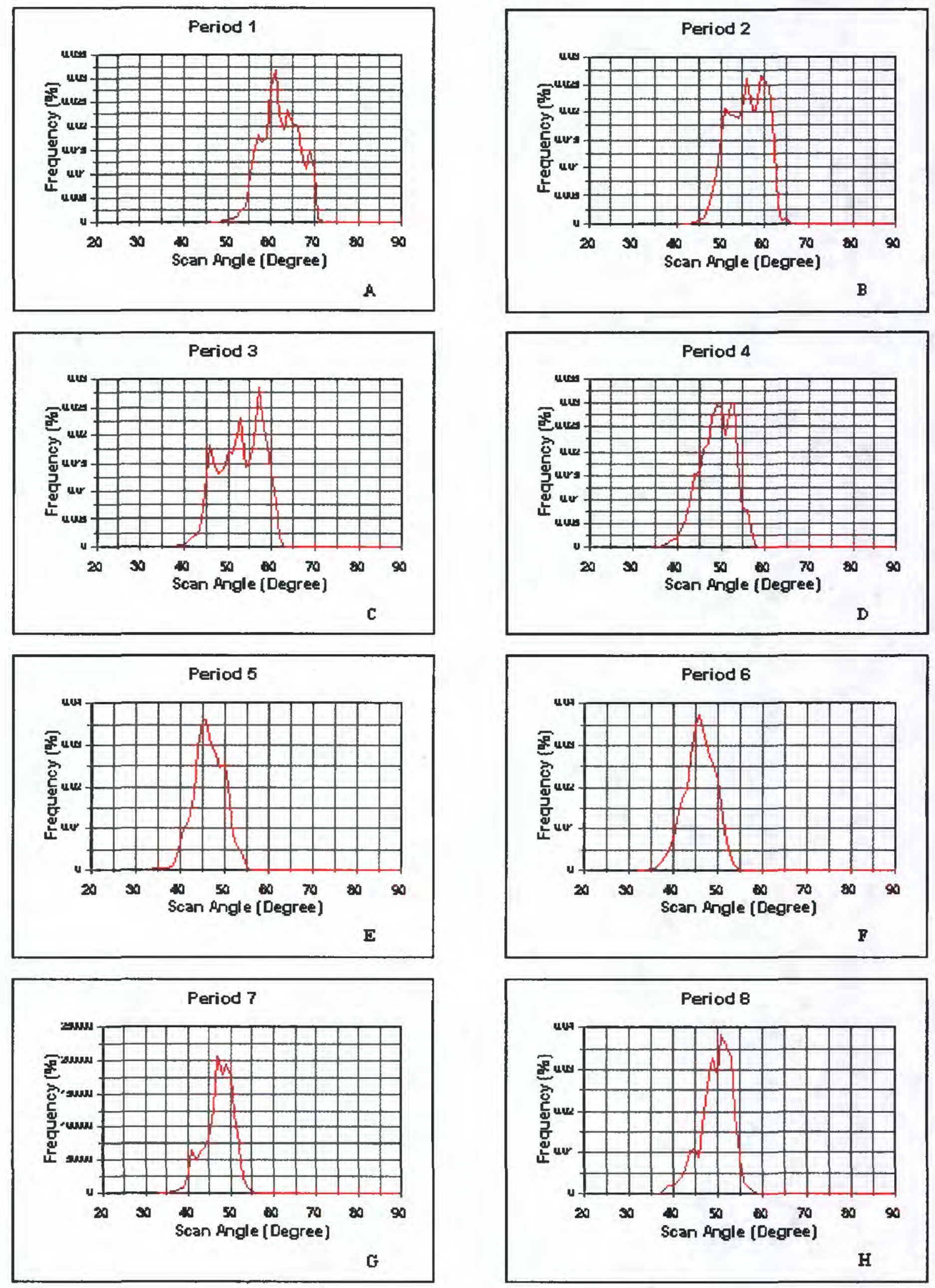

Figure 20. Distribution of solar zenith angles for 1992 AVHRR data set 

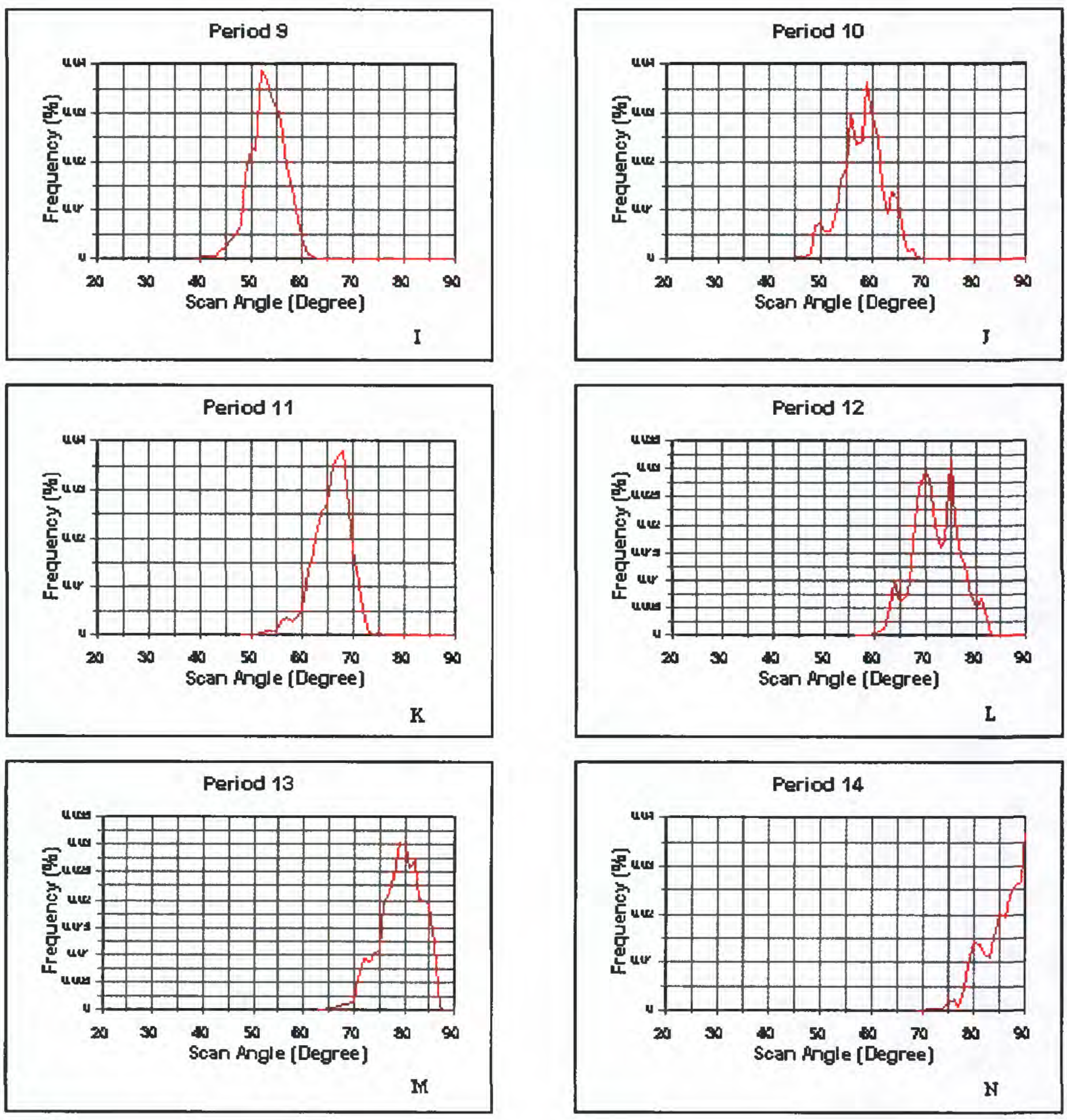

Figure 20. Distribution of solar zenith angles for 1992 AVHRR data set (continued) 

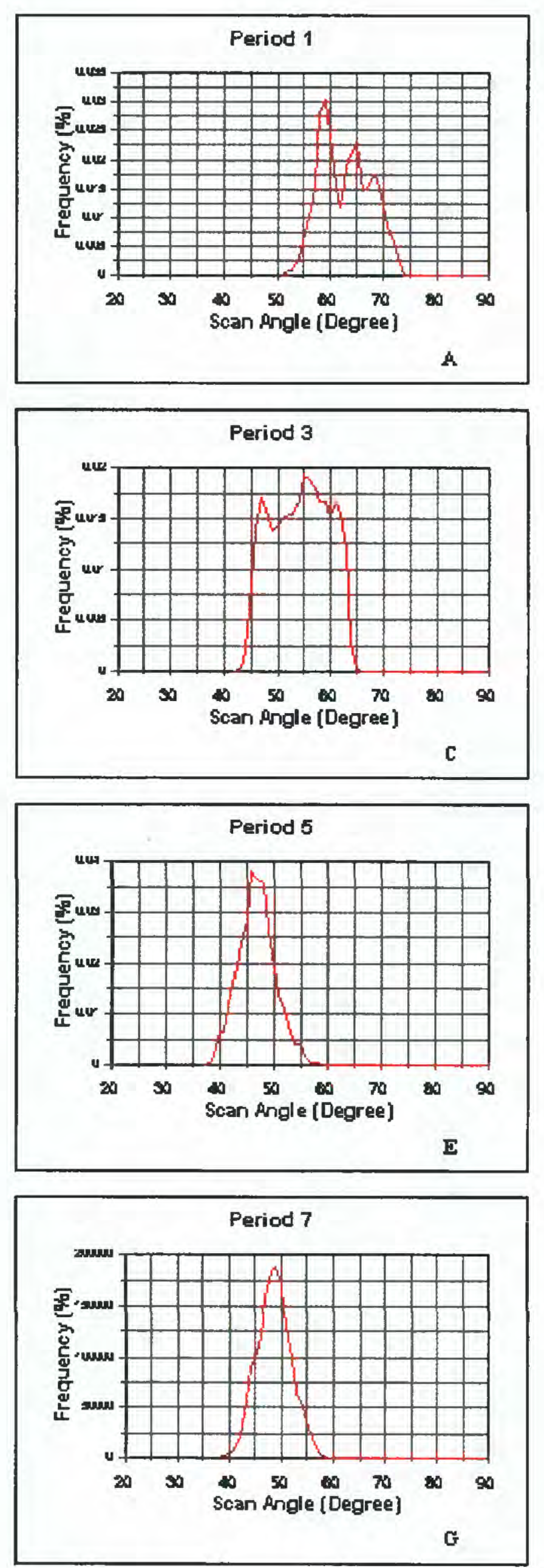
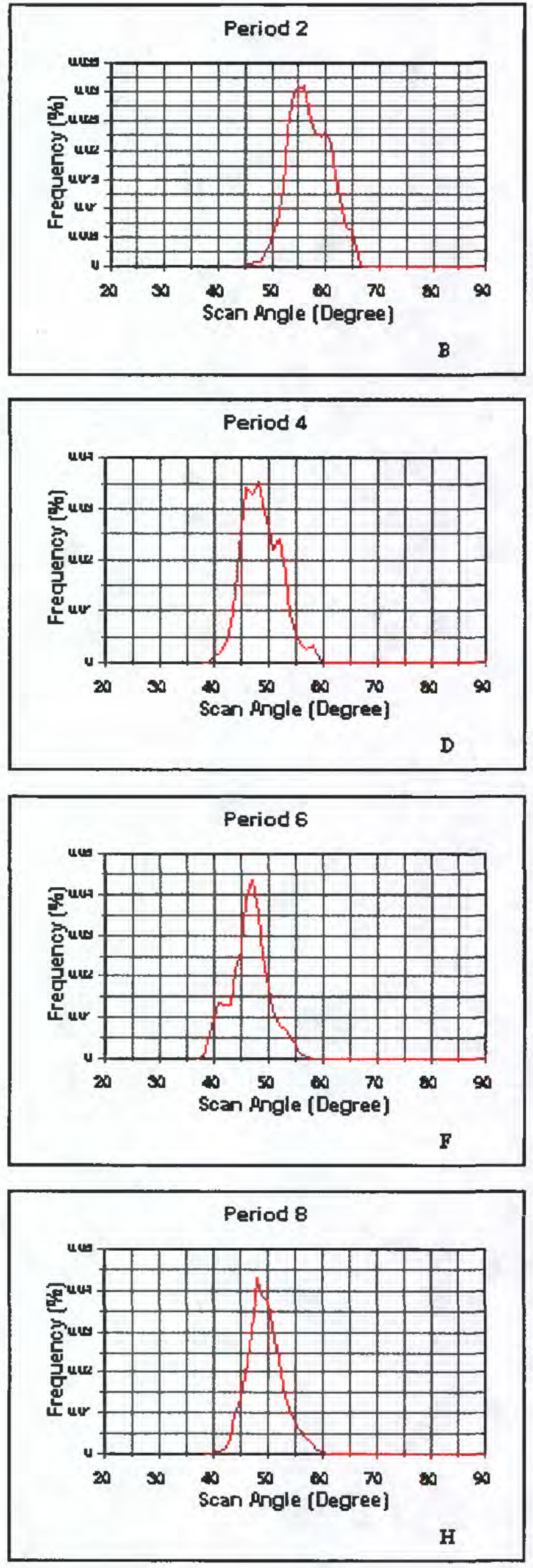

Figure 21. Distribution of solar zenith angles for 1993 AVHRR data set 

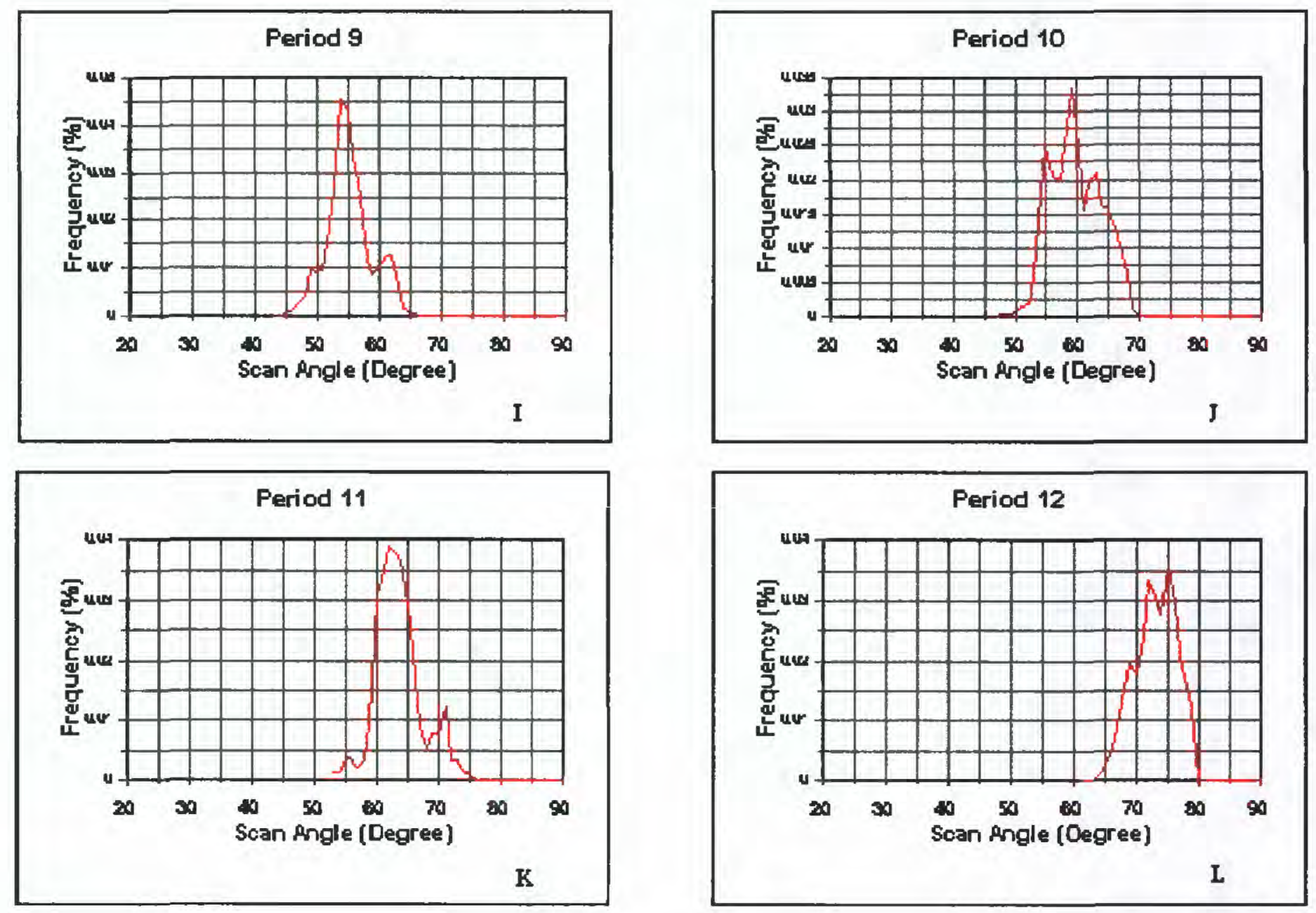

Figure 21. Distribution of solar zenith angles for 1993 AVHRR data set (continued) 

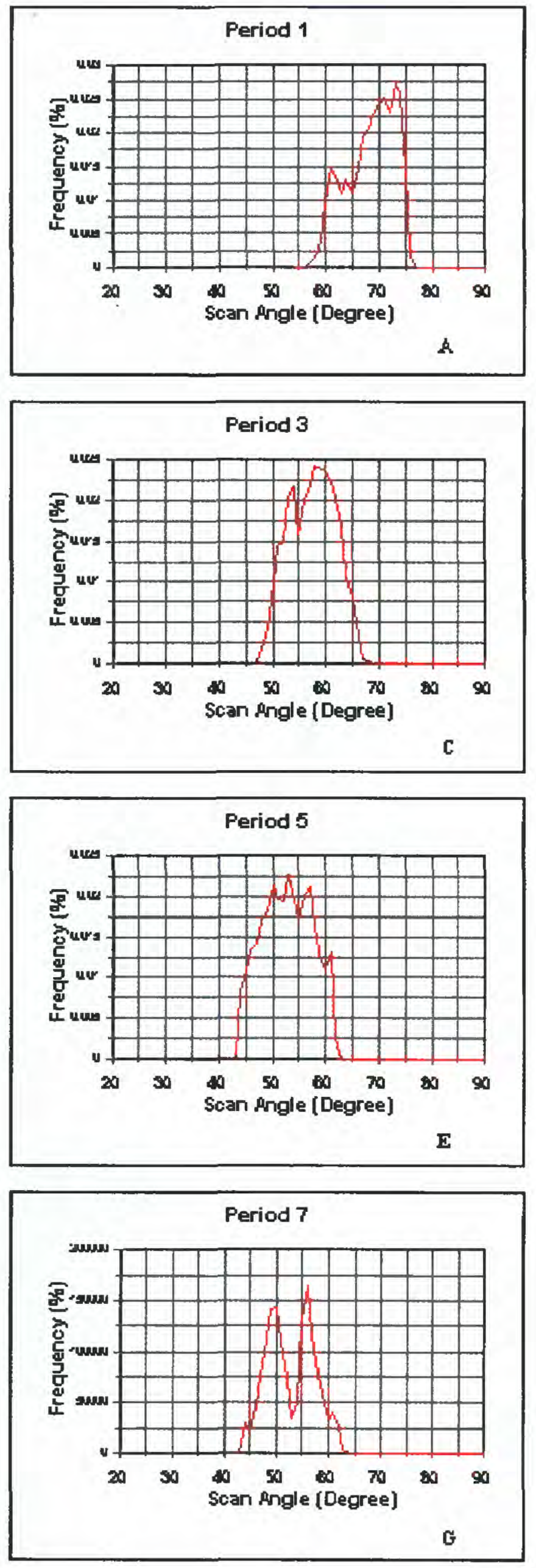

Period 2
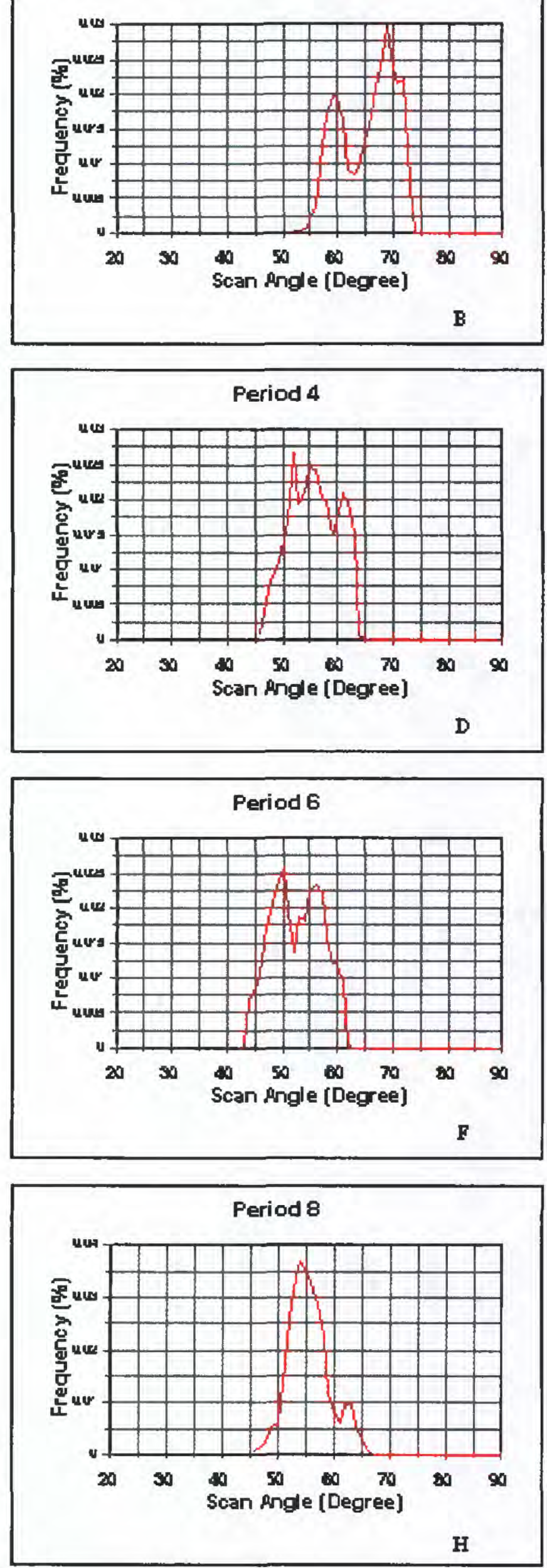

Figure 22. Distribution of solar zenith angles for 1994 AVHRR data set 

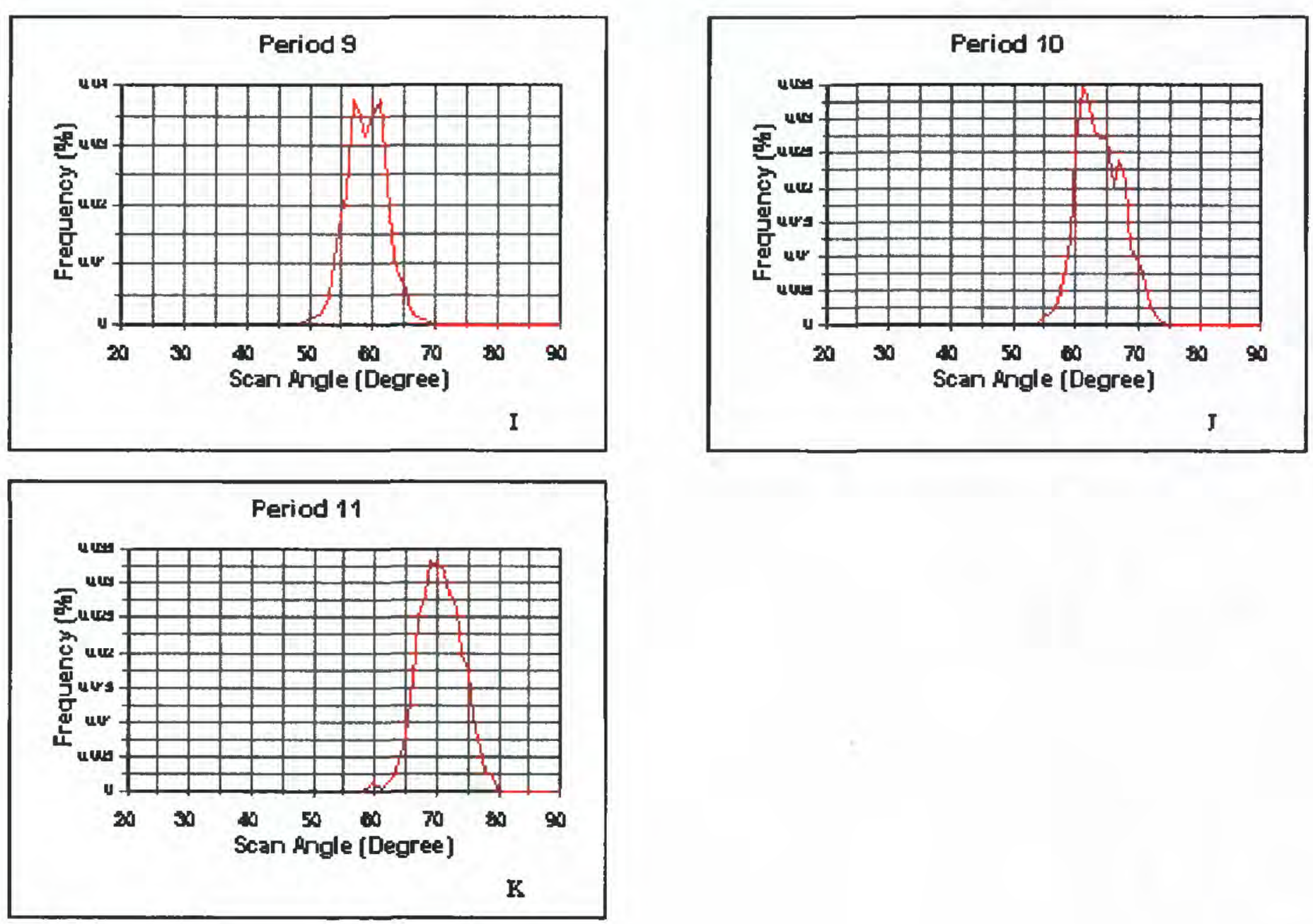

Figure 22. Distribution of solar zenith angles for 1994 AVHRR data set (continued) 

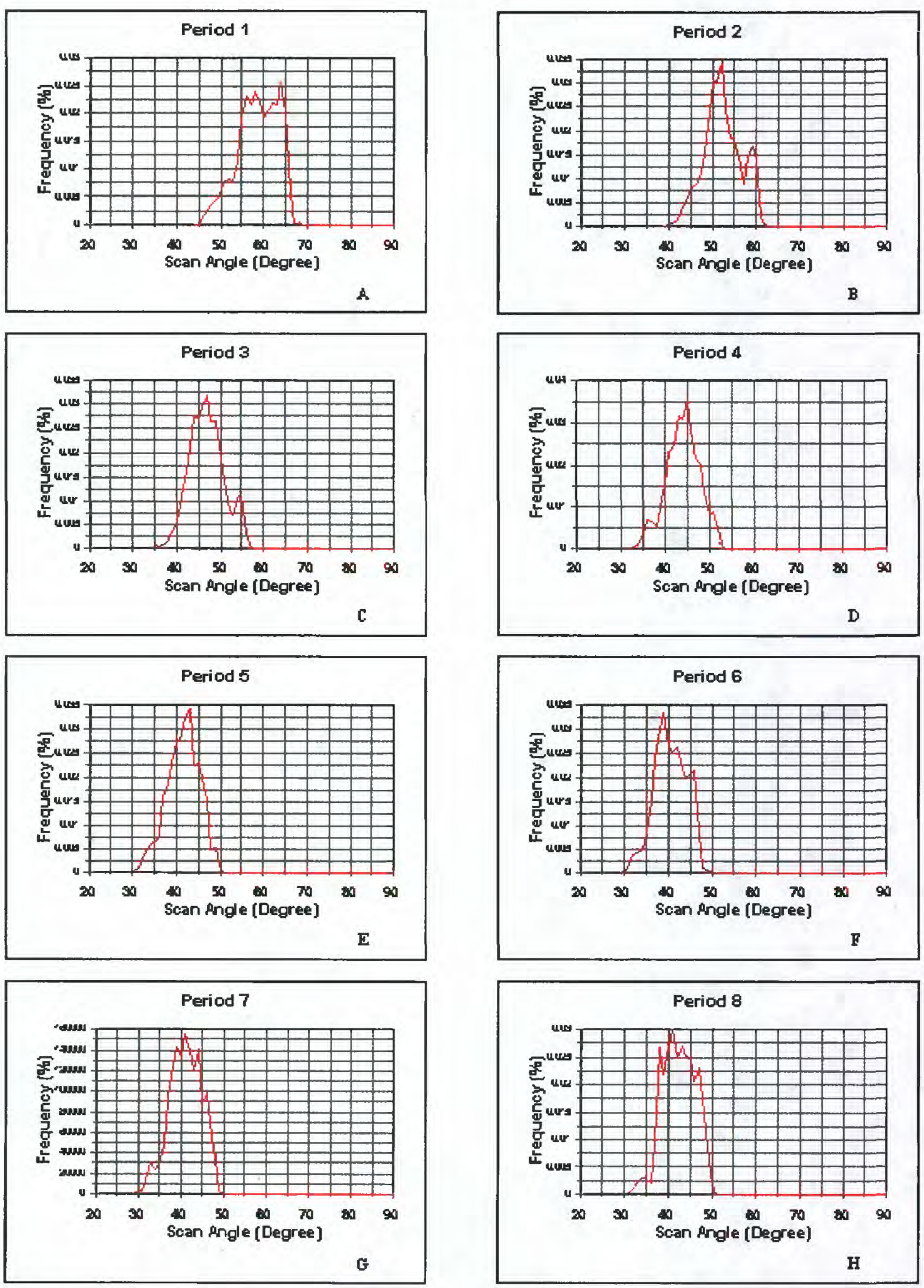

Figure 23. Distribution of solar zenith angles for 1995 AVHRR data set 

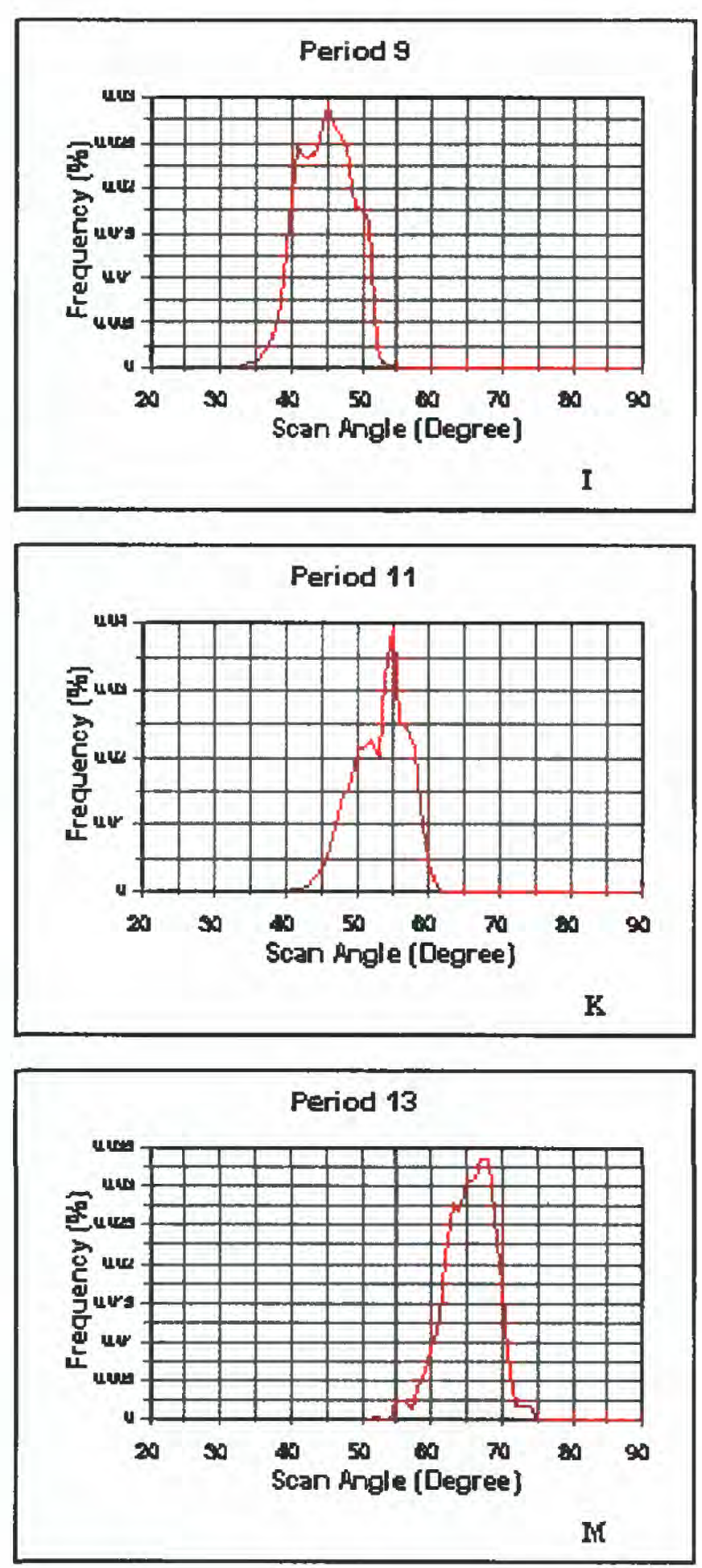
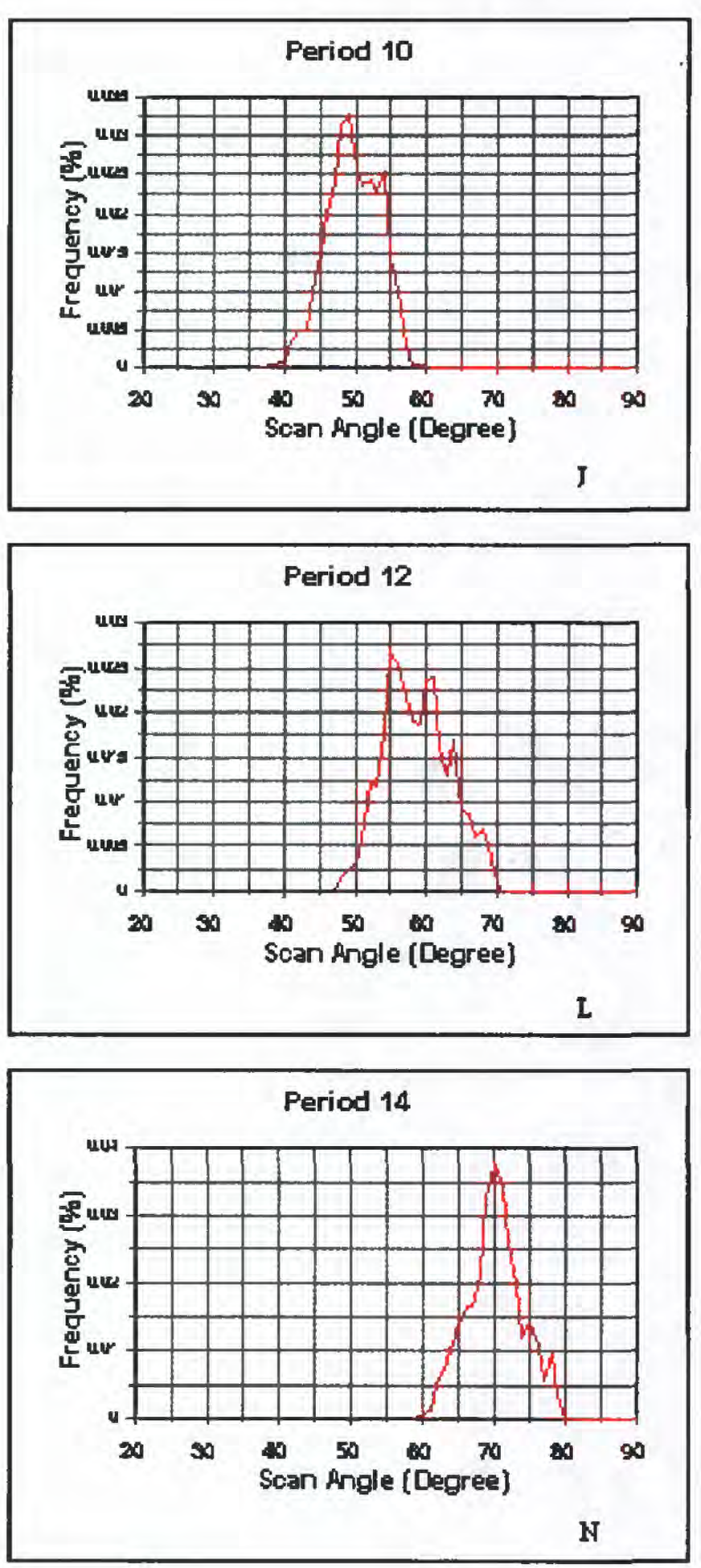

Figure 23. Distribution of solar zenith angles for 1995 AVHRR data set (continued) 

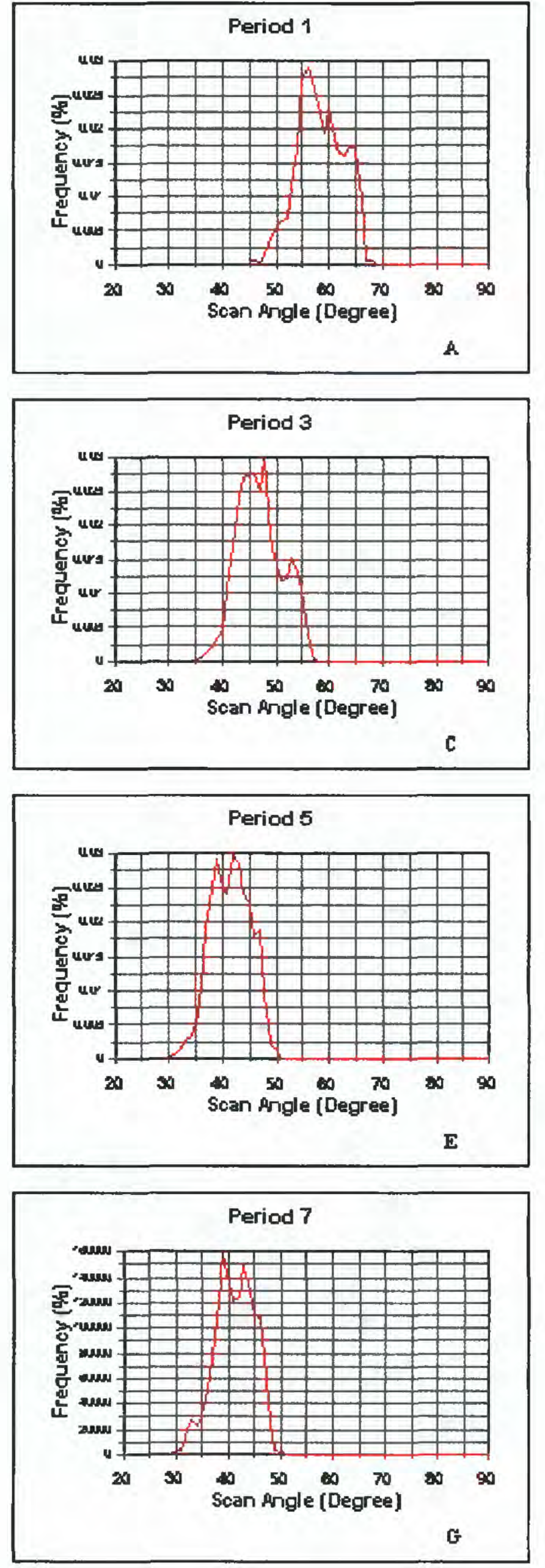
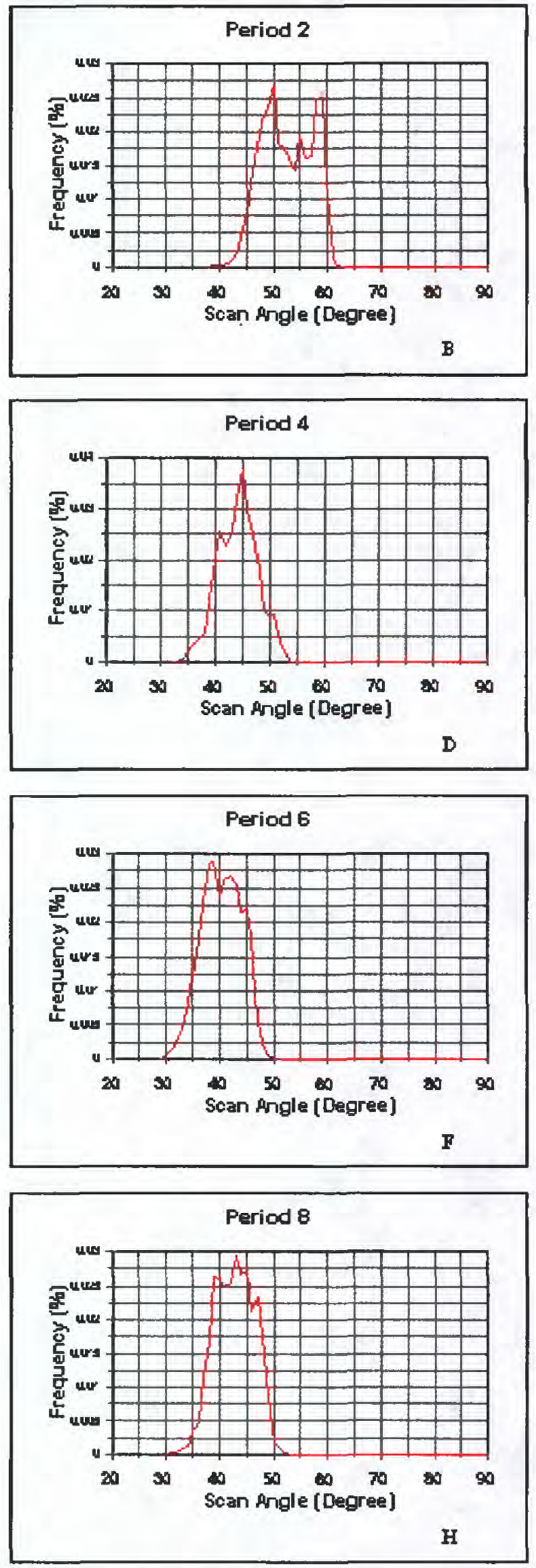

Figure 24. Distribution of solar zenith angles for 1996 AVHRR data set 

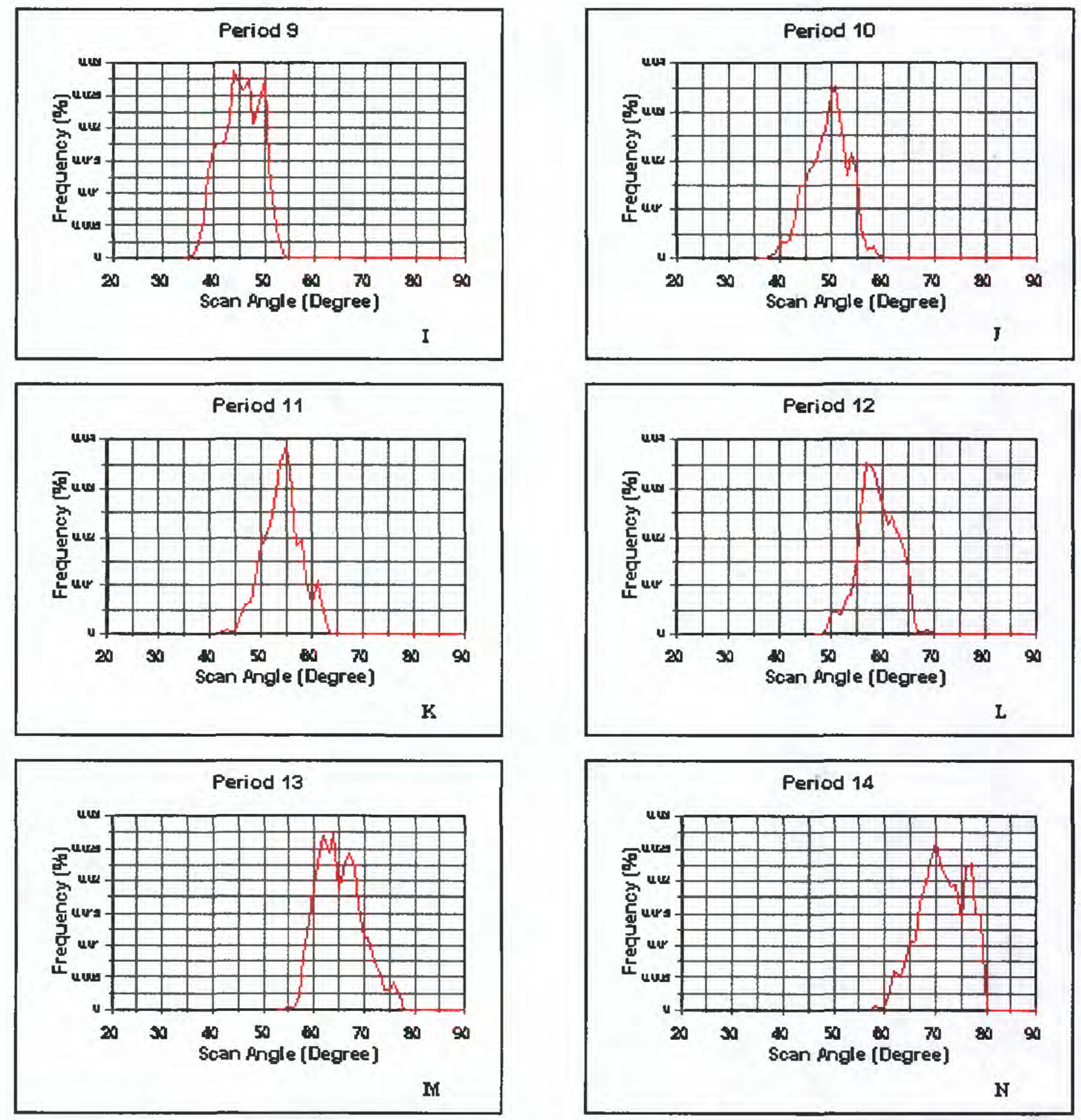

Figure 24. Distribution of solar zenith angles for 1996 AVHRR data set (continued) 

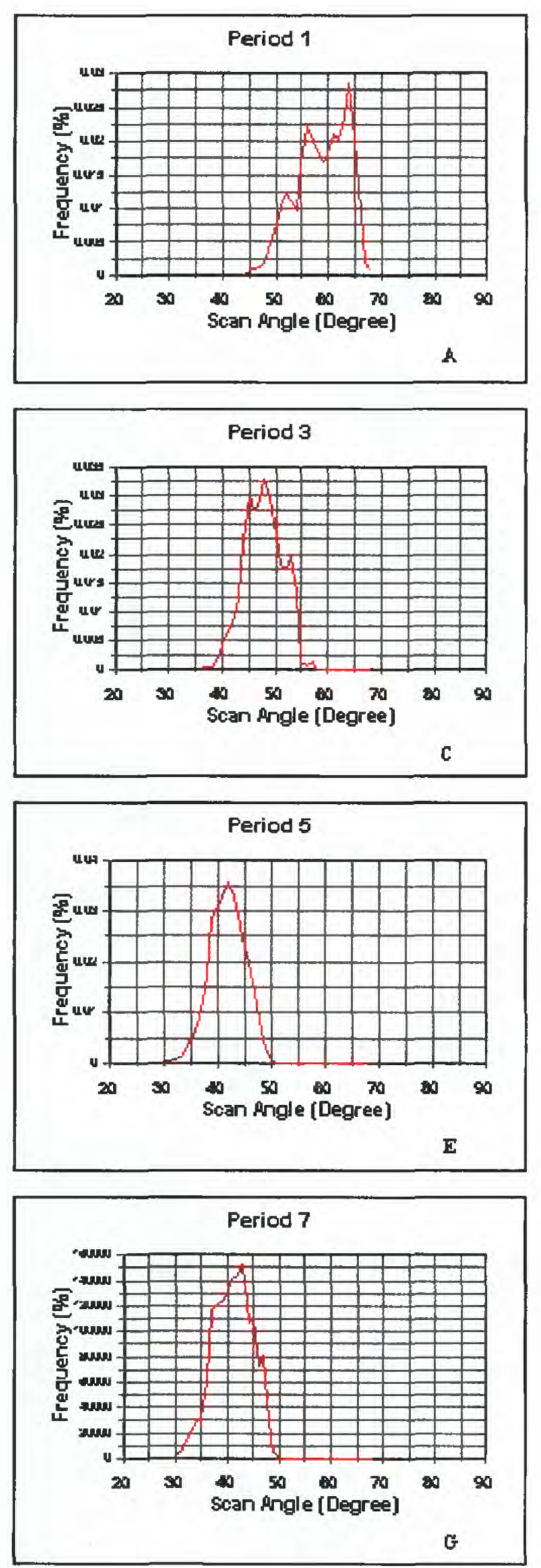
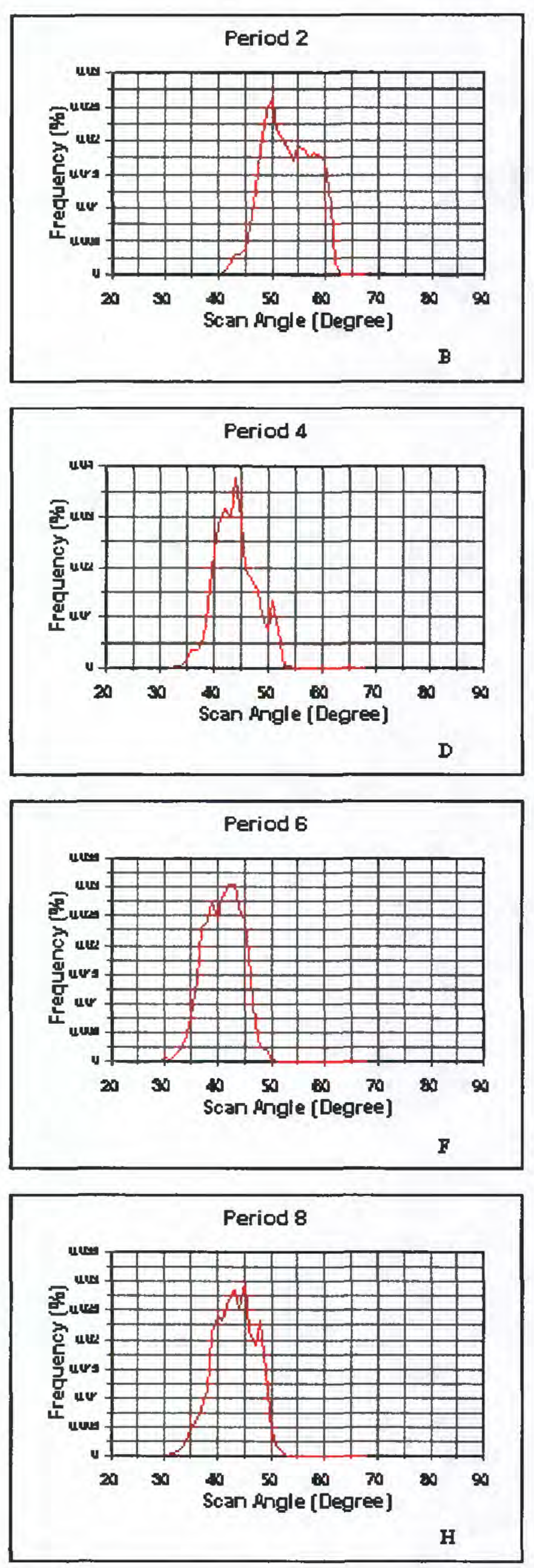

Figure 25. Distribution of solar zenith angles for 1997 AVHRR data set 

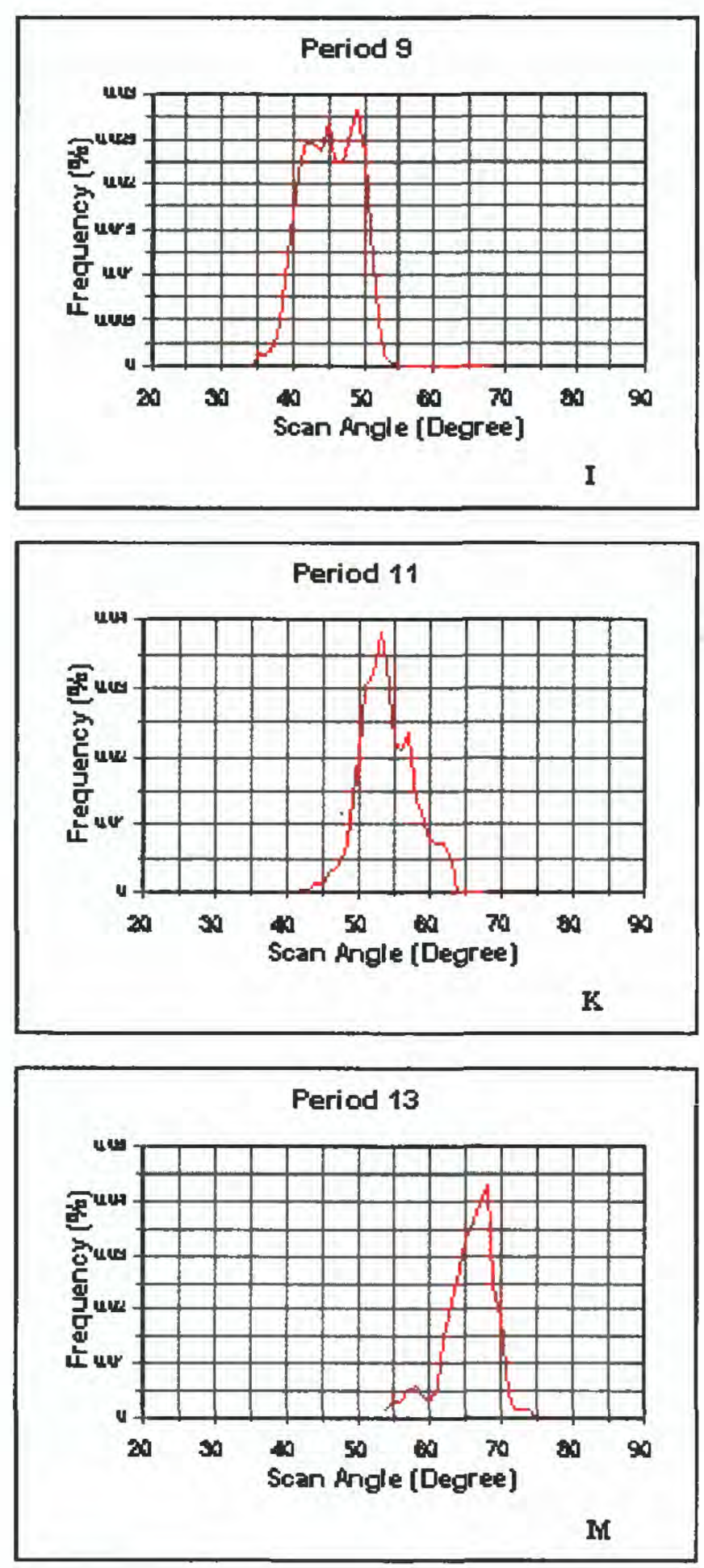
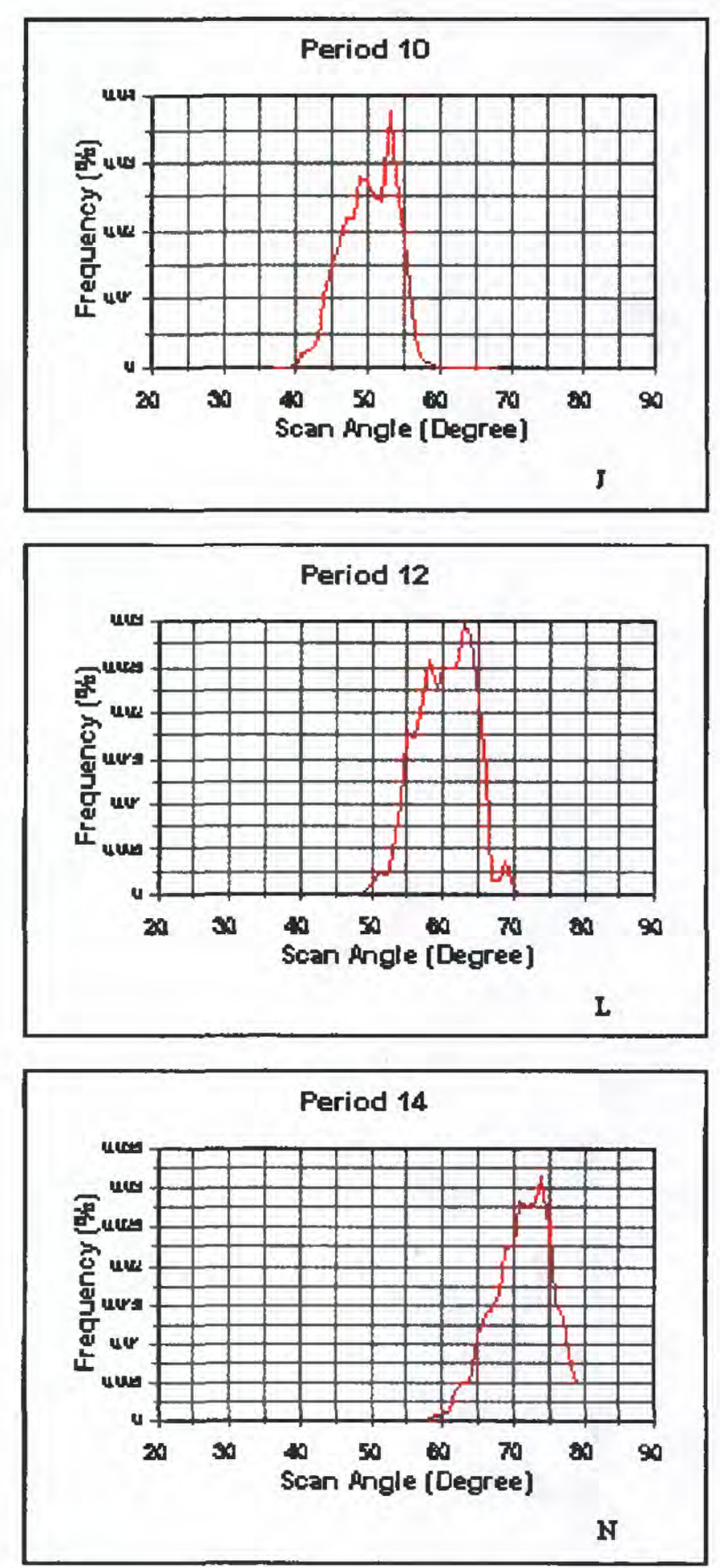

Figure 25. Distribution of solar zenith angles for 1997 AVHRR data set (continued) 


\section{Cloud Cover}

Estimates of cloud cover for each data set which were based on a systematic 10 percent sample, are summarized for each year in figure 26 and analyzed more completely in table 15. Figure 26 summarizes and divides the data into three categories. The first category indicates that a pixel passed all three cloud tests (that is, did not equal or exceed the thresholds used). The second category indicates that a pixel passed one or more tests, but failed on at least one test (exceeded threshold). The third category indicates that a pixel failed all three tests (exceeded all three thresholds). Pixels were determined to be cloud free if the passed all three tests.

As seen in figure 26, very few pixels in the data set failed to pass all three tests during the growing season, indicating that very little of the data are affected enough by clouds to be unusable (or at least minimally usable) for vegetation studies. During 3 years $(1992,1995$, and 1996), a vast majority of the data is questionable, having failed one or more of the tests. It is also interesting to note that in each of the three cases, cloud free data (that is, pixels passing all three tests) did not occur in these years until period 7 (July 1-15 in 1992, and June 26 - July 7 in 1995 and 1996). The other years showed what might be assumed to be a normal occurrence, with cloud (or snow) conditions being present in the spring, decreasing throughout the summer, and then increasing toward the fall.

Table 15 gives a more complete breakdown of how many pixels failed for each period and year. Categories listed are Cloud Free (passed all three tests), Reflectance Gross Cloud Test (RGCT), Three Minus Four (TMF), Four Minus Five (FMF), Cloud (failed all tests), and paired combinations of the three tests.

Few pixels failed the RGCT, TMF, or both (TMF+RGCT) while passing other tests. Most cases contained less than 2 to 3 percent of the total, indicating that few pixels associated with a bright surface also manifested warmer temperatures (than cloud or snow), such as might be found over barren areas.

Tests that detected the most instances of probable presence of clouds were the FMF and FMF+RGCT tests. The FMF test is based on brightness temperatures of the pixel, in which a cold temperature indicates a thin cirrus cloud. Normally less than 10-15 percent of the pixels failed this test, except during early and late season periods and for most of the time in 1992 and 1996; most pixels failed the test during large parts of those years. When the FMF is used in combination with the RGCT test, both highly reflective surfaces and thin cirrus clouds may exist, thereby precluding warmer barren Earth surfaces. As one would expect, the combination of FMF+RGCT would be highest in the early periods when snow covers much of the State, then decrease during the summer periods, and slightly increase again during the later periods, depending on the weather for that year and early snowfalls.

Few pixels failed both the FMF and TMF tests concurrently, indicating that relatively few areas had low brightness temperatures in channel 4 , high reflective surfaces, and a high brightness temperatures in channel 3.

\section{Geographic Registration Errors}

It was very difficult to properly assess the accuracy of pixel locations within the seven different data sets because each composite image is made up of numerous subimages from different dates (although each subimage was georeferenced to a base image). Results from the 


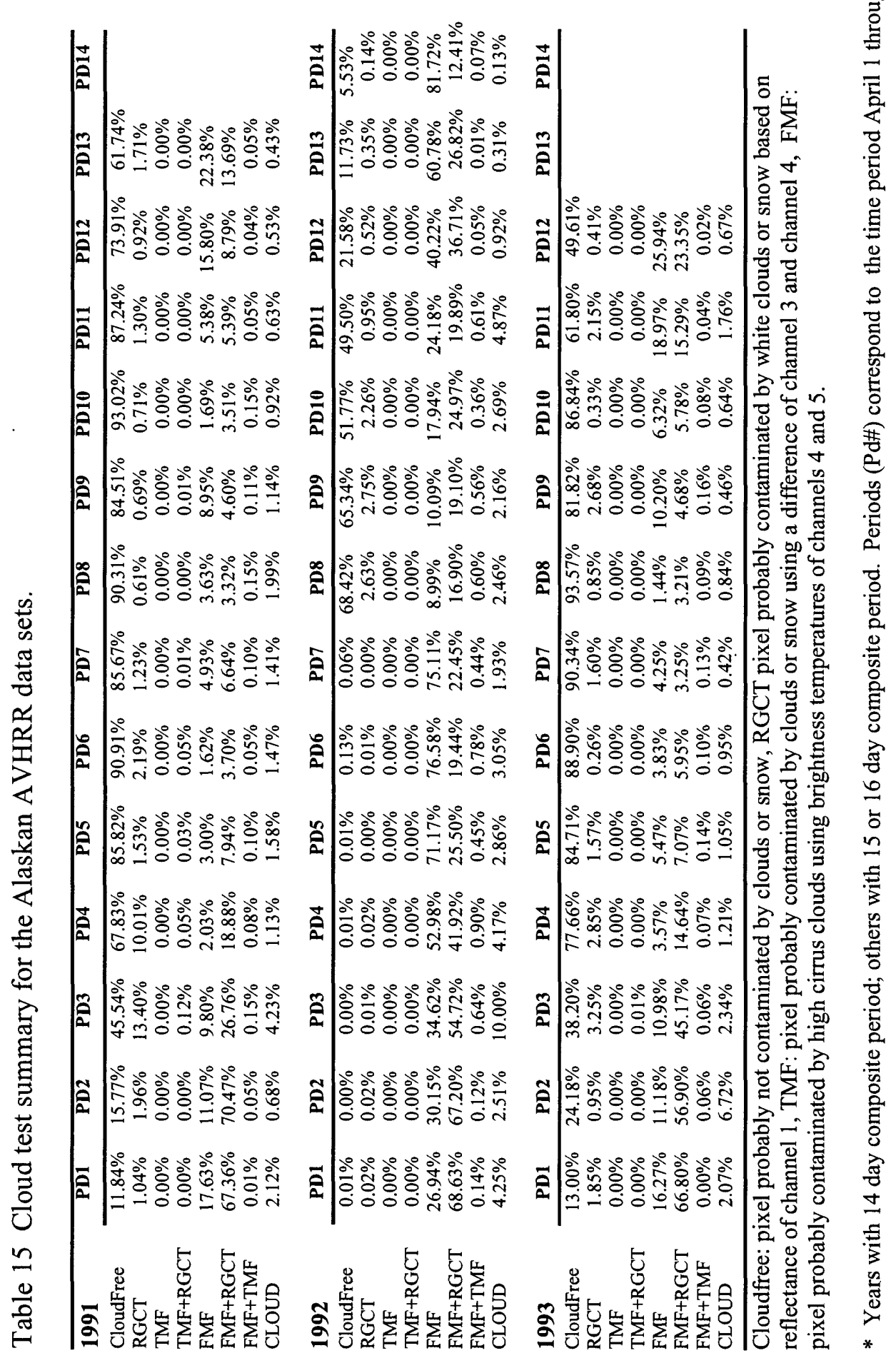




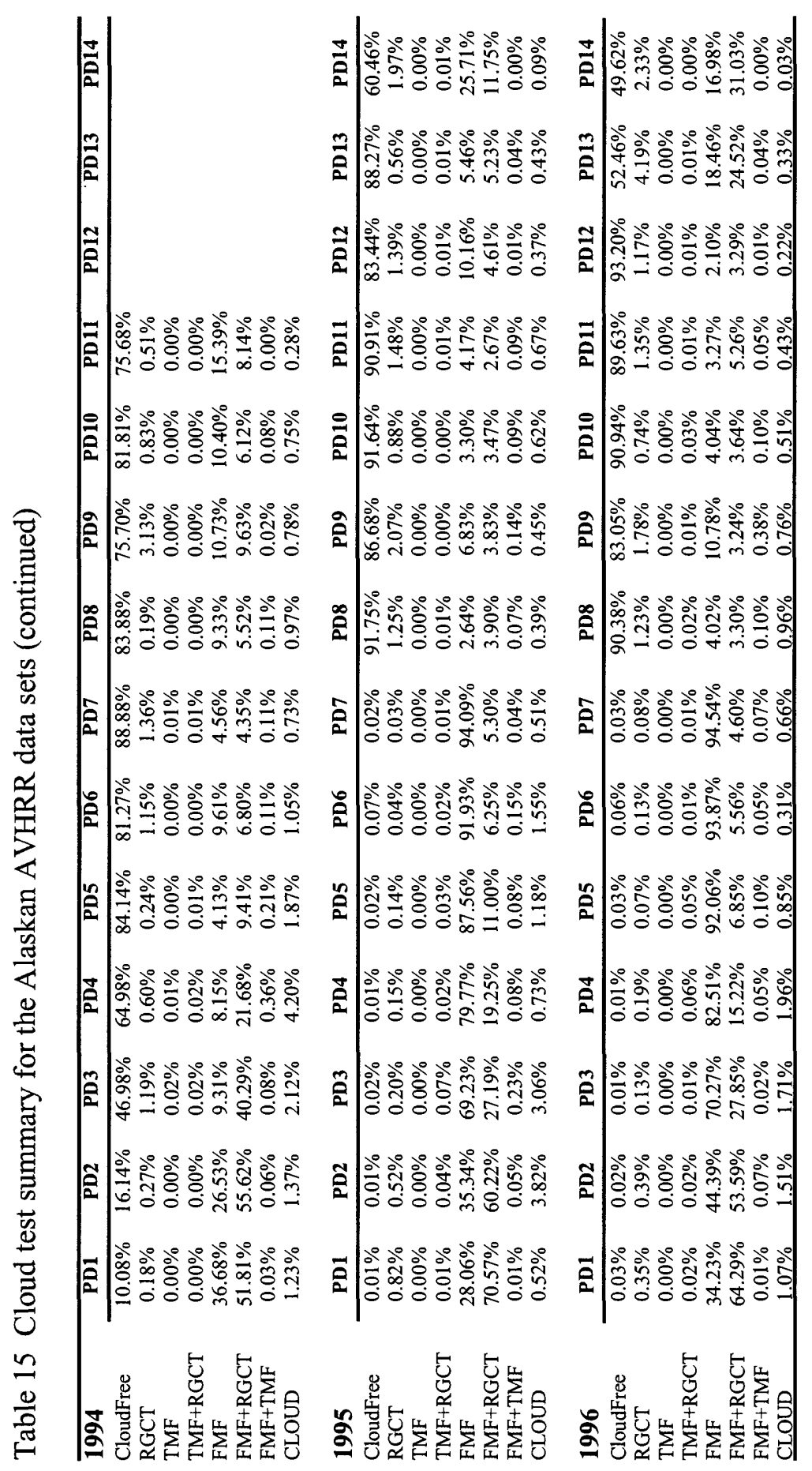

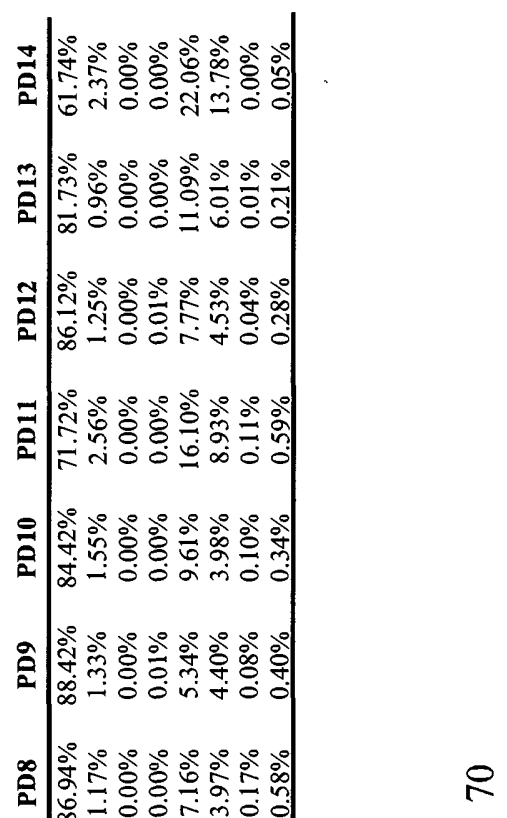

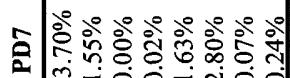

는

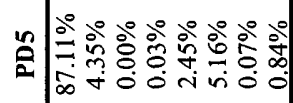

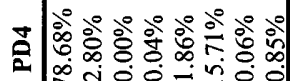

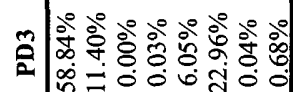

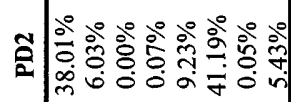

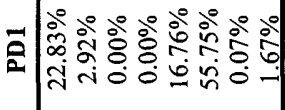

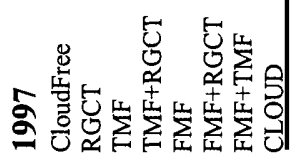



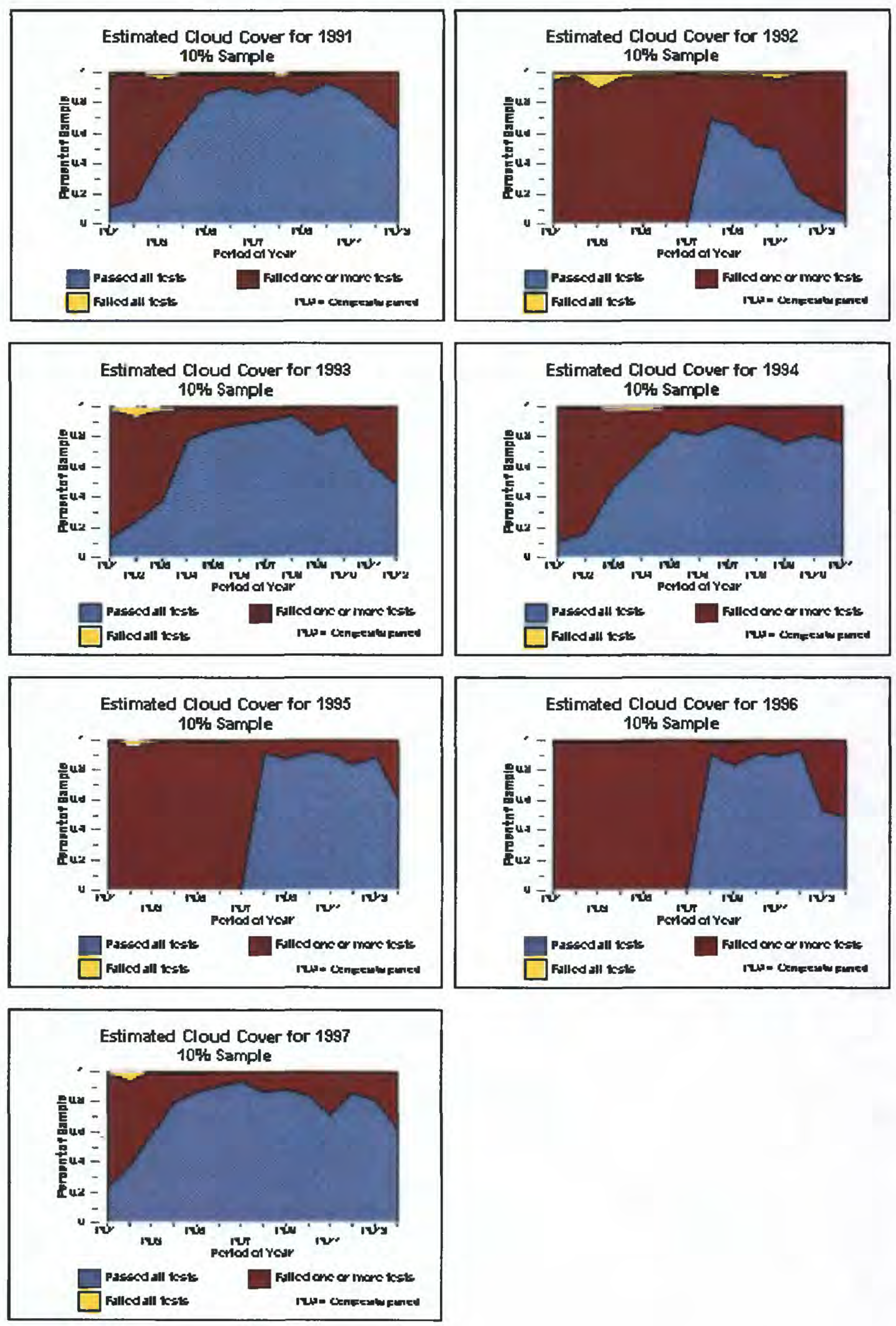

Figure 26. Estimates of cloud cover for the Alaskan AVHRR data sets 
autocorrelation and verification indicate a wide range of pixel misregistrations or offsets from the base image (tables 16 to 22). Registration errors (deviations from the base image) were as high as 17,800 meters (just under 18 pixels) in both the line and sample directions, although on average, line and sample residuals were less than 1,000 meters (1 pixel) and total RMSE errors rarely exceeded 8,000 meters ( 8 pixels) in any given year. As shown in figure 27 , highest registration errors normally occurred in the early or late parts of the year, probably a result of land surface variations due to snow or clouds (providing false peaks). As would be expected, the number of image chips being accepted from the correlation is low on either end of the year, and increases to a maximum in middle to late summer. Total image chips accepted for assessment never exceeded 264 (out of the possible 1,209). In some cases, as few as 28 chips were accepted (spring of 1992). However, it should be noted that not all of the 1,209 image chips are applicable for correlation. Because it is an automated procedure, there are built-in checks that will prevent chips from being used. Chips may be automatically disqualified because (1) the chip is too near the edge of the image, (2) the chip falls outside the area of interest (for example, over water), (3) one or more peaks within an image chip are too comparable in strength to the main peak, (4) the strength of the peak falls below the specified minimum, or (5) the diagonal displacement exceeds the maximum specified. As stated above, disqualification of most of the chips would be due to the presence of snow (especially in the early parts of the year) or clouds (more prevalent during the later parts of the year). Another problem is simple gray-level changes between the composite image and the base image used for the registration check; these changes are due to differences in growing season anomalies (short perturbations in climate, fires, or other natural disturbances), changes in sun angle, or other atmospheric effects (haze, subpixel clouds, or thin, high cirrus clouds).

Although this method of assessing the georeference accuracy of the individual data sets has many problems (involving many caveats and assumptions), it is at present a logical one because of its automated capabilities.

\section{DISCUSSION}

The multitemporal Alaskan data set is somewhat different from other AVHRR NDVIbased data sets (for example, global data set, Eidenshink and Faundeen, 1994; North American data set, Zhu and Yang, 1996) in that the data are delivered to the user in a byte format.

Although these data have less dynamic range for some of the original AVHRR data layers, they are still usable for vegetation phenological studies (Reed and others, 1994; Markon and others, 1995). However, some problems may arise if the data are used for certain studies involving thermal determinations about the Earth's surface, where more exact measurements may be needed.

The production of the 1991-97 Alaska AVHRR data sets was based on a maximum NDVI value compositing process (Eidenshink and Faundeen, 1994). Subsequently, the data content in each of the different data layers was based on the outcome of the NDVI value used for the composite period. The NDVI value and compositing process are largely affected by the date on which the data were acquired, the greenness of the pixel value, and satellite viewing and solar zenith angle (Zhu and Yang, 1996; D'Iorio and others, 1991; Li and others, 1996; Leblanc and 
Table 16. Registration error estimate (in meters unless otherwise noted) for the 1991 Alaskan AVHRR data set

\begin{tabular}{|c|c|c|c|c|c|c|c|}
\hline & \multicolumn{7}{|c|}{ PERIOD } \\
\hline & 1 & 2 & 3 & 7 & 5 & 6 & 7 \\
\hline \multirow{2}{*}{ Npoints } & 79 & 45 & 61 & 90 & 134 & 238 & $\overline{214}$ \\
\hline & -314.45 & 895.14 & -828.51 & 32.59 & 77.56 & 284.19 & 25.80 \\
\hline MIN & -15456.60 & -12859.40 & 273.70 & 3987.10 & 6.10 & 4.70 & 592.40 \\
\hline \multirow{4}{*}{\begin{tabular}{c|c} 
I & MAX \\
N & RMSE \\
E & MEDIAN \\
& STD
\end{tabular}} & 16859.40 & 16681.40 & 771.50 & 1264.90 & 5.40 & 1.80 & 7113.50 \\
\hline & 50.20 & 36.48 & 73.70 & 2814.96 & 543.37 & .24 & 2800.22 \\
\hline & 74.92 & 2.71 & 54 & 90 & 2.39 & 52 & 14.1 \\
\hline & 4210.16 & 4806.63 & & 2810.90 & 2537.67 & & 2806.6 \\
\hline \multirow{6}{*}{$\begin{array}{c}\text { AVE } \\
\text { MIN } \\
\text { MAX } \\
\text { RMSE } \\
\text { MEDIAN } \\
\text { STD }\end{array}$} & 48 & 978.13 & 887.88 & 222 & 400.00 & .82 & -121.8 \\
\hline & -12917.60 & -16072.20 & -11058.10 & 6901.00 & -4548.10 & 15868.70 & 4503.20 \\
\hline & 17408.20 & 63.50 & 417.20 & 11320.30 & 16776.60 & 10 & 4335.00 \\
\hline & 3935.87 & 5000.69 & 4526.90 & 3251.03 & 2076.84 & .50 & 2501.98 \\
\hline & -33.76 & 6.35 & 497.28 & 316.24 & 3.54 & .25 & 8.9 \\
\hline & 3899.41 & 4.71 & 775.81 & 261.55 & 2045.00 & 1628.03 & 2004.0 \\
\hline \multirow{6}{*}{\begin{tabular}{|c} 
STD \\
RMSE \\
PIXELS \\
MEDIAN \\
PIXELS
\end{tabular}} & $0 \angle 9 \angle$ & (1.01 & 041.03 & 84 & t & & \\
\hline & 5752.48 & 6956.90 & 725.36 & 300.37 & 3283.60 & 2266.74 & $\overline{3755.14}$ \\
\hline & 5.75 & 6.96 & 6.73 & 4.30 & 3.28 & 2.27 & 3.7 \\
\hline & 960.05 & 1402.90 & 2395.93 & 081.40 & 907.38 & 694.59 & 672.7 \\
\hline & 0.96 & 1.40 & 2.40 & 1.08 & 0.9 & 0.69 & 0.6 \\
\hline & 8 & 9 & 10 & 11 & 12 & 13 & 14 \\
\hline Npoints & 238 & 159 & 253 & 203 & 86 & 70 & \\
\hline & 343.51 & -21.45 & 166.67 & 78.11 & -44.85 & 101.84 & \\
\hline \multirow{3}{*}{\begin{tabular}{c|c} 
AVE \\
MIN \\
I \\
MAX \\
NAMSE \\
RMSE
\end{tabular}} & -2899.90 & -17675.90 & -13705.00 & -13107.30 & -16863.60 & -17451.60 & \\
\hline & 17540.10 & 16354.20 & 12665.40 & 13070.90 & 13947.00 & 16798.10 & \\
\hline & 2098.38 & 2697.03 & 1981.28 & 1675.80 & 3418.41 & 4820.61 & \\
\hline \multirow{2}{*}{$\begin{array}{c}\text { MEDIAN } \\
\text { STD }\end{array}$} & 52.59 & -24.57 & 101.67 & 20.97 & -63.81 & -157.14 & \\
\hline & 2074.44 & 2705.47 & 1978.17 & 1678.12 & 3438.17 & 4854.33 & \\
\hline
\end{tabular}

\begin{tabular}{|c|c|c|c|c|c|c|}
\hline AVE & 129.05 & 163.72 & 55.56 & -28.46 & -261.84 & -760.72 \\
\hline MIN & -11751.50 & -17650.20 & -12722.30 & -12477.30 & -14368.30 & -14822.00 \\
\hline MAX & 7265.10 & 16047.30 & 13168.70 & 5374.70 & 11752.10 & 15103.00 \\
\hline RMSE & 1583.22 & 2996.83 & 1721.91 & 1301.80 & 2907.03 & 5037.70 \\
\hline MEDIAN & 125.74 & 161.68 & 1.24 & 7.60 & -13.68 & 141.52 \\
\hline STD & 1581.27 & 3001.81 & 1724.43 & 1304.71 & 2912.19 & 5015.89 \\
\hline
\end{tabular}

\begin{tabular}{|c|c|c|c|c|c|c|}
\hline \multirow{2}{*}{$\begin{array}{c}\text { STD } \\
\text { RMSE }\end{array}$} & 2044.27 & 3690.91 & 2530.10 & 2210.58 & 3853.03 & 6932.63 \\
\hline & 2628.64 & 4031.74 & 2624.97 & 2122.03 & 4487.35 & 6972.56 \\
\hline PIXELS & 2.63 & 4.03 & 2.63 & 2.12 & 4.49 & 6.97 \\
\hline MEDIAN & 770.63 & 740.30 & 695.97 & 731.49 & 882.63 & 1231.73 \\
\hline PIXELS & 0.77 & 0.74 & 0.70 & 0.73 & 0.88 & 1.23 \\
\hline
\end{tabular}

Npoints = number of sample points used for estimate (see text for explanation)

PIXELS in the TOTAL rows indicate error in terms of $1 \mathrm{~km} \times 1 \mathrm{~km}$ pixels 
Table 17. Registration error estimate (in meters unless otherwise noted) for the 1992 Alaskan AVHRR data set

\begin{tabular}{|c|c|c|c|c|c|c|c|}
\hline \multirow[b]{2}{*}{ Npoints } & \multicolumn{7}{|c|}{ PERIOD } \\
\hline & 49 & 28 & 33 & 53 & 96 & 147 & 204 \\
\hline AVE & 115.92 & -735.40 & 1320.19 & -406.71 & -10.79 & -239.03 & 50.63 \\
\hline MIN & -13333.90 & -16935.90 & -12641.10 & -13383.70 & -11877.50 & -17172.00 & -15285.90 \\
\hline MAX & 17102.20 & 16645.00 & 16852.90 & 16887.20 & 12582.50 & 13261.80 & 17804.80 \\
\hline RMSE & 4380.49 & 7809.70 & 7357.94 & 4167.40 & 3520.13 & 2867.61 & 2225.36 \\
\hline MEDIAN & -5.70 & -666.74 & 196.12 & -196.55 & -71.43 & -380.29 & -23.85 \\
\hline STD & 4424.34 & 7917.67 & 7350.77 & 4187.19 & 3538.59 & 2867.40 & 2230.25 \\
\hline AVE & -588.17 & 67.06 & 1499.13 & 80.69 & 236.87 & 346.25 & 360.16 \\
\hline MIN & -17324.00 & -16644.20 & -14662.40 & -16924.90 & -15941.30 & -7980.20 & -12176.90 \\
\hline MAX & 14474.70 & 14786.90 & 12424.90 & 6714.80 & 14559.70 & 14841.90 & 12250.20 \\
\hline RMSE & 5640.08 & 7207.53 & 6085.87 & 3110.87 & 3444.27 & 2321.81 & 1860.21 \\
\hline MEDIAN & 662.86 & 54.10 & 809.05 & 259.30 & 192.79 & 352.37 & 230.17 \\
\hline STD & 5667.45 & 7339.47 & 5989.79 & 3139.59 & 3454.15 & 2303.70 & 1829.50 \\
\hline STD & 6575.79 & $\overline{12501.13}$ & 11443.21 & 5197.20 & 4702.54 & 3498.03 & 3330.39 \\
\hline RMSE & 7141.37 & 10627.32 & 9548.67 & 5200.45 & 4924.86 & 3689.71 & 2900.44 \\
\hline PIXELS & 7.14 & 10.63 & 9.55 & 5.20 & 4.93 & 3.69 & 2.90 \\
\hline MEDIAN & 2035.59 & 7704.58 & 4458.53 & 1695.12 & 904.74 & 1393.31 & 886.15 \\
\hline PIXELS & 2.04 & 7.70 & 4.46 & 1.70 & 0.90 & 1.39 & 0.89 \\
\hline & 8 & 9 & 10 & 11 & 12 & 13 & 14 \\
\hline Npoints & 161 & 152 & 151 & 120 & 85 & 36 & 31 \\
\hline AVE & -68.34 & 77.09 & -568.74 & -147.04 & 183.59 & 1471.51 & -1638.87 \\
\hline MIN & -13671.90 & -17859.70 & -14355.80 & -16107.10 & -13579.10 & -8237.40 & -14160.30 \\
\hline MAX & 5950.50 & 15154.30 & 16522.30 & 9497.70 & 16873.40 & 16167.80 & 9063.20 \\
\hline RMSE & 1594.28 & 2874.31 & 2783.85 & 2845.74 & 3441.24 & 4866.29 & 4878.74 \\
\hline MEDIAN & -106.14 & -24.43 & -317.37 & 39.02 & 1.16 & 524.12 & -532.77 \\
\hline STD & 1597.79 & 2882.78 & 2734.21 & 2853.85 & 3456.73 & 4704.27 & 4671.20 \\
\hline
\end{tabular}

\begin{tabular}{|l|l|l|l|l|l|l|l|}
\hline S AVE & 523.70 & 669.67 & 349.61 & 457.83 & 555.61 & 1263.20 & 1478.66 \\
\hline
\end{tabular}

A MIN \begin{tabular}{r|r|r|r|r|r|r|r|}
\hline & -14975.60 & -7733.70 & -11021.80 & 15869.40 & -9244.50 & -10279.20 & -17024.80 \\
\hline
\end{tabular}

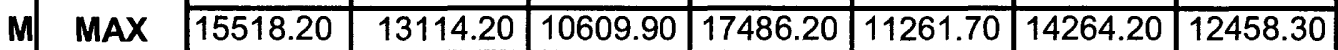

\begin{tabular}{|l|l|r|r|r|r|r|r|} 
P RMSE & 2438.48 & 2694.65 & 2315.19 & 3653.82 & 2592.82 & 5435.83 & 6662.19 \\
\cline { 2 - 8 }
\end{tabular}

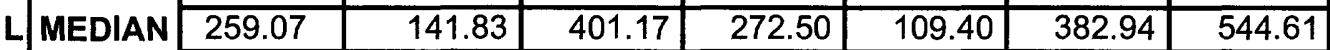

\begin{tabular}{|l|r|r|r|r|r|r|r|} 
E STD & 2389.02 & 2618.74 & 2296.26 & 3640.22 & 2547.62 & 5362.02 & 6603.41 \\
\hline
\end{tabular}

\begin{tabular}{|c|c|c|c|c|c|c|c|}
\hline STD & 2869.05 & 3885.92 & 2698.34 & 4276.84 & 4254.34 & 7433.27 & 7911.92 \\
\hline RMSE & 2913.41 & 3939.90 & 3620.77 & 4631.27 & 4308.69 & 7295.82 & 8257.5 \\
\hline PIXELS & 2.91 & 3.94 & 3.62 & 4.63 & 4.31 & 7.30 & $\overline{8.2}$ \\
\hline MEDIAN & 923.15 & 986.44 & 1155.81 & 995.50 & 950.10 & 2542.50 & 3390.3 \\
\hline PIXELS & 0.92 & 0.99 & 1.16 & 1.00 & 0.95 & 2.54 & 3.3 \\
\hline
\end{tabular}

Npoints = number of sample points used for estimate (see text for explanation)

PIXELS in the TOTAL rows indicate error in terms of $1 \mathrm{~km} \mathrm{x} 1 \mathrm{~km}$ pixels 
Table 18. Registration error estimate (in meters unless otherwise noted) for the 1993 Alaskan AVHRR data set

\begin{tabular}{|c|c|c|c|c|c|c|c|}
\hline & 1 & 2 & 3 & $\begin{array}{c}\text { PERIOD } \\
4\end{array}$ & 5 & 6 & 7 \\
\hline Npoints & 54 & 49 & 65 & 126 & 161 & 160 & 231 \\
\hline AVE & -893.78 & 1192.20 & 474.72 & 52.31 & 332.04 & 236.38 & -60.04 \\
\hline MIN & -15340.80 & -13708.70 & -8311.90 & -10213.70 & -16448.00 & -11505.20 & -16593.40 \\
\hline MAX & 11269.10 & 17789.60 & 12784.40 & 14909.00 & 16828.90 & 13385.60 & 15123.20 \\
\hline N RMSE & 4688.30 & 5551.01 & 3027.80 & 2537.14 & 2965.19 & 2130.98 & 2308.65 \\
\hline MEDIAN & -12.04 & 321.81 & 233.36 & -22.23 & -13.28 & 37.77 & $\overline{43.10}$ \\
\hline STD & 4645.53 & 5477.65 & 3013.62 & 2546.73 & 2955.74 & 2124.48 & 2312.88 \\
\hline AVE & 245.08 & -511.61 & -19.64 & 642.56 & 64.32 & 156.10 & 73.80 \\
\hline MIN & -13332.30 & -17575.10 & -11784.70 & -5514.00 & -11690.00 & -9656.00 & -10735.10 \\
\hline MAX & 14636.90 & 10324.70 & 16152.80 & 15064.00 & 11369.00 & 13363.20 & 12905.30 \\
\hline RMSE & 3978.85 & 4104.22 & 4649.67 & 2585.00 & 2007.04 & 1667.76 & 2052.57 \\
\hline LMEDIAN & -129.93 & -166.65 & 294.15 & 244.83 & 99.33 & 102.08 & 21.11 \\
\hline STD & 4008.59 & 4114.41 & 4685.81 & 2513.86 & 2012.27 & 1665.65 & 2055.70 \\
\hline STD & 4880.53 & 6216.60 & 6102.50 & 3509.69 & 3368.83 & 2392.08 & 2989.07 \\
\hline RMSE & \begin{tabular}{|l|}
6149.10 \\
\end{tabular} & 6903.50 & 5548.60 & 3622.06 & 3580.58 & 2706.01 & 3089.16 \\
\hline T|PIXELS & 6.15 & 6.90 & 5.55 & 3.62 & 3.58 & 2.71 & 3.09 \\
\hline AMEDIAN & 1394.99 & 1487.11 & 1418.57 & 868.05 & 628.32 & 608.93 & 580.16 \\
\hline $\mid$ PIXELS & 1.39 & 1.49 & 1.42 & 0.87 & 0.63 & 0.61 & 0.58 \\
\hline & 8 & 9 & 10 & 11 & 12 & 13 & 14 \\
\hline Npoints & 252 & 175 & 190 & 118 & 92 & & \\
\hline AVE & 17.75 & 259.70 & 287.62 & -108.03 & -454.85 & & \\
\hline MIN & -7574.20 & -15976.40 & -5167.50 & -16529.60 & -17666.90 & & \\
\hline MAX & 16697.40 & 16737.90 & 14708.60 & 14586.30 & 15229.40 & & \\
\hline RMSE & 1532.00 & 3478.55 & 1490.56 & 3494.31 & 3847.99 & & \\
\hline MEDIAN & -25.04 & 27.34 & 97.57 & -109.46 & 12.20 & & \\
\hline STD & 1534.94 & 3478.79 & 1466.42 & 3507.53 & 3841.95 & & \\
\hline AVE & 207.63 & -260.64 & 180.24 & -131.24 & -187.07 & & \\
\hline MIN & 16626.50 & 15550.30 & -12656.90 & -15130.00 & -14320.30 & & \\
\hline MAX & 16314.10 & 8208.70 & 14268.20 & 10564.10 & 11600.10 & & \\
\hline RMSE & 1739.85 & 2280.78 & 2439.07 & 2921.14 & 3485.38 & & \\
\hline MEDIAN & 120.32 & 52.73 & -41.23 & 147.05 & 7.42 & & \\
\hline STD & 1730.86 & 2272.35 & 2438.82 & 2930.64 & 3499.43 & & \\
\hline STD & 2005.07 & 4114.17 & 2958.71 & 4447.33 & 5522.04 & & \\
\hline O RMSE & 2318.21 & 4159.60 & 2858.47 & 4554.48 & 5191.81 & & \\
\hline PIXELS & 2.32 & 4.16 & 2.86 & 4.55 & 5.19 & & \\
\hline MEDIAN & 626.00 & 623.87 & 694.62 & 802.30 & 1110.37 & & \\
\hline PIXELS & 0.63 & 0.62 & 0.69 & 0.80 & 1.11 & & \\
\hline
\end{tabular}

Npoints = number of sample points used for estimate (see text for explanation)

PIXELS in the TOTAL rows indicate error in terms of $1 \mathrm{~km} \mathrm{x} 1 \mathrm{~km}$ pixels 
Table 19. Registration error estimate (in meters unless otherwise noted) for the 1994 Alaskan AVHRR data set

\begin{tabular}{|c|c|c|c|c|c|c|c|c|}
\hline & & 1 & 2 & 3 & $\begin{array}{c}\text { PERIOD } \\
4 \\
\end{array}$ & 5 & 6 & 7 \\
\hline & Npoints & 61 & 47 & 64 & 91 & 142 & 100 & 190 \\
\hline & AVE & -230.31 & 473.27 & -459.72 & -215.10 & 85.26 & 185.68 & 1.92 \\
\hline & MIN & -16597.20 & -12895.40 & -13989.40 & -12397.80 & -16284.90 & -12460.60 & -10181.40 \\
\hline & MAX & 13313.50 & 10516.50 & 7457.80 & 4867.40 & 11779.20 & 15067.90 & 13956.10 \\
\hline & RMSE & 4750.06 & 3413.90 & 3198.73 & 2082.15 & 2560.94 & 3902.38 & 2043.95 \\
\hline & MEDIAN & 80.32 & 185.65 & 176.20 & -68.16 & -16.68 & -60.27 & -3.75 \\
\hline & STD & 4783.85 & 3417.49 & 3190.54 & 2082.49 & 2568.58 & 3917.60 & 2049.35 \\
\hline & AVE & -482.71 & -647.87 & 1127.63 & -44.33 & 300.22 & 606.99 & 279.98 \\
\hline & MIN & -16861.40 & -15983.20 & -11829.60 & 16909.50 & -12255.70 & -12040.50 & -10715.00 \\
\hline & MAX & 15631.30 & 9219.20 & 16089.80 & 3369.10 & 12266.90 & 16210.00 & 10874.30 \\
\hline$P$ & RMSE & 4901.87 & 4254.56 & 4578.21 & 2202.89 & 2085.35 & 3652.65 & 1979.53 \\
\hline & MEDIAN & -32.53 & -342.96 & 81.53 & 100.87 & 45.30 & 109.45 & 29.65 \\
\hline & STD & 4918.53 & 4250.40 & 4472.25 & 2214.64 & 2070.94 & 3620.01 & 1964.81 \\
\hline & STD & 5924.16 & 4540.61 & 5424.72 & 3181.89 & 3198.83 & 5769.76 & 2921.30 \\
\hline & RMSE & 6825.79 & 5454.90 & 5584.97 & 3031.18 & 3302.59 & 5345.13 & 2845.40 \\
\hline & PIXELS & 6.83 & 5.46 & 5.59 & 3.03 & 3.30 & 5.35 & 2.85 \\
\hline & MEDIAN & 1696.29 & 1374.33 & 1606.38 & 908.39 & 605.72 & 725.74 & 491.92 \\
\hline & PIXELS & 1.70 & 1.37 & 1.61 & 0.91 & 0.61 & 0.73 & 0.49 \\
\hline & & 8 & 9 & 10 & 11 & 12 & 13 & 14 \\
\hline & Npoints & 151 & 192 & 187 & 126 & & & \\
\hline & AVE & 4.41 & -138.74 & -168.30 & -82.25 & & & \\
\hline & MIN & -10572.90 & -16282.90 & -14873.20 & -15027.50 & & & \\
\hline I & MAX & 14006.90 & 10550.60 & 11800.40 & 11843.20 & & & \\
\hline & RMSE & 2526.76 & 1932.57 & 2331.81 & 2449.49 & & & \\
\hline & MEDIAN & -31.11 & 15.59 & 31.77 & 10.56 & & & \\
\hline & STD & 2535.16 & 1932.63 & 2331.97 & 2457.88 & & & \\
\hline & AVE & -31.92 & 143.04 & 180.36 & 169.61 & & & \\
\hline & MIN & -16646.10 & -16655.30 & 15671.80 & -14706.40 & & & \\
\hline & MAX & 13179.30 & 12555.80 & 13875.30 & 16199.70 & & & \\
\hline & RMSE & 3327.58 & 1936.30 & 2492.86 & 2357.32 & & & \\
\hline & MEDIAN & 36.03 & 167.33 & 36.16 & 53.11 & & & \\
\hline & STD & 3338.50 & 1936.06 & 2493.00 & 2360.59 & & & \\
\hline & STD & 4283.91 & 2881.04 & 3504.88 & 3240.03 & & & \\
\hline & RMSE & 4178.20 & 2735.71 & 3413.46 & 3399.55 & & & \\
\hline & PIXELS & 4.18 & 2.74 & 3.41 & 3.40 & & & \\
\hline & MEDIAN & 873.55 & 611.01 & 789.99 & 746.69 & & & \\
\hline & PIXELS & 0.87 & 0.61 & 0.79 & 0.75 & & & \\
\hline
\end{tabular}

Npoints $=$ number of sample points used for estimate (see text for explanation)

PIXELS in the TOTAL rows indicate error in terms of $1 \mathrm{~km} \times 1 \mathrm{~km}$ pixels 
Table 20. Registration error estimate (in meters unless otherwise noted) for the 1995 Alaskan AVHRR data set

\begin{tabular}{|c|c|c|c|c|c|c|c|}
\hline & \multicolumn{7}{|c|}{ PERIOD } \\
\hline & 1 & 2 & 3 & 4 & 5 & 6 & 7 \\
\hline Npoints & 59 & 46 & 113 & 112 & 174 & 237 & 262 \\
\hline AVE & 55.47 & 84.67 & 178.68 & 431.13 & 236.04 & 1.41 & 105.71 \\
\hline MIN & -14070.40 & -14429.60 & 4379.80 & -8303.40 & 11125.30 & 5704.30 & 14746.10 \\
\hline MAX & 13229.00 & 13220.60 & 13738.10 & 11931.90 & 15382.70 & 14920.20 & 13754.10 \\
\hline RMSE & 4468.28 & 3621.90 & 3107.42 & 2667.48 & 2772.31 & 9.57 & 1819.04 \\
\hline MEDIAN & -8.71 & 42.45 & 46.25 & -42.92 & 34.59 & -21.70 & 18.74 \\
\hline STD & 4506.29 & 3660.92 & 3116.10 & 2644.24 & 2770.22 & 2244.31 & 1819.44 \\
\hline \multirow{5}{*}{$\begin{array}{c}\text { AVE } \\
\text { MIN } \\
\text { MAX } \\
\text { RMSE } \\
\text { MEDIAN }\end{array}$} & -1172.29 & 550.41 & 632.10 & 327.88 & 167.92 & 268.30 & -35.34 \\
\hline & -17231.20 & -17046.20 & -7186.50 & 16070.00 & 16624.70 & -2328.50 & 12320.50 \\
\hline & 11346.10 & 14772.20 & 16258.50 & 16306.80 & 12355.80 & 13923.00 & 10487.00 \\
\hline & 5174.45 & 5422.82 & 2819.13 & 3217.50 & 2566.97 & 1684.53 & 1591.24 \\
\hline & -160.91 & 306.18 & 140.56 & 193.50 & -0.83 & 4.45 & -36.56 \\
\hline E| STD & 5083.17 & 5454.43 & 2759.59 & 3215.14 & 2568.87 & 1666.55 & 1593.89 \\
\hline \multirow{5}{*}{$\begin{array}{c}\text { STD } \\
\text { RMSE } \\
\text { PIXELS } \\
\text { MEDIAN } \\
\text { PIXELS }\end{array}$} & 5648.91 & 6942.97 & 4134.78 & 4046.95 & 3706.89 & 3114.90 & 2477.01 \\
\hline & 6836.70 & 6521.13 & 4195.66 & 4179.45 & 3778.24 & 2802.38 & 2416.81 \\
\hline & 6.84 & 6.52 & 4.20 & 4.18 & 3.78 & 2.80 & 2.42 \\
\hline & 1306.33 & 30.70 & 875.08 & 827.77 & 35.47 & 79.05 & 477.41 \\
\hline & 1.31 & 1.33 & 0.88 & 0.83 & 0.64 & 0.48 & 0.48 \\
\hline \multirow[b]{2}{*}{ Npoints } & 8 & 9 & 10 & 11 & 12 & 13 & 14 \\
\hline & 260 & 201 & 242 & 193 & 140 & 154 & 41 \\
\hline AVE & -4.33 & 380.75 & -120.86 & 39.25 & 291.75 & 54.92 & -138.36 \\
\hline MIN & -13856.40 & -2533.30 & -17605.30 & 14265.50 & -13352.70 & -10499.80 & -17711.60 \\
\hline MAX & 3665.10 & 17271.00 & 13412.90 & 9582.10 & 15840.20 & 12702.20 & 10320.10 \\
\hline RMSE & 1575.44 & 2075.96 & 2052.99 & 1875.09 & 2691.54 & 1756.16 & 4639.65 \\
\hline MEDIAN & 68.51 & 47.67 & & 38.84 & -32.20 & -26.17 & 60.55 \\
\hline STD & 1578.47 & 2045.84 & 2053.68 & 1879.56 & 2685.29 & 1761.03 & 4695.20 \\
\hline
\end{tabular}

\begin{tabular}{|c|c|c|c|c|c|c|c|}
\hline AVE & -8.00 & 75.35 & -69.66 & -0.17 & -150.63 & -55.69 & 2403.00 \\
\hline MIN & -16994.80 & 5521.00 & -11811.70 & 3007.40 & -16904.10 & -15157.70 & -13542.50 \\
\hline MA & 12525.50 & 11890.20 & 14369.80 & 11644.20 & 16946.30 & 14967.10 & 17670.50 \\
\hline RMSE & 1841.46 & 2212.88 & 1729.94 & 2191.45 & 3651.81 & 2077.33 & 6100.83 \\
\hline MEDIAN & 7.13 & 29.46 & 1.99 & 42.50 & 53.20 & -64.06 & 924.97 \\
\hline STD & 1844.9 & 2217.12 & 1732.12 & 2197.15 & 3661.80 & 2083.36 & 5677.31 \\
\hline STD & 2713.79 & $\overline{3254.24}$ & 2748.74 & 3093.61 & 4891.61 & 2923.35 & $\overline{6571.78}$ \\
\hline RMSE & 2423.42 & 3034.21 & 2684.67 & 2884.17 & 4536.53 & $\overline{2720.18}$ & 7664.63 \\
\hline PIXELS & 2.42 & 3.03 & 2.69 & 2.88 & 4.54 & 2.72 & 7.67 \\
\hline & 523.09 & 420.26 & 502.61 & 484.83 & 943.45 & 712.48 & 1708.40 \\
\hline & 0.52 & 0.42 & 0.50 & 0.48 & $\overline{0.94}$ & 0.7 & 17 \\
\hline
\end{tabular}

Npoints = number of sample points used for estimate (see text for explanation)

PIXELS in the TOTAL rows indicate error in terms of $1 \mathrm{~km} \times 1 \mathrm{~km}$ pixels 
Table 21. Registration error estimate (in meters unless otherwise noted) for the 1996 Alaskan AVHRR data set

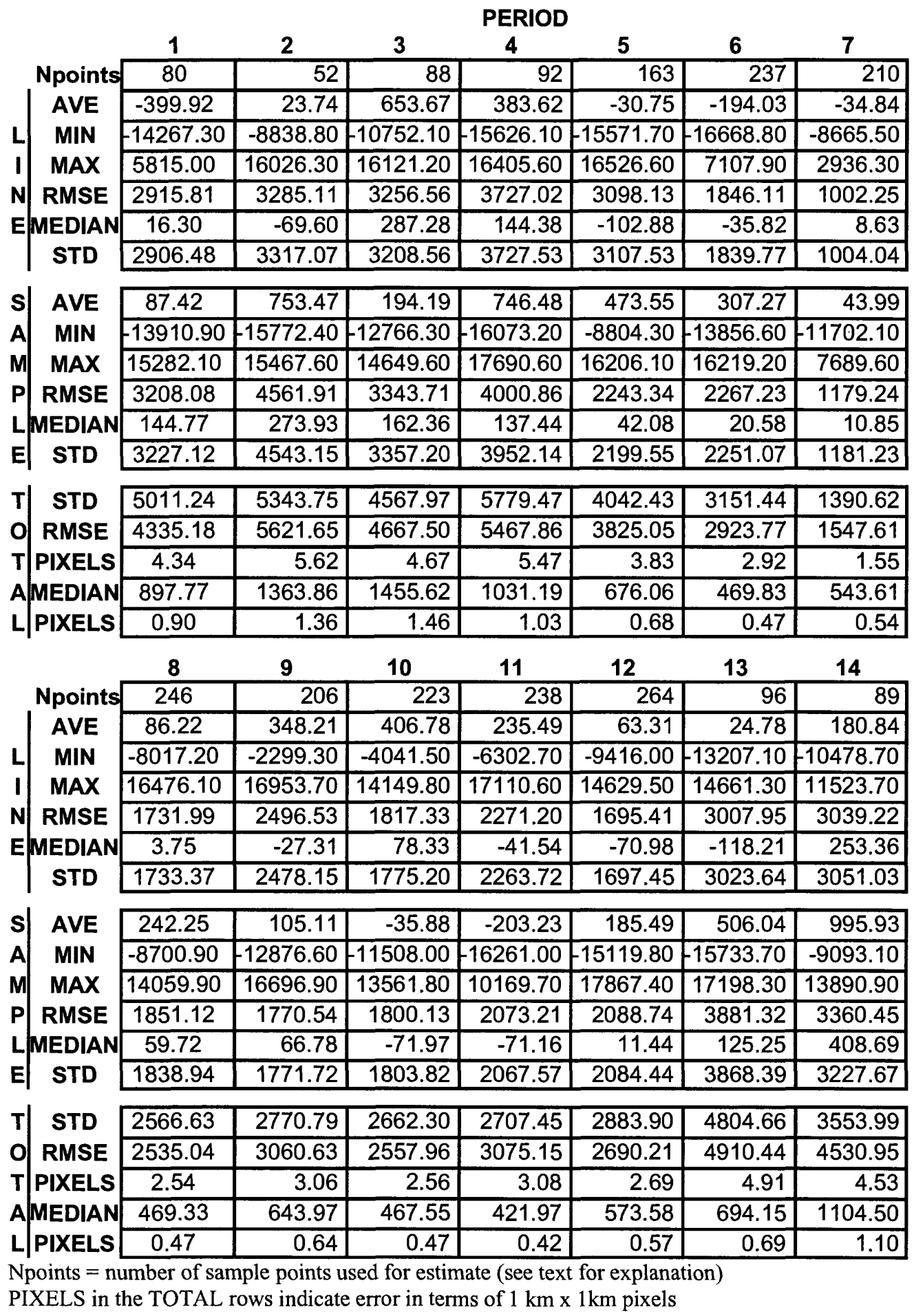


Table 22. Registration error estimate (in meters unless otherwise noted) for the 1997 Alaskan AVHRR data set

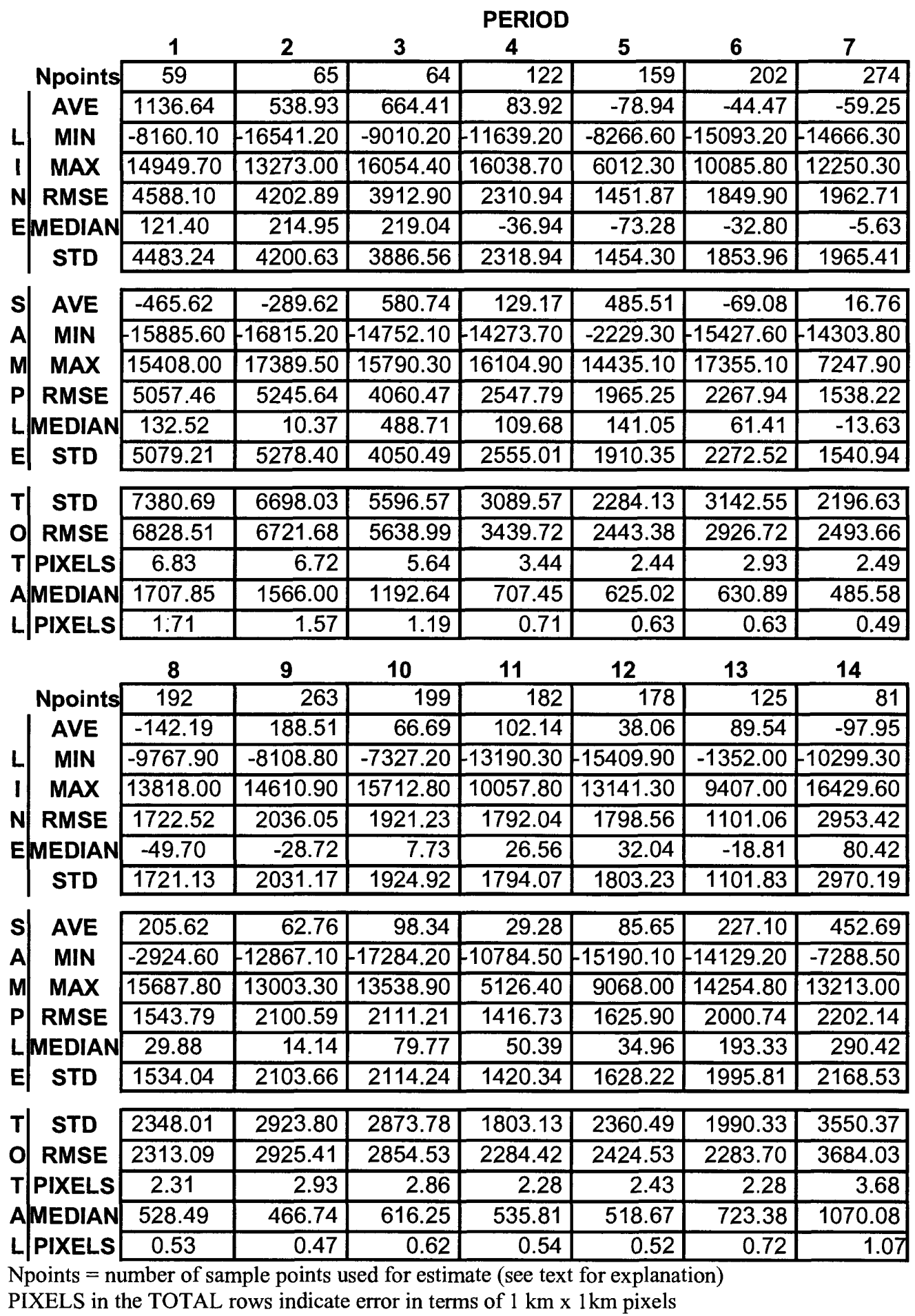



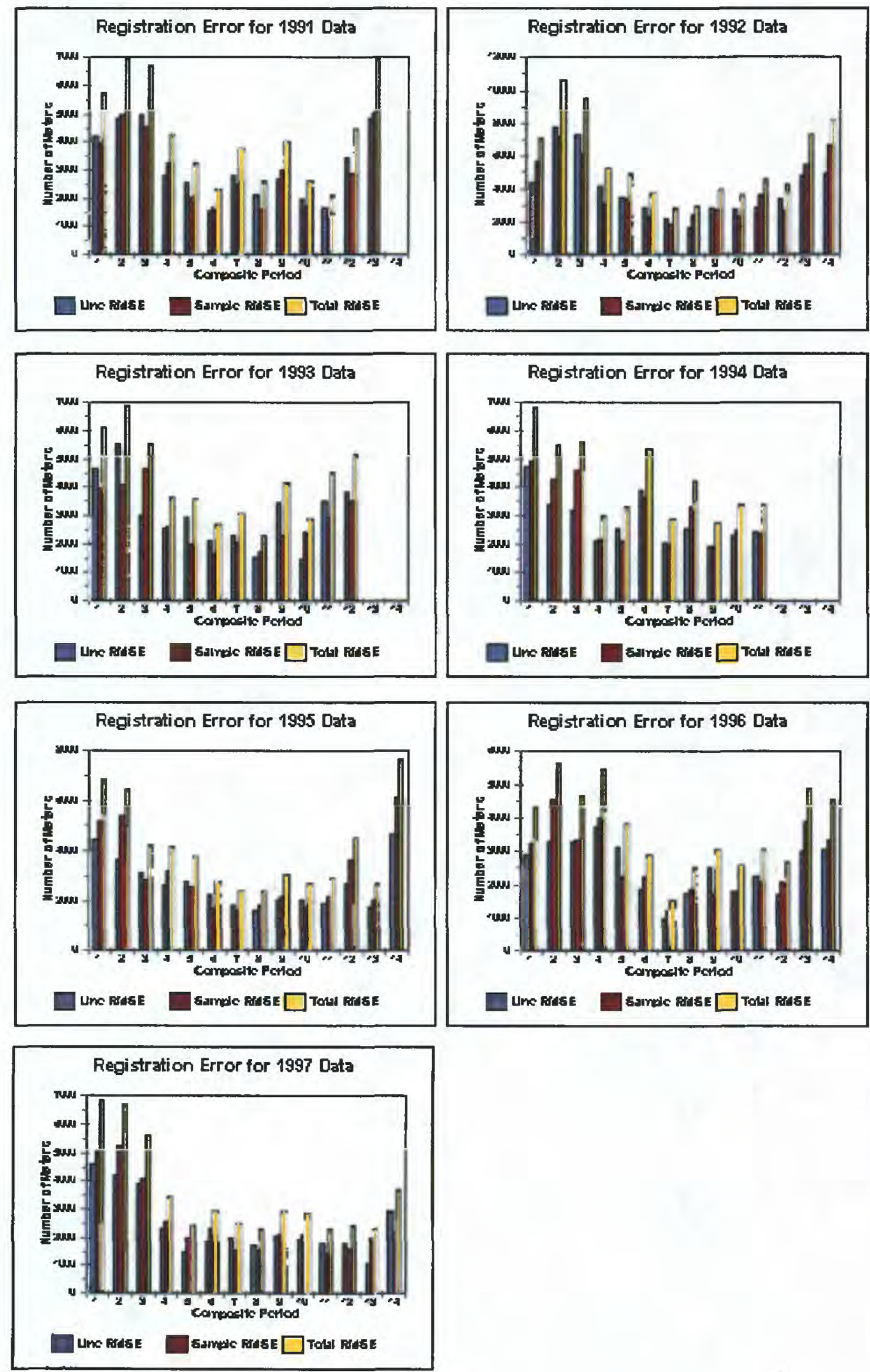

Figure 27. Registration error estimates for the Alaskan AVHRR data sets 
others, 1997). The NDVI values in the Alaskan data sets were computed without prior correction for atmospheric effects. The use of atmospherically corrected data before compositing has been shown to influence the quality and usefulness of the resulting data by selecting pixels from higher view angles (Cihlar and Huang, 1994; D'Iorio and others, 1991).

Other recent studies that reviewed the characteristics of AVHRR NDVI-based data sets overlooked the importance of the date on which data were acquired and used for each composite period (for example, Zhu and Yang, 1996). However, in studies dealing with vegetation phenological aspects of the data (for example, Reed and others, 1994)), the date of data acquisition within any given period may be important. Acquisition dates that are pooled toward the beginning or end of a period may not be true representations of the average or dominant greenness that actually occurred during the period. Data that were pooled toward the end of one period and then toward the beginning of the next period may not be truly representative of either period. This is most important in geographical areas where important phenological events (such as onset of greenness, peak of greenness, and senescence) happen in a relatively short period of time, such as in northern latitudes. In Alaska, data acquired during April, and perhaps the first week in May, may have little effect on the temporal qualities of measured greenness because much of the Alaskan surface is still covered with snow, or in a state of pre-leaf emergence. However, it is important to begin with these early periods to assess possible changes in growing season length that are due to early or late green-up between years, or for comparison with future data sets.

Critical time periods for assessing green-up rates and times for Alaska occur during May, and for more northern latitudes, middle to late June. Late June through mid-July are important for obtaining maximum greenness time frames, and early or late September periods are important for assessing senescence times and rates.

The ground area contained within an individual pixel is often a function of satellite viewing angle, those pixels farther away from nadir representing larger areas in both across-track and along-track directions. Most satellite systems used for vegetation studies have limited offnadir scan widths. For example, Landsat multispectral scanner has a 6- to 7.5-degree scan width, Landsat thematic mapper has a 7.5-degree scan width, and the French SPOT satellite has a 2.5degree (excluding off-nadir viewing capabilities; Goward and others, 1991). The AVHRR sensor, however, has an off nadir-viewing angle of 55 degrees. The results presented here indicate that the majority of the Alaska AVHRR pixels in the composited data sets have ground dimensions much greater than the $1.1 \mathrm{~km}$ nominal size. As was shown in tables $7-13,50$ percent or more of the pixels for most of the years had scan angles of $+/-30$ degrees (with the exception of the first two or three periods of each year, which had less than 50 percent of the scan angle within $+/-30$ degrees). As such, approximately 50 percent of the pixels have dimensions roughly less than $1.5 \times 1.3 \mathrm{~km}$; however, the remaining pixels may have dimensions in excess of 2.4 X $6.5 \mathrm{~km}$ (Goward and others, 1991). These off-nadir view angles are higher than those reported for the North American data set (Zhu and Yang, 1996), partly because the North American data set was limited to a 48-degree scan angle.

Even though the probability of acquiring good, near-nadir viewing angles should be greater in the northen latitudes because of the increased frequency of overpasses by the satellite, that does not seem to be the case here, perhaps in part because of the compositing process itself. 
In general, if pixels near nadir are cloud covered during one pass but cloud free during a subsequent pass, the off-nadir pixels will be selected. Similarly, if pixels are further along phenologically on a later day that is captured during off-nadir overpasses, those pixels will be selected rather than those from near-nadir overpasses that are a day or two earlier. Compositing also may select off-nadir pixels because they tend to have slightly higher NDVI values as a result of scattering, shadowing, and projected canopy cover which tend to increase the near-infrared (channel 2) signal and decrease the red (channel 1) signal (Moody and Strahler, 1994; Stoms, Bueno, and Davis, 1997; Leblanc and others, 1997). This is especially evident in the forescatter direction with afternoon overpasses in the western hemisphere when foliage orientation increases at large zenith angles (Moody and Strahler, 1994). Also, off-nadir views tend to cause redundancy in the ground area covered, with overlap occurring in each pixel as further off-nadir viewing occurs.

Solar zenith angle is dependent upon the time of day, season, and latitude. Since the data content of each of the yearly data sets is basically determined by NDVI value, solar zenith angle may become an important aspect, especially when vegetation cover is being compared in different latitudes and seasons (Gutman, 1991). In northern latitudes, this angle dependancy may become important at either end of the growing season when solar angles can be large, especially in the late season. Holben (1986) discusses a NDVI terminator response whereby NDVI values may actually increase over areas of snow and ice when solar zenith angles are greater than 80 degrees owing to atmospheric absorption and large solar path lengths. In the North American data set described by Zhu and Yang (1996) solar zenith angles greater than 80 degrees were flagged and no NDVI values were calculated. In the Alaskan data set for years 1991-94, no angles were flagged and NDVI was calculated on all pixels, regardless of solar zenith angle. Beginning in 1995, data processing methods were designed to be equivalent to global data sets, and solar zenith angles greater than 80 degrees were flagged to be masked. However, no data in the 1995-97 data sets had solar zenith angles greater than 80 degrees (table 14).

Some studies have shown that NDVI may increase with increasing solar zenith angles, largely owing to shadowed components having higher NDVI values than more direct sunlit canopies and so decreasing the amount of red light penetration through the atmosphere (Gutman, 1991; Leblanc and others, 1997). Mean solar zenith angles for the Alaskan data sets occur at or below 60 degrees, except for early (April 1-14), or later (August or later) in the season, indicating that solar zenith angles may have a minimal effect on the bulk of the NDVI values during the growing season. Hence, for general ecological studies, the effects of solar zenith angles on NDVI may be minimal, except for those time periods on either side of the main growing season.

One of the main reasons for using a compositing process is to minimize the amount of clouds present within a time interval by selecting the highest NDVI value for that period. However, northern latitudes are often more cloudy than more temperate regions, especially along coastlines and during some shorter time periods, when some areas may never be cloud free (for example, the Aleutian Islands). Also, the presence of subpixel clouds is often common but generally undetectable because much of the surface reflectance may still be detectable by the sensor. For the Alaskan data sets, the number of sampled pixels that failed all three clouds tests (affected by clouds) was relatively small (table 15), generally less than 2 percent for each period. This is similar to the North American data set, which was based on 10-day composites for a 
period of 1 complete year. A notable exception was 1992, in which the number of cloudcontaminated pixels exceeded 2 percent (but generally less than 5 percent). Because the tests were based on thresholds for the entire State, crossing roughly 20 degrees of latitude and eight climate zones, there may be some error in the validity of a test that was passed. Local variations in temperature and ground conditions may cause the sensor to record false brightness temperatures. Also, a large percentage of the pixels for the early seasonal periods failed the FMF and RGCT tests at the same time. Failure of the FMF test is probably due to different cloud conditions or surface temperatures (Saunders and Kriebel, 1988), while the failure of the RGCT test is probably due to the presence of snow over the landscape early in the season.

Until now, there has not been any detailed assessment of the geolocation accuracy of any of these data sets. The results from the automated assessment indicate that more work is needed in this area, not only to do an overall assessment of the data following compositing, but perhaps to take a closer look at the process of georeferenceing the individual data sets that make up the composite; an assessment should also be done on what effects compositing itself has on the location accuracy of any individual pixel.

\section{CONCLUSION}

The Alaskan 7-year temporal data set is unique because it encompasses the entire State of Alaska at a 1-km pixel resolution and gives a nearly complete 7-year representation of the landscape's seasonal characteristics. It is different from the global and North American data sets in that each year's data is contained on one or two CD-ROM's, with each of the data layers being provided in a byte format so that the data can be read by any commonly used software/hardware configuration. Another notable difference is that the data are only for certain parts of the year (that is, predominantly the growing season), whereas the North American data set encompasses 1 full year. There is increasing concern about changing climate scenarios and their effects on vegetation and about associated biophysical factors (for example, carbon storage or release), and data sets such as these give a unique and unprecedented view of the temporal characteristics of northern latitude vegetation.

Depending on the data's ultimate use, some of its intrinsic qualities need to be known to ascertain whether the data will be usable and to what extent. Information about date of acquisition, satellite view and solar zenith angles, and amount of cloud coverage is important because it can provide additional clues to the utility of the data as well as explanations of results. For example, date of acquisition can be important for establishing onset of greenness dates, which can be used for the classification of wetland soils. If acquisition dates are congregated at one end of a composite period and the highest NDVI value fell on the last day of the period, they may shift the onset of the growing season as much as 14 days. If a general policy states that wetlands in northern latitudes retain surface water 14 days after the onset of greenness, the values derived from composited data may not be wholly applicable if the composite period is equal to the temporal quality in question.

Off-nadir view angles also may be of concern. Larger scan angles cause more ground area to be sensed, resulting in data redundancy for any given pixel obtained off-nadir. Depending on the extent of off nadir viewing and the heterogeneity of the landscape, comparable 
measurements between two different dates of the same area may be difficult (Goward and others, 1991).

Generally, clouds are seen as contributing to problems in the overall usefulness of the data sets. However, the presence of clouds may offer clues to understanding various trends that are revealed by multitemporal data. If a multitemporal data set such as the ones described here shows changes in greenness values early in the growing season (that is, earlier green-up dates), it could be due in part to the presence of clouds. In a preliminary report by the University of Alaska (1998) one study showed that clouds in the early growing season warm the lower atmosphere, which advances the date of snow melt by as much as a month. If a trend of earlier green-up dates is being indicated by multitemporal data sets, it would be reasonable to look at the cloudiness of the data from early in the growing season. Data sets with a high occurrence of cloud cover may support indications of an earlier than normal green-up for any particular year.

Knowing the intrinsic characteristics of satellite-borne data is important in any type of land analysis exercise. This is especially true for studies that may include interyear comparisons, atmospheric effects on the data, or comparisons to other similar data obtained from different satellites, both of the same series (that is, other AVHRR sensors) and from different series (for example, the French VEGETATION sensor). The information presented here may help in answering many types of questions when comparing information derived from these data with that of other data.

\section{REFERENCES}

Ailts, B., Akkerman, D., Quirk, B., and Steinwand, D., 1990, LAS 5.0 - An image processing system for research and production environments: Bethesda, Md., ACSM/ASPRS: , v. 4, p. 1-12.

Baglio, J.V., Jr., and Holroyd, E.W., 1989, Methods for operational snow cover area mapping using the Advanced Very High Resolution Radiometer: San Juan Mountains Test Study Area: Sioux Falls, S. Dak., U.S.A., U.S. Geological Survey, EROS Data Center. 1 p.

Binnian, E.F., and Ohlen, D.O., The 1992 Alaska Advanced Very High Resolution Radiometer twice-monthly composites, Readme File, 1992: Sioux Falls, S. Dak., EROS Data Center, U.S. Geological Survey.

Cihlar, J,. and Huang, F., 1994, Effect of atmospheric correction and viewing angle restriction on AVHRR data composites: Canadian Journal of Remote Sensing, v. 20, p. 132-137.

Cihlar, J., Manak, D., and Voisin, N., 1994, AVHRR bidirection reflectance effects and compositing: Remote Sensing Environment, v. 48, p. 77-88.

Cracknell, A.P., 1997, The Advanced Very High Resolution Radiometer. Bristol, Pa., Taylor and Francis, $534 \mathrm{p}$.

Curran, P., 1981, Multispectral remote sensing for estimating biomass and productivity, in Smith, H., ed., Plants and the Daylight Spectrum: London, Academic Press, p. 65-99.

D'Iorio, M.A., Cihlar, J., and Morasse, C.R., 1991, Effect of the calibration of AVHRR data on the normalized difference vegetation index and compositing: Canadian Journal of Remote Sensing, v. 17, p. 251-262. 
D'Souza, G., Belward, A.S., and Malingreau, J.P., 1996, Advances in the use of NOAA AVHRR data for land applications: Dordrecht, The Netherlands, Kluwer Academic Publishers, $479 \mathrm{p}$.

Eidenshink, J.C., 1992, The 1990 conterminous U.S. AVHRR data set.: Photogrammetric Engineering and Remote Sensing, v. 58, p. 809-813.

Eidenshink, J.C. and Faundeen, J.L., 1994, The 1-km AVHRR global land data set: first stages in implementation: International Journal of Remote Sensing, v. 15, p. 3443-3462.

Goward, S.N., Tucker, C.J., and Dye, D., 1985, North American vegetation patterns observed with the NOAA-7 advanced very high resolution radiometer.: Vegetatio, 64, p. 3-14.

Goward, S.N., Markham, B., Dye, D.G., Dulaney, W., and Yang, J., 1991, Normalized difference vegetation index measurements from the advanced very high resolution radiometer: Remote Sensing Environment, v. 35, p. 257-277.

Gutman, G.G., 1991, Vegetation indices from AVHRR: an update and future prospects: Remote Sensing Environment, v. 35, p. 121-136.

Holben, B.N., 1986, Characteristics of maximum-value composite images from temporal AVHRR data: International Journal of Remote Sensing, v. 7, p. 1417-1434.

Kidwell, K.B., 1997, NOAA Polar Orbiter Data User's Guide: Suitland Md., National Climate Data Center,: NOAA, National Environmental Satellite, Data, and Information Center.

Leblanc, S.G., Chen, J.M., and Cihlar, J., 1997, NDVI directionality in boreal forests: a model interpretation of measurements: Canadian Journal of Remote Sensing, v. 23, p. 39-380.

Li, Z., Cihlar, J., Zheng, X., Moreau, L., and Ly, H., 1996, The bidirectional effects of AVHRR measurements over boreal regions: IEEE Transactions on Geoscience and Remote Sensing, v. 34, p. 1308-1321.

Li, Z., Moreau, L., Cihlar, J., and Deering, D.W., 1997, An evaluation of kernel-driven bidirectional models using PARABOLA measurements: Canadian Journal of Remote Sensing, v. 23, p. 120-130.

Liu, J., Chen, J.M., Cihlar, J., and Park, W.M., 1997, A process-based boreal ecosystem productivity simulator using remote sensing inputs: Remote Sensing Environment, v. 62, p. 158-175.

Lloyd, D., 1990, A phenological classification of terrestrial vegetation cover using shortwave vegetation index imagery: International Journal of Remote Sensing, v. 11, p. 2269-2279.

Loveland, T.R. and Belward, A.S., 1997, The IGBP-DIS global 1-km land cover data set, DISCover: first results: International Journal of Remote Sensing, v. 8, p. 3289-3295.

Loveland, T.R., Merchant, J.W., Ohlen, D.O., and Brown, J.F., 1991, Development of a land cover characteristics database for the conterminous U.S.: Photogrammetric Engineering and Remote Sensing, v. 57, p. 1453-1463.

Markon, C.J., Fleming, M.D., and Binnian, E.F., 1995, Characteristics of vegetation phenology over the Alaskan landscape using AVHRR time series data.: Polar Record, v. 31, p. 179190.

Moody, A., and Strahler, A.H., 1994, Characteristics of composited AVHRR data and problems in their classification: International Journal of Remote Sensing, v. 15, p. 3473-3491.

Myneni, R.B., and Williams, D.L., 1994, On the relationship between FAPAR and NDVI: Remote Sensing Environment, v. 49, p. 200-211. 
Prince, S.D., 1991, A model of regional primary production for use with coarse resolution satellite data: International Journal of Remote Sensing, v. 12, p. 1313-1330.

Reed, B.C., Brown, J.F., VanderZee, D., Loveland, T.R., Merchant, J.W., and Ohlen, D.O., 1994, Measuring phenological variability from satellite imagery: Journal of Vegetation Science, v. 5, p. 703-714.

Reeves, R.G., Anson, A., and Landen, D., 1975, Manual of Remote Sensing. Falls Church, Va., American Society of Photogrammetry and Remote Sensing, $867 \mathrm{p}$.

Saunders, R.W., and Kriebel, K.T., 1988, An improved method for detecting clear sky and cloudy radiance from AVHRR data: International Journal of Remote Sensing, v. 9, p. 123-150.

Snyder, J.P., 1982, Map Projections Used by the U.S. Geological Survey: Washington, D.C., U.S.A., U.S. Geological Survey, 313 p.

Steinwand, D., 1994, Mapping raster imagery to the Interrupted Goode Homolosine projection.: International Journal of Remote Sensing, v. 15, p. 3463-3471.

Stoms, D.M., Bueno, M.J., and Davis, F.W., 1997, Viewing geometry of AVHRR image composites derived using multiple criteria: Photogrammetric Engineering and Remote Sensing, v. 63, p. 681-689.

Stowe, L., McClain, E.P., Carey, R., Pellegrino, P., Gutman, G.G., Davice, P., Long, C., and Hart, S., 1991, Global distribution of cloud cover derived from NOAA/AVHRR operational satellite data: Advanced Space Research, v. 11, p. 51-54.

Teillet, P., 1998, A status overview of earth observation calibration/validation for terrestrial applications: Canadian Journal of Remote Sensing, v. 23, p. 291-308.

Tucker, C.J., 1996, History of and the use of AVHRR data for land applications: Advances in the use of NOAA AVHRR data for land applications: Boston, Mass.. Kluwer Academic Publishers, v. 5, p. 1-19.

Tucker, C.J. and Sellers, P.J., 1986, Satellite remote sensing of primary production: International Journal of Remote Sensing, 7, p. 1395-1416.

University of Alaska, F., 1998, The 1995-96 Geophysical Institute Biennial Report: University of Alaska, Fairbanks, Ak.

Wahrhaftig, C., 1965, Physiographic divisions of Alaska: Washington, D.C., U.S. Geological Survey. Professional Paper 482, 1 p.

Zhu, Z.L., and Yang, L., 1996, Characteristics of the 1-km AVHRR data set for North America: International Journal of Remote Sensing, v. 17, p. 1915-1924. 